University of Louisville

ThinkIR: The University of Louisville's Institutional Repository

$5-2011$

\title{
Partial vs. full support of the heart with a continuous-flow left ventricular assist device : implications for myocardial recovery.
}

Carlo Renato G. Bartoli

University of Louisville

Follow this and additional works at: https://ir.library.louisville.edu/etd

\section{Recommended Citation}

Bartoli, Carlo Renato G., "Partial vs. full support of the heart with a continuous-flow left ventricular assist device : implications for myocardial recovery." (2011). Electronic Theses and Dissertations. Paper 78. https://doi.org/10.18297/etd/78

This Doctoral Dissertation is brought to you for free and open access by ThinkIR: The University of Louisville's Institutional Repository. It has been accepted for inclusion in Electronic Theses and Dissertations by an authorized administrator of ThinkIR: The University of Louisville's Institutional Repository. This title appears here courtesy of the author, who has retained all other copyrights. For more information, please contact thinkir@louisville.edu. 


\title{
PARTIAL vS. FULL SUPPORT OF THE HEART WITH A CONTINUOUS-FLOW LEFT VENTRICULAR ASSIST DEVICE: IMPLICATIONS FOR MYOCARDIAL RECOVERY
}

\author{
by \\ Carlo Renato G Bartoli \\ B.S. Cornell University, 2004 \\ M.L.A. Harvard University, 2007 \\ M.S. University of Louisville, 2010
}

\begin{abstract}
A Dissertation
Submitted to the Faculty of the

Graduate School of the University of Louisville

In Partial Fulfillment of the Requirements

For the Degree of
\end{abstract}

Doctor of Philosophy

Department of Physiology and Biophysics

University of Louisville

Louisville, $\mathrm{KY}$

May 2011 
Copyright 2011 by Carlo Renato G Bartoli

All Rights Reserved 



\title{
PARTIAL vS. FULL SUPPORT OF THE HEART WITH A CONTINUOUS-FLOW LEFT VENTICULAR ASSIST DEVICE: IMPLICATIONS FOR MYOCARDIAL RECOVERY
}

\author{
by \\ Carlo Renato G Bartoli \\ B.S. Cornell University, 2004 \\ M.L.A. Harvard University, 2007 \\ M.S. University of Louisville, 2010
}

A Dissertation Approved on

April 14, 2011

By the following Dissertation Committee:

Sumanth D. Prabhu, M.D.

Steven C. Koenig, Ph.D.

William B. Wead, Ph.D.

Stanley E. D’Souza, Ph.D.

John C. Passmore, Ph.D. 


\section{DEDICATION}

This dissertation is dedicated to my father, Dr. Renato Bartoli, and my mother, Anna Bartoli, who have made countless sacrifices so that I may pursue my dream to become a cardiac surgeon and physician scientist. Thank you for teaching me the power of education, hard work, and self-discipline. 


\section{ACKNOWLEDGEMENTS}

I acknowledge and thank the many contributors to the work in which I have been privileged to participate at the University of Louisville. This work was not possible without the guidance and mentorship of Dr. Sumanth Prabhu, Dr. Steven Koenig, and Dr. William Wead as well as the input from Dr. Stanley D'Souza and Dr. John Passmore. Dr. Mark Slaughter, Dr. Laman Gray, Dr. Paul Spence, Dr. Guruprasad Giridharan, Dr. Robert Acland, Dr. Anna Meyer, Dr. George Pantalos, Dr. Sanjeev Aggarwal, Dr. Leslie Sherwood, Dr. Jay Hoying, Dr. Tariq Hamid, Dr. Michael Flaherty, Dr. Utpal Sen, Dr. Paras Mishra, Dr. Robert Lewis, Dr. Daniel Conklin, Dr. Steven Ellis, Dr. Kevin Soucy, Dr. Srinivas Sithu, Dr. Gregory Wilson, Dr. Justin Kingery, Michael Sobieski, Mary Anne Hauck, Ernest Cardwell, Laura Lott, Karen Lott, Kenneth Brittian, Sujith Dassanayaka, Erin Justice, Cary Wollard, Mickey Ising, Arun Nadar, Tim Horrell, Andrew Luckett, Heather Clair, Amanda Burkhart, Aaron denDekker, Philipp Frieslederer, Daiga Koenig, Sean Warren, Landon Tompkins, Troy Nukes, Steven Anderson, and the University of Louisville veterinary staff were indispensable during the completion of this project. I would especially like to thank Dr. Steven Koenig, Dr. Sumanth Prabhu, Dr. Stanley D'Souza, Dr. Suresh Tyagi, and Dr. Syed Khundmiri for the opportunity to work in their laboratories. Finally, I would like to thank Dr. Menaka Nadar, Dr. William Wead, Dr. Robert Dowling, and Dr. Quinn Chipley for their quiet support, patience, and guidance as I collected data and prepared this thesis. 


\title{
ABSTRACT \\ PARTIAL vS. FULL SUPPORT OF THE HEART WITH A CONTINUOUS-FLOW LEFT VENTICULAR ASSIST DEVICE: IMPLICATIONS FOR MYOCARDIAL RECOVERY
}

\author{
Carlo Renato G Bartoli
}

April 14, 2011

INTRODUCTION: Heart failure is a major and growing public health concern. Although heart failure has been considered an inexorable and progressive disorder, emerging evidence suggests that some patients may have reversible left ventricular dysfunction. Indeed, recent reports have documented the potential for myocardial recovery in humans in response to prolonged mechanical circulatory support with a left ventricular assist device (LVAD). However, myocardial recovery remains uncommon, and a strategy of unloading the failing left ventricle with a continuous-flow (non-pulsatile) LVAD has not been specifically developed to promote favorable myocardial remodeling. As a preliminary investigation, we developed a bovine model of chronic, ischemic heart failure and quantified the effects of different levels of support with a continuous-flow LVAD on myocardial mechanoenergetics.

METHODS: Normal cows $(n=8)$ and cows with chronic, ischemic heart failure $(n=9)$ were studied. To induce heart failure, $90 \mu \mathrm{m}$ microspheres were percutaneously injected into the 
left main coronary artery. Heart failure developed over 60 days. In an acute surgery, a continuous-flow LVAD was implanted and operated at Low Partial Support $(\sim 1.5 \mathrm{~L} / \mathrm{min}$ support, aortic valve opening every beat), High Partial Support ( $\sim 3 \mathrm{~L} / \mathrm{min}$ support, aortic valve opening every beat) and Full Support $(\sim 5 \mathrm{~L} / \mathrm{min}$, aortic valve maintained closed, left ventricle maximally unloaded). Cardiac and systemic arterial hemodynamics were measured with flow probes and pressure catheters. Myocardial blood flow was mapped with $15 \mu \mathrm{m}$ fluorescent-labeled microspheres. After termination, molecular and histological markers of heart failure were quantified.

RESULTS: In normal animals, increasing levels of non-pulsatile support deranged the profile of cardiac and arterial hemodynamics. As cardiac workload decreased, myocardial vascular resistance increased, and myocardial blood flow decreased. The ratio between blood supply and demand did not change and indicated appropriate coronary autoregulation and the presence of an intact coronary reserve. Animals with chronic, ischemic heart failure exhibited hallmark signs of severe left ventricular systolic dysfunction that included a $50 \%$ reduction in ejection fraction, left ventricular dilatation, decreased cardiac output and arterial pressures, decreased end-organ blood flow, severe myocardial fibrosis, myocyte hypertrophy, and increased myocardial apoptosis. In animals with chronic heart failure, increasing levels of non-pulsatile support similarly deranged the profile of cardiac and arterial hemodynamics. As cardiac workload decreased, myocardial vascular resistance increased. However myocardial blood flow did not change and indicated a lack of a coronary reserve. Importantly, during full but not partial support, the ratio between blood supply and demand improved significantly to levels observed in normal control animals. 
CONCLUSIONS: After the implantation of an LVAD, full but not partial support of the failing left ventricle with an LVAD normalizes the myocardial blood supply/demand relationship. In the immediate postoperative period, the left ventricle should be completely unloaded. Chronic studies are necessary to determine whether a transition to partial support may prevent myocardial atrophy and fibrosis that is seen with prolonged full support. Our bovine model of chronic, ischemic heart failure is appropriate for such a study. 


\section{TABLE OF CONTENTS}

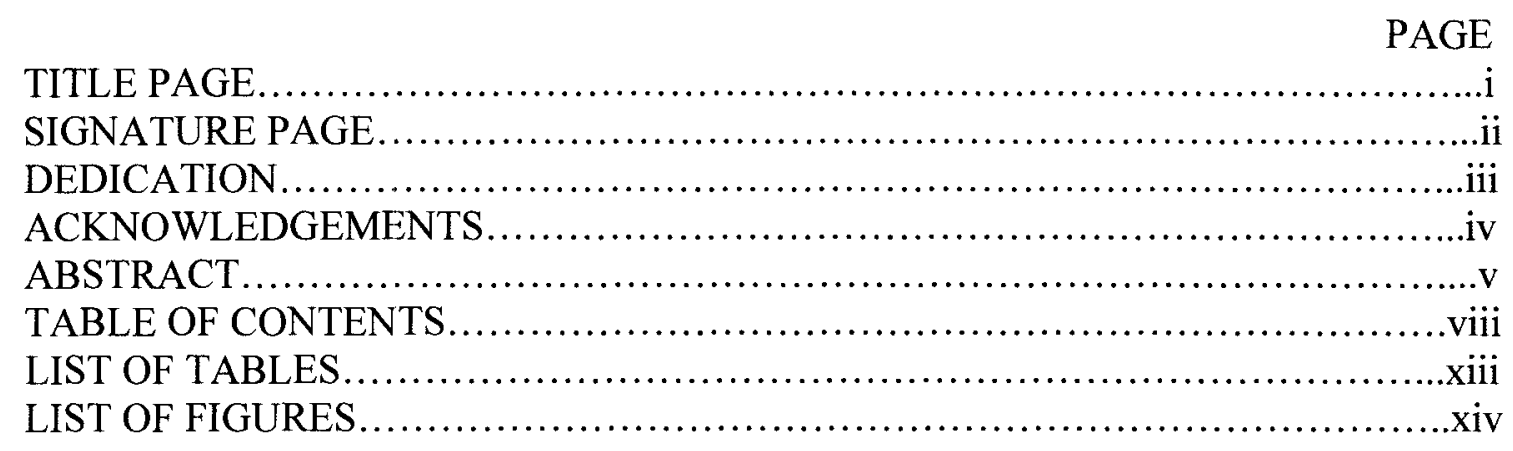

CHAPTER I: INTRODUCTION

I. Introduction........................................................

\section{CHAPTER II: BACKGROUND AND LITERATURE REVIEW}

I. Pulsatility during Mechanical Circulatory Support.....................7

II. Partial vs. Full Mechanical Unloading of the Failing Left Ventricle......11

\section{CHAPTER III: FUNDAMENTAL QUESTIONS}

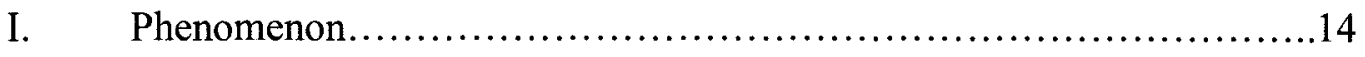

II. Proposed Concepts................................................. 14

III. Experimental Design...............................................

IV. Hypotheses and Specific Aims........................................ 15

CHAPTER IV: Aim \#1: PARTIAL vs. FULL SUPPORT OF THE NORMAL LEFT VENTRICLE WITH A CONTINUOUS-FLOW LVAD

I. Introduction. .18 


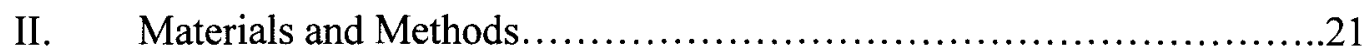

Animals.....................................................21

Anesthesia ......................................................

Surgical Instrumentation...................................21

LVAD Implantation.........................................22

Experimental Design........................................22

Quantification of Microspheres and Regional

Myocardial Blood Flow.......................................23

Data Reduction.....................................................24

Statistics.....................................................25

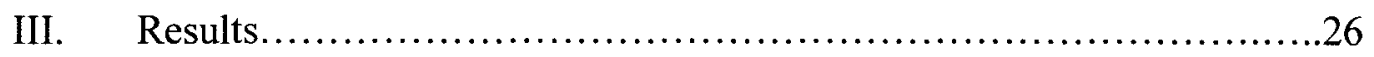

Left Ventricular Hemodynamics.............................26

Arterial Hemodynamics....................................27

Myocardial Blood Supply/Demand Relationship.................27

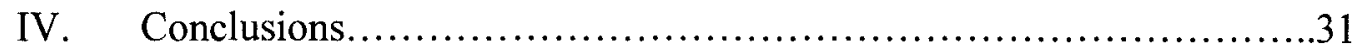

Systemic Effects........................................... 31

Effects on the Heart...............................................32

Effects on the Arterial System....................................33

Potential Mechanism for Unfavorable Histological

Changes during Prolonged LVAD Support .......................33

CHAPTER V: Aim \#2: DEVELOPMENT OF A BOVINE MODEL OF CHRONIC, ISCHEMIC HEART FAILURE

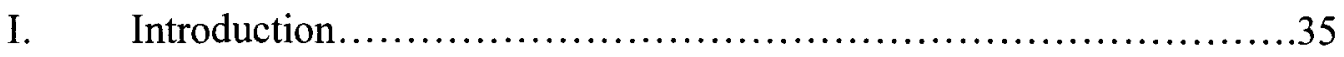

II. Materials and Methods............................................38 
Animals.......................................................

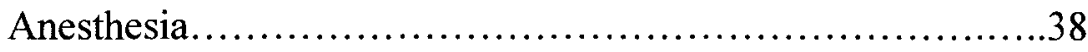

Cardiac Catheterization and Baseline Hemodynamics............39

Cardiac Catheterization and Baseline End-Organ

Blood Flow Measurement......................................39

Coronary Catheterization and Microembolization..............39

Clinical Management........................................41

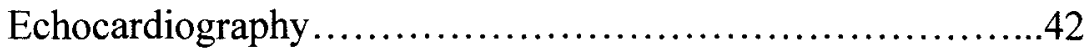

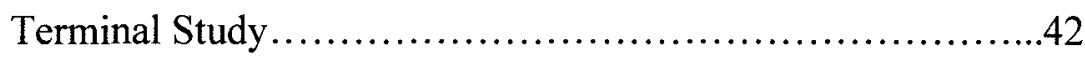

Experimental Design.......................................43

Quantification of Microspheres and End-Organ Blood Flow...44

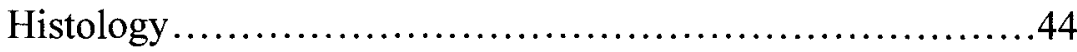

Data Reduction................................................45

Statistics................................................... 46

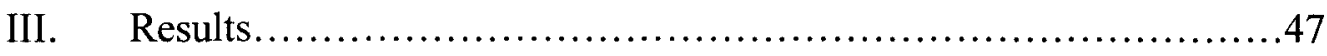

Survival, Clinical Findings, and Data Collected...............47

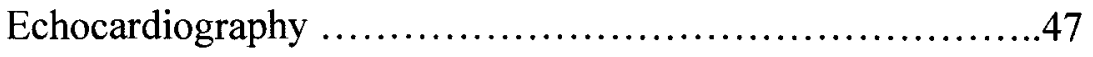

Acute and Chronic Hemodynamics...........................48

End-Organ Blood Flow....................................50

Regional Myocardial Blood Flow.............................51

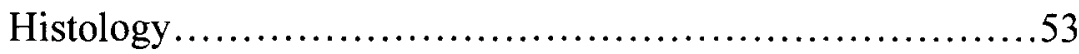

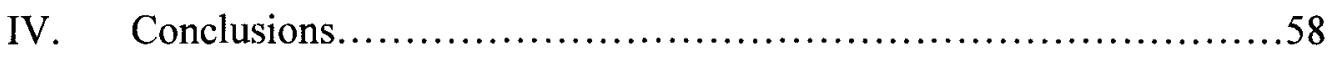




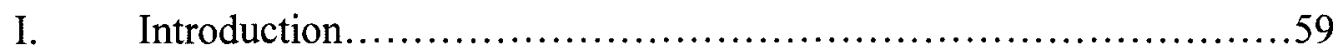

II. Materials and Methods................................................63

Animals...................................................63

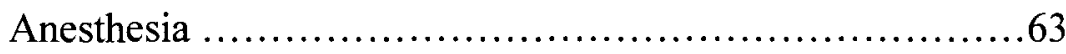

Surgical Instrumentation..................................64

LVAD Implantation.......................................64

Experimental Design....................................64

Quantification of Microspheres and Regional

Myocardial Blood Flow........................................65

Data Reduction..................................................66

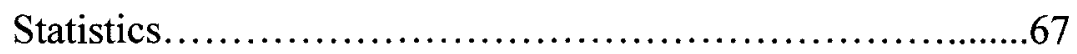

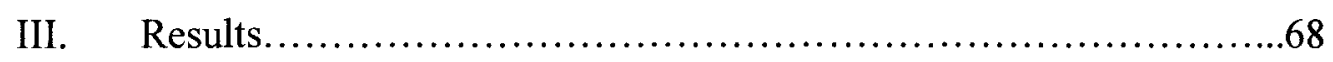

Left Ventricular Hemodynamics.............................68

Arterial Hemodynamics.......................................69

Myocardial Blood Supply/Demand Relationship.............69

Comparison to Normal Animals.............................72

IV. Conclusions................................................... 73

Systemic Effects........................................73

Effects on the Heart..........................................74

Effects on the Arterial System and Emerging Novel Pathologies ................................................77

Clinical Implications.....................................78 
CHAPTER VII: SUMMARY AND FUTURE RESEARCH DIRECTIONS...........80

I. Summary of Findings.......................................... 80

II. Future Directions.................................................

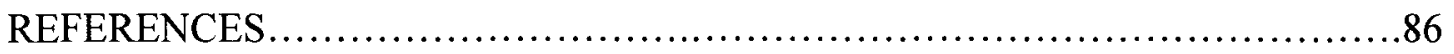

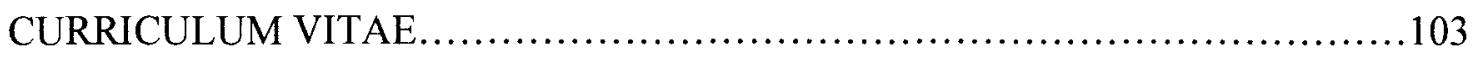




\section{LIST OF TABLES}

TABLE

PAGE

\section{Partial vs. Full Support in Normal Animals}

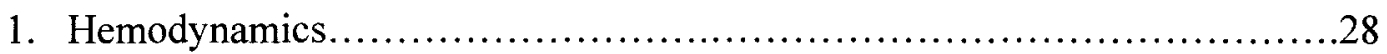

2. Regional Myocardial Vascular Resistance...............................29

3. Regional Myocardial Blood Flow..........................................29

4. Regional Myocardial Blood Supply/Demand Relationship.................29

\section{Chronic, Ischemic Heart Failure Animals}

5. Acute Hemodynamics................................................... 49

6. Chronic Hemodynamics..............................................49

\section{Partial vs. Full Support in Animals with Chronic, Ischemic Heart Failure}

7. Hemodynamics.................................................. 70

8. Regional Myocardial Vascular Resistance.............................71

9. Regional Myocardial Blood Flow...................................... 71

10. Myocardial Blood Supply/Demand Relationship.........................72 


\section{LIST OF FIGURES}

FIGURE PAGE

Introduction

1. Pulsatile vs. Continuous-Flow LVADs.....................................

2. Hemodynamics with a Pulsatile vs. Continuous-Flow LVAD .................8

\section{Partial vs. Full Support in Normal Animals}

3. Summary of Physiological Findings............................................ 30

\section{Chronic, Ischemic Heart Failure Animals}

4. Acute Embolization Findings.........................................40

5. Echocardiographic Findings............................................ 48

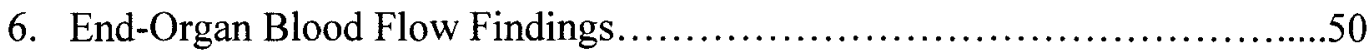

7. Regional Myocardial Blood Flow Findings....................................52

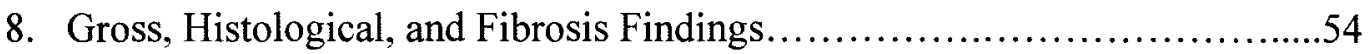

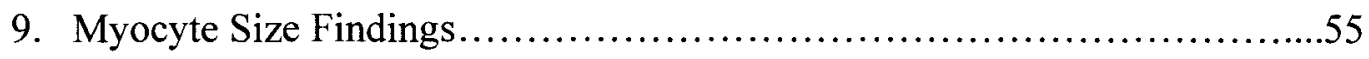

10. Total Cardiac Apoptosis...............................................56

11. Myocyte-Specific Apoptosis..........................................57

Partial vs. Full Support in Animals with Chronic, Ischemic Heart Failure

12. Summary of Physiological Findings................................... 72

13. Myocardial Blood Supply/Demand Maps.................................75 


\section{CHAPTER I}

\section{INTRODUCTION}

Adult patients with advanced heart failure that is refractory to pharmacological and electrical resynchronization therapies have a limited prognosis. For select patients, heart transplantation offers the best opportunity for long-term survival. However, the number of available donor hearts $(\sim 3,500$ annually worldwide $)$ are inadequate to meet the needs of more than 30,000 patients listed for heart transplantation worldwide each year ${ }^{1}$. As a result, cardiac transplant waiting lists have the highest mortality rate $(30 \%)$ of any of the solid organ waiting lists ${ }^{2}$.

If a patient decompensates while on a transplant waiting list and he or she is not granted high-urgency status, or if the rate of decompensation is rapid, limited options exist. If a patient does receive a donor heart, chronic rejection and sequelae of long-term immunosupression limit post-transplant survival to $55 \%$ at 10 years ${ }^{3}$. Furthermore, many patients are not considered for transplantation due to age, comorbidities, or even inadequate insurance coverage. As a result, many patients are being considered for therapy with a permanent, left ventricular assist device (LVAD). Indeed, over the past decade mechanical circulatory support therapies have emerged as a standard, long-term 
therapy for adult patients with advanced, intractable heart failure as a bridge to cardiac transplantation ${ }^{4}$, a destination therapy ${ }^{4}$, or a bridge to myocardial recovery ${ }^{5-9}$.

The recent, widespread success of mechanical circulatory support has ushered in a new era of cardiovascular medicine in which multiple implantable options exist to treat advanced heart failure. Currently, more than 20 novel cardiac assist devices are under development or in clinical trials with nearly a dozen new systems poised to begin clinical trials during the first half of the decade ${ }^{10-25}$. Each device entails unique surgical and physiological considerations and offers benefits and drawbacks for the patient and the physician. For example, currently available LVADs require extensive, invasive surgery such as sternotomy or thoracotomy. However, these "full-support" devices are able to salvage end-stage heart failure patients by replacing cardiac function and reinstating an adequate circulation. Consequently, full-support devices are reserved as a final treatment option only for patients with life-threatening heart failure. As such, full-support LVADs have not been specifically designed to recover a sick heart, and physicians may be reluctant to refer less-sick patients for an invasive therapy.

In order to expand the role of mechanical circulatory support for the treatment of lesssevere stages of heart failure, investigators and industry partners are miniaturizing LVADs for less-invasive and earlier therapy. Small devices that are designed to provide moderate or "partial-support" in heart failure patients with less advanced disease may be employed before the onset of irreversible myocardial damage and end-organ dysfunction. It has been speculated that partial unloading of the failing left ventricle will interrupt the 
progressive hemodynamic deterioration observed in heart failure ${ }^{14}$ as well as increase functional capacity and improve quality of life. Partial support initiated in patients with less severe myocardial damage may increase the rate of myocardial recovery. Although there is limited data to support these hypotheses, initial clinical results with partialsupport devices are encouraging ${ }^{14,24,26,27}$.

As mechanical circulatory support gains prevalence in the clinical management of cardiovascular disease, it is increasingly important to characterize the physiological response to different devices and mechanical strategies to support the failing heart. Each new LVAD system unloads the left ventricle by a distinctive mechanism. Pulsatile devices mimic pulsatile heart function, whereas continuous-flow devices continuously (and non-physiologically) unload the heart. Full-support devices replace intrinsic cardiac function, whereas partial-support devices augment native hemodynamics. The diversity of strategies to support the failing circulation, the anticipated arrival of numerous novel devices, and the increasing prevalence of patients undergoing long-term mechanical circulatory support raise important basic physiological and clinical questions.

For example, what is the optimal strategy of support to promote myocardial recovery with an LVAD? Mounting evidence suggests that full support of the failing left ventricle with an LVAD can reverse pathologic myocardial remodeling and permit LVAD explantation in select patients ${ }^{5-9}$. Yet, strategies to promote myocardial recovery with a full-support LVAD have demonstrated limited success. In fact, the current strategy of prolonged full support of patients in end-stage heart failure with irreversible myocardial 
damage may actually be detrimental to the cardiovascular system. As the level of continuous unloading increases, the native workload of the heart decreases ${ }^{28}$. During full support, cardiac workload is nearly eliminated because native cardiac function is no longer needed for adequate circulation. As a result, myocyte atrophy ${ }^{29-31}$ and ventricular stiffening ${ }^{31,32}$ may occur and preclude myocardial recovery. Therefore, an understanding of effects of mechanical unloading of the heart on myocardial mechanoenergetics is needed in order to develop better support strategies to promote myocardial recovery.

It is generally recognized that varying the level of support with an LVAD affects myocardial workload and coronary blood flow ${ }^{33}$. Yet this relationship has not been well characterized and the implications of altered workload and coronary blood flow for myocardial recovery are unclear. As a starting point, characterization of the blood supply/demand relationship during LVAD support may answer fundamental questions necessary to begin to develop a protocol to promote myocardial recovery with a continuous-flow LVAD. The purpose of this dissertation project was to examine cardiac and arterial hemodynamics, coronary blood flow, and myocardial workload during varying levels of support with a continuous-flow $\mathrm{LVAD}^{28}$. To this end, a bovine model of chronic heart failure was developed. Continuous-flow LVADs were implanted in normal calves and calves with chronic, ischemic heart failure. During partial and full support with a continuous-flow LVAD, hemodynamics and myocardial blood flow were measured. The data presented within this dissertation document four important findings: 
1) Left main coronary artery microembolization induced chronic, ischemic heart failure in calves. A stable and reproducible large-animal model of chronic heart failure is possible with many phenotypic similarities to clinical heart failure.

2) In normal animals and animals with chronic heart failure, full but not partial support with a continuous-flow LVAD deranged the physiological profile of pulsatile cardiac and arterial hemodynamics.

3) In normal animals, neither full nor partial support with a continuous-flow LVAD affected the myocardial blood supply/demand relationship. However, in animals with chronic heart failure, full but not partial support normalized the myocardial blood supply/demand relationship.

4) Divergent results were observed between normal animals and animals with chronic heart failure. Normal animals do not reproduce the complex pathophysiological presentation of chronic heart failure and are not ideal for validation and proper translation of mechanical circulatory support strategies into clinical practice.

The major finding of this study is that in the immediate postoperative period after the implantation of an LVAD, complete unloading of the failing left ventricle will rebalance the myocardial blood supply/demand relationship. However, full support with a 
continuous-flow LVAD dramatically changes cardiac and systemic arterial hemodynamics and may have long-term consequences. Therefore, chronic studies are necessary to determine whether a transition to partial support may alleviate or prevent myocardial atrophy and fibrosis that is seen with prolonged full support. Our bovine model of chronic, ischemic heart failure is appropriate for such a study. 


\section{CHAPTER II}

\section{BACKGROUND AND LITERATURE REVIEW}

\section{Pulsatility during Mechanical Circulatory Support}

Over the past two decades, full-support LVADs have evolved into a standard therapy for patients with end-stage heart failure. In 2002, the milestone Randomized Evaluation of Mechanical Assistance for the Treatment of Congestive Heart Failure (REMATCH) trial demonstrated clinical success with pulsatile LVADs as a long-term therapy for end-stage heart failure patients ${ }^{34}$. Subsequently, the United States Food and Drug Administration (FDA) approved use of the first-generation, pulsatile HeartMate XVE (Figure 1, Left) as a destination therapy in patients ineligible for cardiac transplantation ${ }^{35}$.

More recently, pulsatile LVADs, which mimic pulsatile cardiac function, have been replaced by rotary blood pumps, which continuously (and non-physiologically) unload the left ventricle. In 2008, the FDA approved use of the HeartMate II (Figure 1, Right) continuous-flow LVAD in patients for bridge-to-transplant therapy ${ }^{36}$. Such nextgeneration, full-support rotary pumps are smaller, more reliable, more energy efficient, and less surgically traumatic to implant. Notably, superior clinical outcomes have been 
established with next-generation continuous-flow devices ${ }^{37}$. Yet continuous-flow

LVADs do not generate normal pulsatility (Figure 2$)^{28}$. As a result, a new population of "pulseless" patients undergoing long-term LVAD support has emerged.
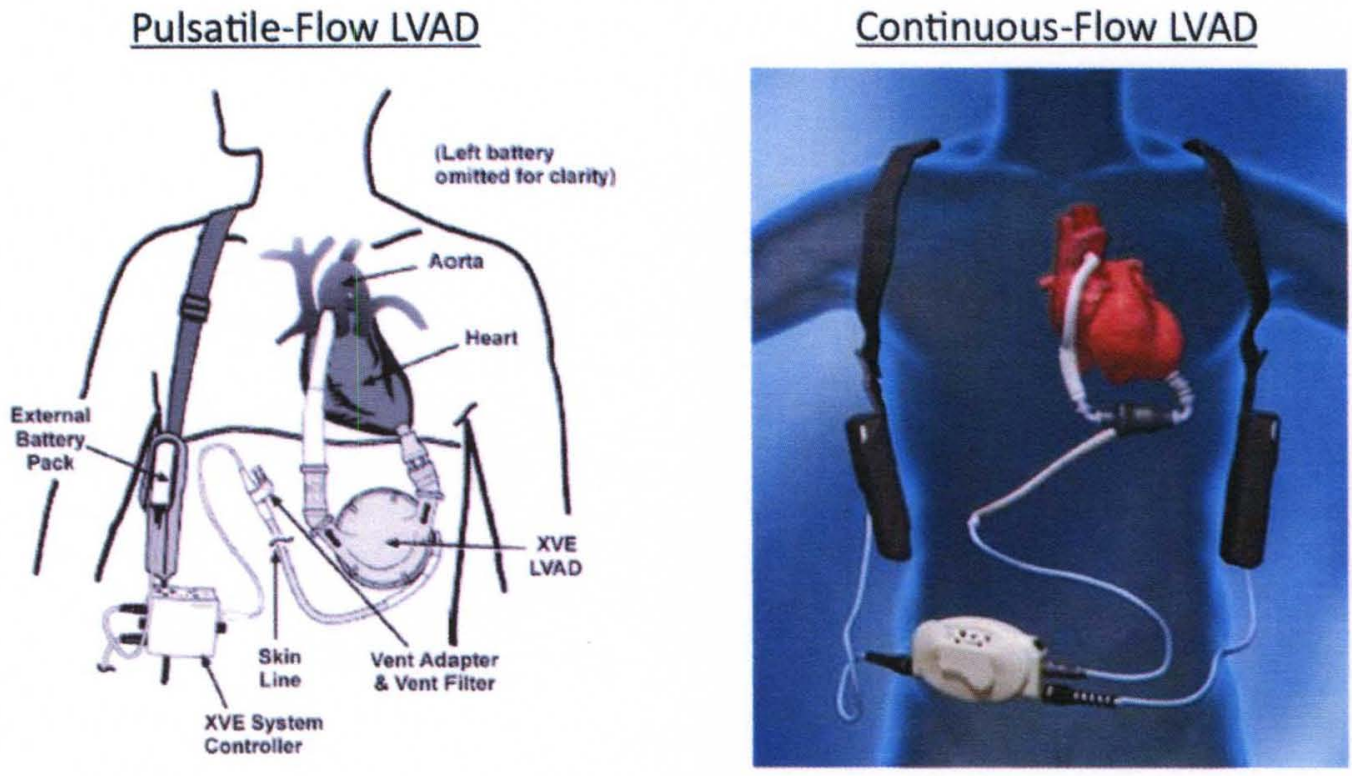

Figure 1, Left: A pulsatile HeartMate XVE is shown. First generation pulsatile devices mimic native cardiac function. However, these devices are large, difficult to implant, and less reliable for long-term therapy. Right: A continuous-flow (non-pulsatile) HeartMate II is shown. Second generation continuous-flow devices are smaller, easier to implant, and operate with excellent durability for prolonged LVAD therapy. However, the nonpulsatile mechanism dramatically alters the circulation of blood.
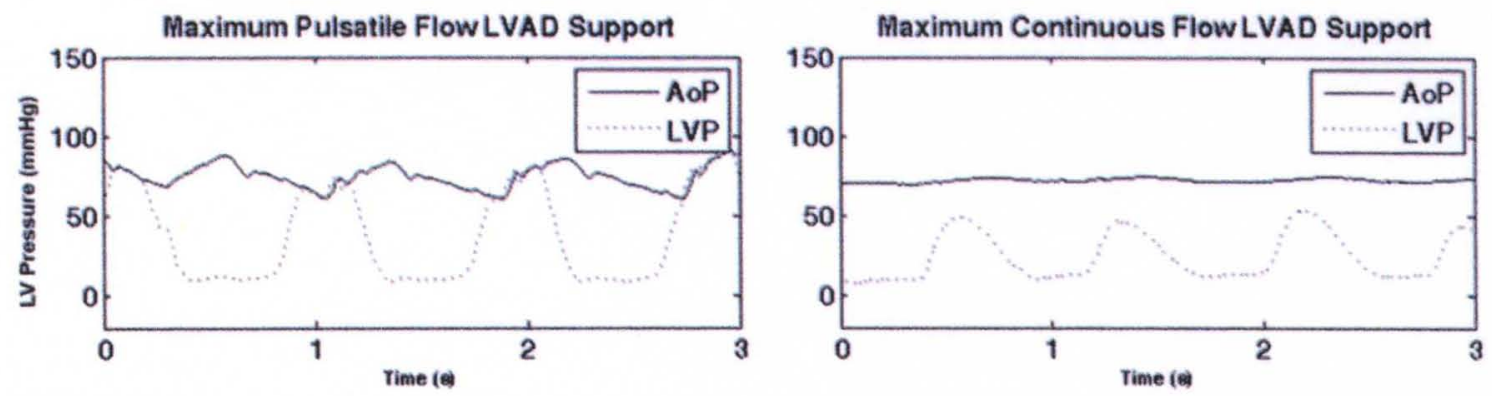

Figure 2, Left: Full support with a pulsatile LVAD demonstrates a normal pulsatile arterial pressure. As blood volume is removed from the left ventricle in a phasic manner, an arterial pulse is generated. Additionally, sufficient preload permits the left ventricle to eject through the aortic valve, which preserves a normal pulsatile circulation. Right: In contrast, full support with a continuous-flow LVAD demonstrates a nearly flat arterial pressure. As blood volume is continuously removed from the left ventricle into the aorta, insufficient preload prevents ejection of blood through the aortic valve. As a result, left ventricular pressure never exceeds aortic pressure, the aortic valve remains chronically closed, and the systemic circulation is non-pulsatile. AoP, aortic pressure; LVP, left ventricular pressure 
In this patient population, investigators have raised concerns about the effect of chronic, non-pulsatile blood flow on myocardial and end-organ perfusion, cardiovascular architecture, and long-term patient outcomes ${ }^{38}$.

Pulsatility and mechanical stretch of cardiac myocytes, endothelial cells, and vascular smooth muscle cells are fundamental to cardiovascular homeostasis. On day 26 of human embryogenesis, the immature fetal heart begins to beat and pump blood through a rudimentary vascular system ${ }^{39}$. From this day forward until the last day of life, cardiac contraction, stroke volume ejection, and cardiac relaxation with one-way valves expose every cardiovascular cell (and most cells in the body) to rhythmic mechanical forces that mediate intracellular and extracellular events. Seemingly, pulsatility is a vital component of normal mammalian physiology.

Indeed, numerous investigators have demonstrated the superiority of pulsatile blood flow over non-pulsatile flow during short-term and long-term mechanical circulatory support in experimental models as well as in adult and pediatric patients ${ }^{40-52}$. However, despite the evidence in favor of pulsatile perfusion techniques, a debate still exists as to which mode of circulatory support is better. A separate set of investigators have reported no difference between continuous and pulsatile perfusion modes ${ }^{53-59}$.

Nevertheless, continuous-flow LVADs constitute the current clinical gold standard for prolonged mechanical circulatory support ${ }^{37}$. Yet the effect of continuous support of the left ventricle and reduced pulsatility on cardiac workload, coronary blood flow, and 
regional myocardial perfusion remain largely uncharacterized. During heart failure, the supply/demand ratio of available oxygen in blood to myocyte workload becomes unbalanced $^{60}$. Likely, appropriate support with an LVAD may rebalance this relationship, which may have important implications as the initial step toward myocardial recovery. 


\section{Partial vs. Full Mechanical Unloading of the Failing Left Ventricle}

If a patient awaiting a cardiac transplant decompensates and an appropriate organ is not available, a full-support LVAD may be the only option for survival. Yet many heart failure patients are not ill enough or have contraindications to placement of a full-support LVAD. In these patients, the notion of combining the benefits of partial support with a minimally invasive and short operation without cardiopulmonary bypass may be feasible.

A recent National Heart, Lung, and Blood Institute (NHLBI) mission statement included the pursuit of long-term hemodynamic support with minimally invasive surgery to provide moderate levels of mechanical assistance earlier in the progression of heart failure (NHLBI, Clinical Use of Ventricular Assist Devices Working Group, March 2728,2008 Crystal City, VA) ${ }^{61}$. The long-term benefits of chronic, partial support are unknown but may soon be partially characterized by ongoing clinical trials ${ }^{14}$. Significant clinical benefits have been predicted ${ }^{62}$ that may decrease the number of patients that require a heart transplant.

For example, a large gap in available therapies exists for patients in NYHA class III heart failure that have not responded to biventricular pacing. If these patients are transplant ineligible or have not met hemodynamic and clinical criteria to justify risks and comorbidities of sternotomy and a full-support LVAD, limited options exist. In these patients, partial support with a less-invasive device is an attractive option. If partial support is administered early enough, favorable reverse myocardial remodeling may 
restore sufficient native cardiac function and permit explantation of the device ${ }^{7}$. This hypothesis has not been rigorously tested but is conceptually appealing.

Indeed, in rare instances, full support with an LVAD has resulted in myocardial recovery ${ }^{5-9}$. In these patients, functional recovery has accompanied favorable changes at the molecular and histological levels ${ }^{7,63,64}$. Yet, strategies to promote reverse myocardial remodeling with a full-support LVAD have demonstrated limited success and myocardial recovery remains uncommon. As it turns out, prolonged full support of the left ventricle with a continuous-flow LVAD may produce numerous unfavorable results. For example, as the level of full-support increases, variation in end-systolic and end-diastolic volumes diminish and eliminate the native workload of the heart ${ }^{28}$. Myocyte atrophy $y^{29,30}$ and ventricular stiffening ${ }^{32}$ may occur and produce a noncompliant ventricular chamber incapable of sustained, independent function. Simultaneously, complete volume unloading of the left ventricle decreases peak systolic pressures to the point where the aortic valve remains chronically closed. As a result, fused valve leaflets, acquired aortic stenosis, or total occlusive thrombosis of prosthetic aortic valves may occur ${ }^{65}$. Excessive ventricular unloading with an LVAD may also result in suction events and ventricular collapse, which may trigger episodes of fatal ventricular tachyarrhythmias ${ }^{66,67}$.

Of additional concern, during therapy with a full-support LVAD, approximately $30 \%$ of patients develop right ventricular dysfunction ${ }^{68}$ with an associated mortality rate of $43 \%{ }^{69}$. During left heart failure, full support with an LVAD may abruptly increase systemic arterial flow, acutely overload the right ventricle, and cause right ventricular 
failure. For these reasons, full support of the left ventricle with a continuous-flow LVAD may cause adverse consequences and limit myocardial recovery.

Furthermore, patients in NYHA class III or early class IV heart failure with lessadvanced disease may not require full support with an LVAD. Accordingly, rather than completely unloading the failing heart, earlier and partial unloading may reduce but not eliminate native ventricular workload, preserve myocardial structure, and prevent myocyte atrophy and ventricular stiffening. By reducing ventricular workload and augmenting myocardial blood flow while still allowing the heart to fill and empty over a controlled range of ventricular volumes, partial support may be an effective strategy not only to augment hemodynamics but also to promote favorable myocardial remodeling in hearts with less disease. Importantly, patients with healthier hearts may have a higher likelihood of myocardial recovery ${ }^{62}$.

With this strategy in mind, preclinical studies are necessary to determine effects of partial support on cardiovascular physiology. Therefore, the purpose of this dissertation project was to initiate in vivo, large-animal experiments to characterize the effect of full and partial support with a continuous-flow LVAD on systemic hemodynamics and the myocardial blood supply/demand relationship. Our findings have important clinical utility and may increase the public-health impact of mechanical circulatory support with next-generation, continuous-flow LVADs. 


\section{CHAPTER III}

\section{FUNDAMENTAL QUESTIONS}

\section{Phenomenon}

Full-support devices constitute the current gold standard for the treatment of end-stage heart failure with an LVAD. Myocardial recovery with a continuous-flow LVAD is rare, and effective strategies to facilitate reverse myocardial remodeling have not been developed. The field of mechanical circulatory support is trending toward miniaturized LVADs that can be implanted with minimally invasive surgery and that provide partial support for earlier therapy in healthier patients. The clinical utility of partial support is unknown. However, partial support of patients in earlier stages of heart failure may be a better strategy to promote myocardial recovery.

\section{Proposed Concepts}

Important hemodynamic differences exist between partial vs. full support of the cardiovascular system. The effect of continuous unloading of the left ventricle on cardiac and systemic hemodynamics, myocardial workload, and coronary blood flow is not well characterized. The effect of partial support with a continuous-flow LVAD on myocardial 
mechanoenergetics is unknown, and the clinical role of partial support is yet to be defined.

\section{Experimental Design}

A series of experiments were designed to compare effects of partial vs. full support with a continuous-flow LVAD on cardiac and systemic hemodynamics, myocardial workload, and coronary blood flow. In normal animals without cardiovascular pathology, continuous-flow LVADs were implanted to determine effects of partial support in the normal cardiovascular system. In parallel, a model of chronic, ischemic heart failure was developed in calves. Experiments were repeated in the heart failure model to determine effects of partial support in the failing cardiovascular system.

\section{Hypotheses and Specific Aims}

Hypothesis \#1: In normal animals, increasing levels of support with a continuous-flow LVAD will alter the pulsatile cardiac and systemic arterial hemodynamic profile. Continuous mechanical unloading of the normal left ventricle will reduce left ventricular but not right ventricular workload and blood flow in a manner dependent on the degree of support. The left ventricular blood supply/demand relationship will not change.

\footnotetext{
Aim \#1: Characterize and Compare Hemodynamics and Myocardial Blood Flow during Partial and Full Unloading of the Normal Left Ventricle with a Continuous-Flow LVAD
} 
The goals of this aim were to determine how support with a continuous-flow LVAD affected hemodynamics, cardiac workload, and myocardial blood flow in normal animals. Regional myocardial blood flow was related to cardiac and arterial hemodynamics.

Hypothesis \#2: Coronary microembolization will produce stable and reproducible chronic, ischemic heart failure in calves.

Aim \#2: Develop and Characterize a Bovine Model of Chronic Heart Failure The goals of this aim were to establish and characterize a stable and reproducible model of microembolization-induced chronic, ischemic heart failure. This model was used to test the hypothesis of Aim \#3.

Hypothesis \#3: In animals with chronic heart failure, increasing levels of support with a continuous-flow LVAD will alter the pulsatile cardiac and systemic arterial hemodynamic profile. Continuous mechanical unloading of the failing left ventricle will reduce left ventricular but not right ventricular workload in a manner dependent on the degree of support. As a result, the unbalanced blood supply/demand relationship in the chronically hypoperfused myocardium will rebalance. 
Aim \#3: Characterize and Compare Hemodynamics and Myocardial Blood Flow during Partial and Full Unloading of the Failing Left Ventricle with a Continuous-Flow LVAD

The goals of this aim were to determine how support with a continuous-flow LVAD affected hemodynamics, cardiac workload, and myocardial blood flow in animals with chronic heart failure. Regional myocardial blood flow was related to cardiac and arterial hemodynamics. 


\section{CHAPTER IV}

\section{Aim \#1: PARTIAL vs. FULL SUPPORT OF THE NORMAL LEFT VENTRICLE WITH A CONTINUOUS-FLOW LVAD}

\section{Introduction}

Ongoing theoretical debate exists regarding the merits and limitations of partial vs. full circulatory support. With nearly 3,000 patients logged, the Interagency Registry for Mechanically Assisted Circulatory Support (INTERMACS) recently documented a 1year survival rate of $75 \%$ with full-support $\operatorname{LVADs}^{70}$. Clearly, end-stage heart failure patients are benefiting from full-support LVADs. Yet, better clinical outcomes are necessary before prolonged LVAD support is more widely accepted. For example, currently approved devices contain parts that wear down such as polymeric valves and diaphragms or mechanical contact bearings. To counter this limitation and increase device durability, third-generation, full-support devices include a bearingless, magnetically suspended impeller that does not wear over time or generate frictional heat $^{13}$. As a result, many continuous-flow devices have been miniaturized. In patients 
with moderate heart failure, earlier and minimally invasive partial support may preserve a near-normal pulsatile hemodynamic profile and reduce but not eliminate cardiac workload.

Partial support with a minimally invasive surgical approach may also expand the potential patient population for LVAD therapy. As LVADs are miniaturized, lessinvasive surgical approaches may increase acceptance by physicians who are more likely to refer patients for minimally invasive therapies ${ }^{71}$. Earlier intervention in less-sick patients should increase the public-health impact of mechanical circulatory support.

In our laboratory, preliminary work in a mock circulatory system demonstrated marked differences in pulsatility, ventricular pressure-volume relationships, and coronary blood flow during partial vs. full support with a continuous-flow $\mathrm{LVAD}^{72}$. However, in this in vitro study it was not possible to determine the effect of partial support on regional myocardial blood flow or the myocardial blood supply/demand relationship. A recent study in sheep demonstrated that increasing levels of support with a continuous-flow LVAD progressively decreased myocardial oxygen consumption, and coronary blood flow did not change ${ }^{33}$. However, the authors did not normalize coronary blood flow to myocardial oxygen consumption, and the effect on the oxygen supply/demand ratio was not reported. Furthermore, this study was performed in normal animals without cardiovascular pathology. 
In order to more rigorously characterize the effect of continuous unloading on the myocardial blood supply/demand relationship, Aim \#1 was a first step in understanding the chronic consequences of full vs. partial support with a continuous-flow LVAD. The major goal was to examine acute responses in normal animals. Standard indices of cardiovascular performance and regional myocardial blood flow were measured during partial and full support of the normal left ventricle. The implication for reverse myocardial remodeling and myocardial recovery were considered. The results of this study will help to guide future investigation into acute and chronic effects of continuousflow mechanical circulatory support in large-animal models of chronic cardiac pathology. 


\section{Materials and Methods}

$\underline{\text { Animals }}$

Male Jersey and mixed-breed calves $(\mathrm{n}=8,126 \pm 13 \mathrm{~kg})$ were used. All animals received humane care and were handled in accordance with National Institutes of Health and University of Louisville animal care committee guidelines. Experimental procedures followed the University of Louisville Institutional Animal Care and Usage Committee approved protocol \#08073.

\section{Anesthesia}

Animals were pre-anesthetized with Atropine $(30 \mathrm{mg})$ and prepared for acute, non-sterile surgery. In the operating room, general anesthesia was administered with Isoflurane (3$5 \%$ ) and room air. The animal was placed on the operating table in right lateral recumbency. Tidal volume and respiratory rate were adjusted to maintain arterial oxygen saturation above $90 \%$. Fluid-filled arterial and venous catheters were placed in the left carotid artery and jugular vein for blood sampling. A left thoracotomy was performed. Ribs \#4 and \#5 were resected. The pericardium was opened. The animal was anticoagulated with a single bolus of intravenous Heparin (100 units $/ \mathrm{kg})$. For the remainder of the procedure, the activated clotting time (ACT) was maintained above 250 $\mathrm{s}$ with additional boluses of Heparin (1,000 to 2,000 units).

\section{Surgical Instrumentation}

A single-tip high-fidelity micromanometer catheter (Millar Instruments, Houston, TX) 
was placed in the aorta and a dual pressure-volume conductance catheter (Millar Instruments, Houston, TX) was advanced from the left atrium across the mitral valve into the left ventricle for, simultaneous measurement of aortic, left atrial, and left ventricular blood pressures. A transit-time ultrasonic flow probe (Transonics, Ithaca, NY) was placed around the pulmonary artery to measure cardiac output. In six animals, a silicone catheter (7-French, Access Technologies, Skokie, IL) was advanced in the left atrial appendage chamber for administration of $15 \mu \mathrm{m}$ fluorescent-labeled polystyrene microspheres as described below. The depth and angle of catheter entry parallel to the surface of the left atrial appendage ensured that the catheter did not interfere with mitral valve function.

\section{LVAD Implantation}

A continuous-flow LVAD (HeartWare HVAD n=4, Thoratec HeartMate II $n=2$ ) was implanted with cardiopulmonary bypass. The outflow graft was anastomosed to the descending aorta. The left ventricular apex was cored and cannulated. The device and outflow graft were de-aired. A transit-time ultrasonic flow probe (Transonics, Ithaca, NY) was placed around the outflow graft to measure LVAD flow.

\section{Experimental Design}

In each animal, blood pressure and flow waveforms were recorded during Baseline (pump off, outflow graft clamped), Low Partial Support $(\sim 1.5 \mathrm{~L} / \mathrm{min}$ support, aortic valve opening every beat), High Partial Support ( $\sim 3 \mathrm{~L} / \mathrm{min}$ support, aortic valve opening every beat), and Full Support ( $\sim 5 \mathrm{~L} / \mathrm{min}$, aortic valve maintained closed, left ventricle 
maximally unloaded). Baseline and support modes for each device were maintained for 10 minutes each to achieve steady-state conditions prior to collection of 30 second data sets. During each condition, a single color of fluorescent-labeled microspheres $(5.25$ million microspheres) was injected into the left atrial catheter. Simultaneously, a reference blood sample was withdrawn from the arterial line at a rate of $15 \mathrm{ml} / \mathrm{min}$ for 100 seconds.

\section{Quantification of Microspheres and Regional Myocardial Blood Flow}

The microsphere technique enabled the precise measurement of regional blood flow in vascular beds of interest as follows. In the left ventricle, the microspheres mixed with the blood and were ejected into the aorta to disseminate throughout the body to every organ according to the physiological distribution of blood flow during that experimental condition. As the microspheres approached capillaries, they lodged within the smallest pre-capillary arterioles based on regional tissue blood flow patterns. With the quantity used, $15 \mu \mathrm{m}$ spheres do not cause ischemia and did not induce pathology $\mathrm{y}^{73}$.

The aortic blood sample acted as a reference for later determination of flow in tissues of interest. The number of counted microspheres in the reference blood sample (known counted with flow cytometry) was compared to the number of microspheres that lodged in pre-capillary arterioles and were counted in a tissue sample of interest (knowncounted with flow cytometry). The ratio between the two sphere counts was equal to the ratio between the calibrated rate of aortic withdrawal (known $-15 \mathrm{ml} / \mathrm{min}$ ) and flow in 
the tissue of interest (unknown) and provided accurate determinations of tissue specific flows in milliliters per minute per gram of tissue $(\mathrm{ml} / \mathrm{min} / \mathrm{g})^{73,74}$.

At the completion of the study, while under anesthesia, euthanasia was performed with a fatal intravenous bolus injection of Beuthanasia-D Special $(1 \mathrm{ml} / 5 \mathrm{~kg})$. The heart was removed. One to two gram tissue sections from the left ventricular free wall, right ventricular free wall, interventricular septum, and left ventricular epicardium, midmyocardium, and endocardium were collected. Myocardial and reference blood samples were sent to IMT/Stason Laboratories (Irvine, CA) for automated digestion, counting of fluorescent microspheres with flow cytometry, and calculation of tissue specific blood flows in $\mathrm{ml} / \mathrm{min} / \mathrm{g}$ of tissue.

\section{Data Reduction}

All transducers were pre- and post-calibrated against known physical standards to ensure measurement accuracy. Calibration curves for the volume conductance catheter were constructed using static and dynamic tests pre- and post-experiment. Data were collected at $400 \mathrm{~Hz}$, signal conditioned, and A/D converted for digital analysis using our Good Laboratory Practices (GLP) compliant data acquisition system ${ }^{75}$.

To determine hemodynamic performance during each support mode, pressure and flow waveforms were used to derive LVAD flow (LVADF), heart rate (HR), left ventricular stroke volume (LV SV), pulmonary artery flow (PAF) as an index of cardiac output (CO), mean left atrial pressure (LAP), left ventricular end-diastolic pressure (LVP end 
diastolic $)$, left ventricular peak systolic pressure $\left(\mathrm{LVP}_{\text {peak systolic }}\right), \pm \mathrm{dP} / \mathrm{dt}$, aortic systolic blood pressure ( $\left(\mathrm{AoP}_{\text {systolic }}\right)$, aortic diastolic blood pressure $\left(\mathrm{AoP}_{\text {diastolic }}\right)$, mean aortic pressure $\left(\mathrm{AoP}_{\text {mean }}\right)$, and aortic pulse pressure $\left(\mathrm{Ao} \mathrm{P}_{\text {pulse }}\right)$. Rate-pressure product $(\mathrm{HR} x$ $\mathrm{LVP}_{\text {peak systolic }}$ ), a standard index of cardiac metabolic demand ${ }^{76}$, was calculated.

Myocardial vascular resistance was calculated as $\mathrm{AoP}_{\text {mean }} / \mathrm{region}^{- \text {specific myocardial }}$ blood flow. Hemodynamic variables were calculated on a beat-to-beat basis for each 30 second data set with the Hemodynamic Evaluation and Assessment Research Tool (HEART) program ${ }^{77}$ developed in Matlab (Version 6.5, MathWorks, Natick, MA). All analyzed beats in each data set (approximately 30 to 50 beats $/ 30$ second data set) were averaged to obtain a single representative mean value for each calculated variable.

\section{$\underline{\text { Statistics }}$}

GraphPad, version 4.00 (Prism, La Jolla, CA) was used to perform statistical analyses and plot data. One-way repeated measures ANOVA with Tukey post-test was performed for each hemodynamic index, region of myocardial blood flow, and myocardial blood flow normalized to HR $x$ LVP $_{\text {peak systolic }}$ to compare Baseline, Low Partial Support, High Partial Support, and Full Support modes within each animal. All analyses were twotailed, and a p-value $<0.05$ (95\% confidence) was considered statistically significant. All data are presented as mean \pm standard error. 
III. Results

Table 1 demonstrated that in normal animals, as the level of support with a continuousflow LVAD increased, the cardiac and systemic arterial hemodynamic profile progressively changed. An increase in continuous support decreased HR and CO. Although the difference between Baseline and Full Support were not statistically different, the reductions were quantitatively large ( $\mathrm{HR},-16 \mathrm{bpm} ; \mathrm{CO},-0.9 \mathrm{~L} / \mathrm{min}$ ).

\section{Left Ventricular Hemodynamics}

Left ventricular pressures demonstrated the most robust changes. The progressive increase in continuous support significantly decreased LAP ( $p=0.01), \mathrm{LVP}_{\text {end diastolic }}$ $(p<0.001)$, and $\mathrm{LVP}_{\text {peak systolic }}(\mathrm{p}=0.05)$ with a dose-dependent response. These reductions were greatest and indicated maximum unloading during Full Support. Smaller reductions were observed during partial-support modes. Increasing levels of continuous support did not affect $\pm \mathrm{dP} / \mathrm{dt}$.

During Full Support, the variation between peak-systolic and end-diastolic pressures decreased to non-physiologically low values and resulted in chronic closure of the aortic valve. In this situation, the average $\mathrm{LVP}_{\text {peak systolic }}(77 \pm 11 \mathrm{mmHg})$ did not exceed the AoP diastolic $_{\text {( }}(80 \pm 6 \mathrm{mmHg})$. As a result, the aortic valve remained closed, and $\mathrm{HR} \mathrm{x}$ $\mathrm{LVP}_{\text {peak systolic }}$ decreased significantly $(\mathrm{p}=0.05)$ to values that are not seen in normal animals. This finding indicated that unloading the heart with a continuous-flow LVAD 
dramatically reduced myocardial metabolic demands and with a dose-dependent response.

\section{$\underline{\text { Arterial Hemodynamics }}$}

Systemic arterial pressures demonstrated less robust changes. As continuous support increased, $\mathrm{AoP}_{\text {mean }}$ and $\mathrm{AoP}_{\text {systolic }}$ did not change. However, during Full Support AoP $\mathrm{P}_{\text {diastolic }}$ trended toward an increase of nearly $10 \mathrm{mmHg}(\mathrm{p}=0.11)$, and $\mathrm{AoP} \mathrm{pulse}_{\text {se }}$ decreased significantly from $28 \pm 8$ to $14 \pm 11(\mathrm{p}<0.0001)$. In contrast, during partialsupport modes, the arterial pulse pressure was not significantly changed from baseline.

\section{Myocardial Blood Supply/Demand Relationship}

In normal animals, continuous support of the left ventricle did not affect right ventricular myocardial vascular resistance or blood flow. However, in the left ventricle and interventricular septum, increasing levels of continuous support reduced the cardiac workload, increased myocardial vascular resistance (Table 2), and decreased regional left ventricular blood flow (Table 3) with a significant dose-dependent response. Changes in vascular resistance and blood flow in the epicardial region demonstrated that the coronary arteries and large coronary arterioles were participating in observed changes.

To characterize the relationship between myocardial blood supply/demand, regional myocardial blood flow was normalized to $\mathrm{HR} \times \mathrm{LVP}_{\text {peak systolic. Increasing levels of }}$ continuous support did not alter the ratio between left ventricular myocardial blood flow and left ventricular workload (Table 4). A baseline value of 0.0085 


\begin{tabular}{|c|c|c|c|c|c|c|c|c|c|c|c|c|c|c|}
\hline$n=8$ & $\begin{array}{l}\text { LVADF } \\
\text { (L/min) }\end{array}$ & $\begin{array}{c}\text { HR } \\
\text { (bpm) }\end{array}$ & $\begin{array}{l}\text { LV SV } \\
(\mathrm{ml})\end{array}$ & $\begin{array}{c}\text { PAF } \\
\text { (L//min) }\end{array}$ & $\begin{array}{c}\text { LAP } \\
(\mathrm{mmH})\end{array}$ & $\begin{array}{l}\text { LVP } \text { end diestolic } \\
(\mathbf{m m H g})\end{array}$ & 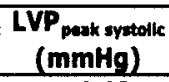 & $\begin{array}{c}+\mathrm{dP} / \mathrm{dt} \\
(\mathrm{mmHg} / \mathrm{s})\end{array}$ & $\begin{array}{c}-\mathrm{dP} / \mathrm{dt} \\
(\mathrm{mmHg} / \mathrm{s})\end{array}$ & $\begin{array}{l}\text { HR } \times \text { LVP penk systolic } \\
\text { (bpm } \times \text { mmHg) }\end{array}$ & $\begin{array}{l}\text { AOP }_{\text {moan }} \\
(m m H g)\end{array}$ & $\begin{array}{l}\text { AOP } \text { rutolic } \\
\text { (mmHq) }\end{array}$ & $\begin{array}{l}\text { AoP dbatolk } \\
(\mathrm{mmH})\end{array}$ & $\begin{array}{l}\text { AoP pulse } \\
(\mathrm{mmHg})\end{array}$ \\
\hline ANOVA & $p<0.0001$ & $p=0.08$ & $p=0.61$ & $p=0.24$ & $p=0.01$ & $p<0.001$ & $p=0.05$ & $p=0.68$ & $p=0.34$ & $p=0.05$ & $p=0.93$ & $p=0.68$ & $p=0.11$ & $p<0.0001$ \\
\hline as & $0.0 \pm 0.0$ & $86 \pm 7$ & $9 \pm 9$ & 8.6 & $16 \pm 6$ & $15 \pm 2$ & $98 \pm 5$ & 04 & $-1,6$ & 8,627 & $34 \pm 5$ & $100 \pm 5$ & 55 & $28 \pm 3$ \\
\hline irtial s & $1.8 \pm 0.2^{*}$ & $72 \pm 5$ & $108 \pm 17$ & $7.9 \pm 1.3$ & $15 \pm 5$ & $16 \pm 2$ & $96 \pm 6$ & $1,517 \pm 295$ & $-1,698 \pm 262$ & $6,935 \pm 577$ & $83 \pm 5$ & $98 \pm 6$ & $69 \pm 4$ & $29 \pm 3$ \\
\hline High & $3.3 \pm 0.3^{*}+$ & $71 \pm 5$ & $106 \pm 13$ & $7.5 \pm 1.1$ & $15 \pm 5$ & $15 \pm 2$ & $91 \pm 8$ & $1,243 \pm 241$ & $-1,420 \pm 175$ & $6,463 \pm 753$ & $83 \pm 5$ & $95 \pm 5$ & $73 \pm 4$ & $22 \pm 3+$ \\
\hline Full S & $5.2 \pm 0.6^{*} \ddagger \neq$ & $70 \pm 5$ & $111 \pm 13$ & $7.7 \pm 0.9$ & $12 \pm 5 *$ & $11 \pm 2^{*+\neq}$ & $77 \pm 11$ & $1,296 \pm 340$ & $-1,299 \pm 349$ & $5,568 \pm 971 *$ & $86 \pm 5$ & $94 \pm 6$ & $80 \pm 6$ & $14 \pm 4^{*}+\ddagger$ \\
\hline
\end{tabular}

Table 1: Hemodynamics during partial vs. full unloading of the normal left ventricle with a continuous-flow LVAD. LVADF, left ventricular assist device flow; HR, heart rate; LV SV, left ventricular stroke volume; PAF, pulmonary artery flow; LAP, left atrial pressure; LVP, left ventricular pressure; AoP, aortic pressure; ${ }^{*} \mathrm{p}<0.05$, support mode vs. Baseline; $\nmid \mathrm{p}<0.05$, support mode vs. Low Partial Support; $\ddagger \mathrm{p}<0.05$, support mode vs. High Partial Support 
$\mathrm{ml} / \mathrm{min} / 100 \mathrm{~g} / \mathrm{bpm} \cdot \mathrm{mmHg}$ was established as the myocardial blood supply/demand

relationship in normal animals. Figure 3 summarizes the gross physiological changes

observed during continuous unloading of the normal left ventricle.

\begin{tabular}{|c|c|c|c|c|c|c|}
\hline$n=6$ & $\underset{(\mathrm{mmHg} / \mathrm{ml} / \mathrm{min} / \mathrm{g})}{\mathbf{R V}}$ & $\underset{(\mathrm{mmHg} / \mathrm{ml} / \mathrm{mln} / \mathrm{g})}{\mathrm{LV}}$ & $\underset{(\mathrm{mmH} / \mathrm{ml} / \mathrm{min} / \mathrm{g})}{\text { Septum }}$ & $\underset{(m m+t g / m 1 / m i n / g)}{\text { Epicardium }}$ & $\begin{array}{c}\text { Mid-Myocardium } \\
\text { (mmitg/mi/min/g) }\end{array}$ & $\begin{array}{l}\text { Endocardium } \\
(\mathrm{mmH} / \mathrm{m} / \mathrm{min} / \mathrm{g})\end{array}$ \\
\hline ANOVA $p$-value & $p=0.47$ & $p=0.07$ & $p=0.04$ & $p=0.07$ & $p=0.02$ & $p=0.08$ \\
\hline Baseline & $138 \pm 28$ & $120 \pm 22$ & $114 \pm 20$ & $138 \pm 30$ & $106 \pm 20$ & $133 \pm 21$ \\
\hline Low Partial Support & $163 \pm 33$ & $151 \pm 30$ & $154 \pm 28$ & $173 \pm 40$ & $138 \pm 30$ & $186 \pm 41$ \\
\hline High Partial Support & $235 \pm 82$ & $238 \pm 86$ & $239 \pm 86$ & $262 \pm 98$ & $199 \pm 65$ & $253 \pm 92$ \\
\hline Full Support & $188 \pm 67$ & $284 \pm 85$ & $304 \pm 86 *$ & $328 \pm 108$ & $277 \pm 75 *$ & $352 \pm 123$ \\
\hline
\end{tabular}

Table 2: Regional myocardial vascular resistance during partial vs. full support of the normal left ventricle with a continuous-flow LVAD. RV, right ventricle; $L V$, left ventricle; ${ }^{*} \mathrm{p}<0.05$, Full Support vs. Baseline

\begin{tabular}{|c|c|c|c|c|c|c|}
\hline$n=6$ & $\begin{array}{c}\text { RV } \\
(\mathrm{m} / \mathrm{min} / \mathrm{g})\end{array}$ & $\begin{array}{c}\mathrm{LV} \\
(\mathrm{ml} / \mathrm{min} / \mathrm{g})\end{array}$ & $\begin{array}{c}\text { Septum } \\
(\mathrm{mi} / \mathrm{min} / \mathrm{g})\end{array}$ & $\begin{array}{l}\text { Epicardium } \\
(\mathrm{m} / / \mathrm{min} / \mathrm{g})\end{array}$ & $\begin{array}{l}\text { Mid-Myocandium } \\
(\mathrm{ml} / \mathrm{min} / \mathrm{g})\end{array}$ & $\begin{array}{l}\text { Endocardium } \\
(\mathrm{m} / \mathrm{min} / \mathrm{g})\end{array}$ \\
\hline ANOVA p-value & $p=0.49$ & $\mathrm{p}=0.05$ & $p=0.07$ & $p=0.07$ & $p=0.01$ & $p=0.11$ \\
\hline Baseline & $0.60 \pm 0.90$ & $0.70 \pm 0.10$ & $0.73 \pm 0.13$ & $0.65 \pm 0.13$ & $0.80 \pm 0.12$ & $0.61 \pm 0.08$ \\
\hline Low Partial Support & $0.47 \pm 0.08$ & $0.63 \pm 0.14$ & $0.60 \pm 0.13$ & $0.58 \pm 0.14$ & $0.69 \pm 0.14$ & $0.53 \pm 0.13$ \\
\hline High Partial Support & $0.47 \pm 0.08$ & $0.52 \pm 0.13$ & $0.52 \pm 0.14$ & $0.51 \pm 0.14$ & $0.58 \pm 0.14$ & $0.47 \pm 0.12$ \\
\hline Full Support & $0.49 \pm 0.09$ & $0.43 \pm 0.11^{*}$ & $0.38 \pm 0.09 *$ & $0.40 \pm 0.10$ & $0.42 \pm 0.10^{*}$ & $0.35 \pm 0.08$ \\
\hline
\end{tabular}

Table 3: Regional myocardial blood flow during partial vs. full support of the normal left ventricle with a continuous-flow LVAD. RV, right ventricle; $L V$, left ventricle; ${ }^{*} p<0.05$, Full Support vs. Baseline

\begin{tabular}{|c|c|c|}
\hline$n=6$ & $\begin{array}{l}\text { LV/HRXLVP } \\
\text { peak systolic } \\
(\mathrm{ml} / \mathrm{min} / 100 \mathrm{~g} / \mathrm{bpm} \cdot \mathrm{mmHg})\end{array}$ & $\begin{array}{c}\text { Septum/HRxLVP } \\
(\mathrm{ml} / \mathrm{min} / 100 \mathrm{~g} / \mathrm{bpm} \cdot \mathrm{mm} \mathrm{Hg})\end{array}$ \\
\hline ANOVA $p$-value & $p=0.72$ & $p=0.91$ \\
\hline Baseline & $0.0082 \pm 0.0011$ & $0.0085 \pm 0.0014$ \\
\hline Low Partial Support & $0.0101 \pm 0.0017$ & $0.0097 \pm 0.0017$ \\
\hline High Partial Support & $0.0082 \pm 0.0017$ & $0.0080 \pm 0.0016$ \\
\hline Full Support & $0.0119 \pm 0.0046$ & $0.0093 \pm 0.0025$ \\
\hline
\end{tabular}

Table 4: Regional myocardial blood supply/demand relationship during partial vs. full support of the normal left ventricle with a continuous-flow LVAD. LV, left ventricle; HR, heart rate; LVP, left ventricular pressure 


\title{
Cardiac Workload
}

\section{Myocardial Vascular Resistance}

Myocardial Flow

\author{
Flow/Workload
}

Figure 3: During support of the normal left ventricle with a continuous-flow LVAD, cardiac workload decreased, myocardial vascular resistance increased, and myocardial blood flow decreased. However, the relationship between blood supply and demand did not change and indicated that an intact coronary reserve and appropriate coronary autoregulation were present. 


\section{Conclusions}

The study of partial vs. full support of the left ventricle with a continuous-flow LVAD was possible in normal animals. Specifically, in animals without cardiovascular pathology, 1) a systemic flow reserve was present, 2) full support with a continuous-flow LVAD deranged pulsatility whereas partial support preserved a more normal pulsatile profile, 3) as continuous support increased, left ventricular workload and blood flow decreased, likely as a result of appropriate coronary autoregulation and an intact coronary reserve. These results will help guide future acute and chronic studies in large-animal models of cardiac pathology to determine effects of partial vs. full support of the left ventricle with a continuous-flow LVAD.

\section{Systemic Effects}

In normal animals, a systemic flow reserve was present. As the level of support with a continuous-flow LVAD increased, HR and CO decreased in a dose-dependent manner. This finding in animals without chronic pathology was not unexpected.

In chronic heart failure, a systemic flow reserve may be absent. Therefore, these results from normal animals likely cannot be generalized to animals with heart failure.

It is possible that a lack of pulsatile blood flow drops systemic metabolism. To generate force, cardiac myocytes consume large quantities of oxygen ${ }^{78}$. Similarly, because of pulsatile stretch and in order to maintain vascular tone, endothelial cells have the greatest oxidative metabolism of any cells in the body ${ }^{79}$. As a result, during the generation and 
regulation of arterial pulsatility, cardiac myocytes, endothelial cells, and vascular smooth muscle cells metabolize large quantities of oxygen. Therefore, the reduction of cardiac metabolic demands and arterial pulsatility with a continuous-flow LVAD is likely to drop total body oxygen requirements and therefore $\mathrm{CO}$. If this is the case, any level of support with a continuous-flow LVAD that reduces cardiac workload and arterial pulsatility will reduce total body oxygen consumption and benefit the heart failure condition.

\section{Effects on the Heart}

In the normal heart, full support of the left ventricle with a continuous-flow LVAD deranged the natural profile of pulsatile cardiac hemodynamics. As continuous support increased, the maximum pressure generated by the left ventricle dropped below the arterial diastolic pressure. Insufficient preload was available to eject through the aortic valve, which did not open. As a result, the workload of the heart was significantly reduced to values that are not normally observed in bovids. As workload decreased, myocardial vascular resistance increased, and myocardial blood flow decreased. The ratio between blood supply and demand did not change and indicated appropriate coronary autoregulation and the presence of an intact coronary reserve. Substantial changes in epicardial vascular resistance and blood flow further suggested that the coronaries were participating in this process and that coronary vasomotor function was normal.

In chronic heart failure, a coronary flow reserve may be absent ${ }^{60}$. Therefore, these results from normal animals likely cannot be generalized to animals with heart failure. 


\section{Effects on the Arterial System}

In normal arteries, full support of the normal left ventricle with a continuous-flow LVAD deranged the natural profile of pulsatile arterial hemodynamics. As continuous support increased, arterial diastolic pressure trended upwards, and $\mathrm{AoP}_{\text {pulse }}$ was reduced by half. In contrast, partial support with a continuous-flow LVAD allowed the aortic valve to open on every beat. A normal profile of cardiac and systemic arterial hemodynamics with a near-normal pulse pressure was preserved.

\section{Potential Mechanism for Unfavorable Histological Changes during Prolonged LVAD}

\section{$\underline{\text { Support }}$}

Our findings suggest mechanisms by which diminished pulsatility may induce histological changes within the cardiovascular system during prolonged support with a continuous-flow LVAD. When cells in the heart and vasculature are exposed to chronically deranged mechanical forces such as during hypertension, pathological remodeling may occur. For example, chronic hypertension is well documented to induce concentric myocardial hypertrophy in the heart as well as tunica medial thickening and alterations of the collagen/elastin ratio in conduit arteries ${ }^{80}$. During isolated systolic hypertension, pulse pressures are known to exceed 80 to $100 \mathrm{mmHg}$ and affect cardiac and arterial tissues. Even the acute blood pressure elevations that are observed in malignant hypertension may induce acute pathological vascular remodeling that include hyperplastic arteriolosclerosis and fibrinoid necrosis. 
During continuous unloading of the cardiovascular system, hemodynamics were similarly deranged but in the opposite direction of hypertension. Full Support reduced the peak left ventricular systolic pressure to a value below the diastolic arterial blood pressure, prevented the aortic valve from opening, and reduced the pulse pressure. As a result, myocardial metabolic demands decreased to values that are not encountered in bovids. Moderate reductions in metabolic demands are likely important, especially if the goal of treatment is myocardial recovery. However, the optimal reduction in cardiac metabolism which allows the heart to rest while maintaining a partial workload has not been established, and excessive myocardial unloading in which the heart performs too little workload may induce myocardial atrophy $y^{29,30}$ and fibrosis ${ }^{31,32}$. As a result, it is likely that the lack of adequate myocardial and arterial stretch during full-support in continuous-flow LVAD patients may induce architectural changes in cardiovascular tissues that have long-term consequences, especially if the goal is myocardial recovery. By maintaining pulsatility and a reduced cardiac workload, partial support may attenuate these effects.

In summary, partial support with a continuous-flow LVAD is feasible and may preserve a more normal cardiac and systemic arterial hemodynamic profile. Effects of partial support during heart failure are unlikely to be the same as in normal animals, and the clinical utility of partial support remains to be determined. 


\section{CHAPTER V}

\section{Aim \#2: DEVELOPMENT OF A BOVINE MODEL OF CHRONIC, ISCHEMIC HEART FAILURE}

\section{Introduction}

The development of a stable and reproducible model of chronic heart failure with a low mortality rate is critical for successful translational research on the clinical treatment of heart failure. A large-animal model which closely mimics the human cardiovascular condition (bovine or ovine) ${ }^{81}$ is necessary for the preclinical testing of implantable devices as well as to examine (patho)physiological processes associated with mechanical circulatory support. In terms of anatomical size of the thorax and physiological function of the cardiovascular system, normal calves have been used for decades as the industry standard to test safety, performance, and reliability of LVAD systems—phylogenetically lower species are too small to accommodate implantable cardiac devices. Yet largeanimal models of chronic cardiac pathology have only been used to a limited extent to investigate mechanical circulatory support ${ }^{82-84}$ and adjunct therapies ${ }^{85}$ and have not been 
used to determine efficacy or to compare the physiological benefits of different strategies of mechanical circulatory support. As a result, mechanisms of reverse myocardial remodeling, myocardial recovery, and pathophysiological responses to mechanical circulatory support such as ischemic and hemorrhagic stroke ${ }^{86}$, acquired von Willebrand disease $^{87,88}$, diastolic hypertension ${ }^{57,58}$, and gastrointestinal arteriovenous malformations and bleeding ${ }^{89}$ are largely uncharacterized.

Rapid-pacing, volume overload, pressure overload, coronary ligation, microembolization, and cardiotoxic drugs have been used to induce chronic heart failure in multiple species ${ }^{90}$. Additionally, spontaneous genetic cardiomyopathy exists in Holstein-Fresian cattle ${ }^{91,92}$. Yet, models of chronic, experimental bovine heart failure ${ }^{83,93}$ are infrequent in the literature.

Ischemic cardiomyopathy is the most prevalent etiology of heart failure in human patients and currently affects more than 3 million people in the United States alone ${ }^{94}$. As such, large-animal models of chronic, ischemic heart failure are necessary to translate basic discoveries into clinical utility. Coronary microembolization models of ischemic heart failure have been developed and validated in sheep ${ }^{95-99}$ and in dogs ${ }^{100}$. In these studies, 50 to $120 \mu \mathrm{m}$ spheres injected into the coronary arteries lodged within pre-capillary arterioles, produced myocardial ischemia distal to the lodged spheres, and induced a severe, global left ventricular dysfunction. Over the course of days to weeks, animals developed a stable and reproducible state of left ventricular failure. 
Similarly, a bovine model of ischemic heart failure is urgently needed for preclinical studies of mechanical circulatory support. Notably, there is experimental evidence for the feasibility of such an approach. Injection of large quantities of 6 to $14 \mu \mathrm{m}$ plastic microspheres into the left main coronary arteries in calves resulted in elevated $L V P_{\text {end }}$ diastolic, reduced SV, CO, mean ejection rate, and left ventricular ejection time, and produced widespread microinfarcts through the left ventricle ${ }^{93}$. Similarly, daily injection of 37 to $70 \mu \mathrm{m}$ polystyrene microspheres into the left coronary artery of 5 calves resulted in diminished cardiac function, marked reductions in $\mathrm{CO}$, and significant increases in $\mathrm{LAP}^{83}$.

To study acute and chronic effects of LVADs on clinical, functional, histological, and molecular markers of myocardial remodeling during heart failure and mechanical circulatory support, Aim $\# 2$ was developed to characterize a bovine model of chronic, ischemic left ventricular failure. Clinically relevant heart failure was defined by a reduction of ejection fraction by greater than $40 \%$, changes in ventricular geometry, hemodynamic imbalance, end-organ hypoperfusion, and histopathological myocardial changes. Results will assist in guiding future investigation into effects of acute and chronic mechanical circulatory support in a large-animal model of chronic cardiac pathology.

The utility of this model extends beyond this project and our laboratory. Our results contribute a novel and clinically relevant, large-animal heart failure model for other investigators, government agencies, and industry. 


\section{Materials and Methods}

\section{$\underline{\text { Animals }}$}

Male Jersey, K-bar, and mixed-breed calves $(\mathrm{n}=15,96 \pm 8 \mathrm{~kg})$ were used. All animals received humane care and were handled in accordance with National Institutes of Health and University of Louisville animal care committee guidelines. Experimental procedures followed the University of Louisville Institutional Animal Care and Usage Committee approved protocol $\# 09080$.

\section{Anesthesia}

Twenty-four hours prior to coronary microembolization, oral Atenolol $(50 \mathrm{mg})$ was administered to decrease post-microembolization mortality as previously reported ${ }^{95}$. Animals were pre-anesthetized with Atropine $(30 \mathrm{mg}$ ) and prepared for strict aseptic surgery. Prophylactic intravenous Cefazolin (15 to $20 \mathrm{mg} / \mathrm{kg}$ ) was administered. In the catheterization laboratory, general anesthesia was administered with Isoflurane (3-5\%) and room air. Tidal volume and respiratory rate were adjusted to maintain arterial oxygen saturation above $90 \%$. An intravenous catheter was placed in the marginal ear vein for administration of normal saline ( 5 to $10 \mathrm{ml} / \mathrm{kg} /$ hour) to maintain arterial blood pressure. An intraarterial catheter was placed in the marginal ear artery to monitor arterial blood pressure. Surface electrocardiographic leads were sutured to the skin in a lead II configuration. Via modified Seldinger technique, a 7-French introducer sheath was introduced into the left common carotid artery. The animal was anticoagulated with a single bolus of intravenous Heparin (100 units $/ \mathrm{kg})$. 


\section{Cardiac Catheterization and Baseline Hemodynamics}

Under fluoroscopic guidance, a 6-French dual-tip pressure-volume conductance catheter (Millar Instruments, Houston, TX) was advanced from the carotid artery into the left ventricle for simultaneous measurement of left ventricular and aortic blood pressures. A 30 second continuous data set was recorded at normal baseline. Approximately 45 minutes after coronary microembolization, this procedure was repeated and a postembolization heart failure baseline data set was recorded.

\section{Cardiac Catheterization and Baseline End-Organ Blood Flow Measurement}

Under fluoroscopic guidance, a 6-French pigtail catheter was advanced from the carotid artery into the left ventricle for injection of $15 \mu \mathrm{m}$ fluorescent-labeled microspheres. A single color of fluorescent-labeled microspheres (5.25 million microspheres) was injected into the left ventricular chamber. Simultaneously, a reference blood sample was withdrawn from the carotid sheath at a rate of $15 \mathrm{ml} / \mathrm{min}$ for 100 seconds. The microsphere technique enables the precise measurement of regional blood flow in vascular beds of interest as previously described in Chapter IV, Section II.

\section{Coronary Catheterization and Microembolization}

Intravenous Lidocaine $(100 \mathrm{mg})$ and Amiodarone $(150 \mathrm{mg})$ were administered to prevent arrhythmia. Under fluoroscopic guidance, a 6-French diagnostic catheter (AL-2) was advanced from the carotid artery to selectively engage the left main coronary artery. Correct catheter placement was confirmed by coronary angiography with radio-opaque 
contrast dye (Iothalamate Meglumine, Conray 43, Mallinckrodt, St. Louis MO) as needed.

To induce global left ventricular ischemia and chronic, ischemic heart failure, $90 \mu \mathrm{m}$ polystyrene microspheres suspended in contrast dye were injected into the left main coronary artery. Real-time observation of electrocardiographic ST-segment changes were observed and confirmed myocardial ischemia, which accompanied hemodynamic impairment (Figure 4).
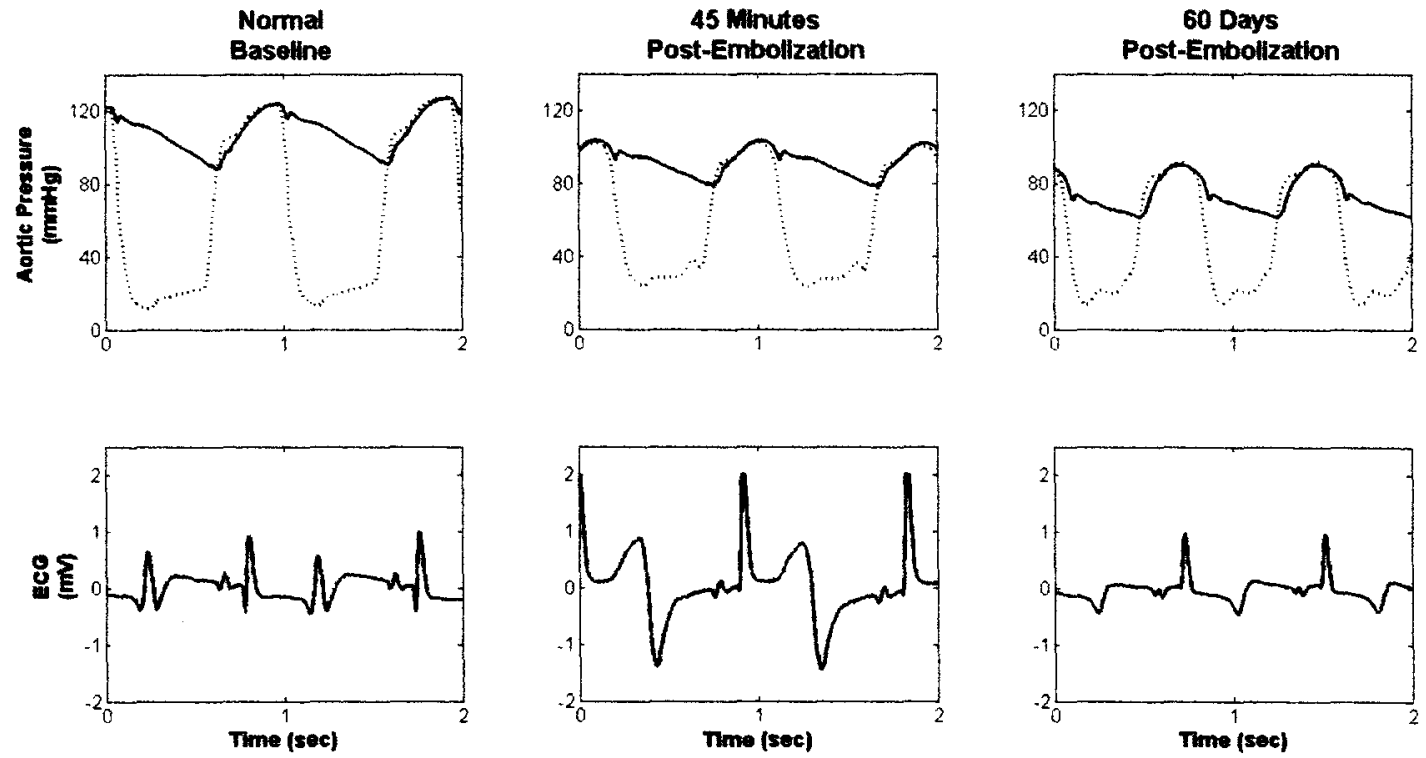

Figure 4: During a typical microembolization session, $90 \mu \mathrm{m}$ microspheres injected into the left main coronary artery produced electrocardiographic changes characteristic of myocardial ischemia. After 45 minutes, ST-segment elevation and hyperacute, biphasic T-waves indicated severe ischemic myocardial injury. These changes were accompanied by a $25 \mathrm{mmHg}$ decrease in mean arterial blood pressure that persisted at 60 days and indicated chronically impaired myocardial functional capacity. ECG, electrocardiogram 
Over the course of 30 to 45 minutes, multiple small boluses of microspheres were injected until severe and sustained electrocardiographic changes were accompanied by impaired hemodynamics. To maintain adequate end-organ blood flow, animals were supported with continuous infusion of intravenous Phenylephrine, Dobutamine, and normal saline to effect. Animals typically exhibited a 10 to $15 \mathrm{mmHg}$ rise in $\mathrm{LVP}_{\text {end }}$ diastolic. As such, prior to awakening an intravenous bolus of Lasix $(80 \mathrm{mg})$ was administered to promote diuresis, mitigate pulmonary effects of elevated left ventricular filling pressures, and promote recovery and survival.

At the end of the procedure, catheters and sheaths were removed, and percutaneous access sites were closed and compressed for 30 minutes until hemostasis was achieved. Animals were recovered.

\section{Clinical Management}

Heart rate, respiratory rate, blood pressure, and ECG were monitored for 48 to 72 hours post-embolization. A constant rate infusion of intravenous Amiodarone $(0.5-1.5 \mathrm{mg} / \mathrm{min})$ was maintained for 12 to 48 hours to prevent tachyarrhythmias. A constant rate infusion of intravenous Nitroglycerine ( $800 \mu \mathrm{g} /$ hour) was administered for 24 to 48 hours postembolization. Oral Atenolol (100 mg) was continued twice daily for three days. Intravenous Cefazolin ( 15 to $20 \mathrm{mg} / \mathrm{kg}$ ) was administered for 48 to 72 hours post embolization. Arterial blood gases and electrolytes were monitored every 2 to 4 hours for abnormalities. Most animals received intravenous Lasix ( 0.5 to $2 \mathrm{mg} / \mathrm{kg}$ ) for respiratory comfort every 4 to 6 hours based on the animals respiratory pattern and effort. 
Surface ECG leads were removed when the constant rate infusions were discontinued. In cases of severe heart failure, oral Lasix ( 0.5 to $4.0 \mathrm{mg} / \mathrm{kg}$ ) was continued twice daily to reduce pulmonary edema and respiratory distress. Blood draws were used to monitor electrolyte and hydration status.

\section{Echocardiography}

Transthoracic echocardiograms were measured at baseline, weekly for 60 days during the progression of heart failure, and while anesthetized during an acute terminal study with the chest open. A Phillips iE-33 machine with S8-3 ultrasound probe was used to obtain 2-dimensional echocardiographic recordings. Parasternal views were used to obtain images. Left ventricular ejection fraction, and end-systolic and end-diastolic volumes were determined from the apical four-chamber view with a modified Simpson technique (summation of discs). Target left ventricular dysfunction was defined as a reduction in left ventricular ejection fraction greater than $40 \%$.

\section{Terminal Study}

Sixty days after microembolization, a terminal study was performed to measure the hemodynamic severity of heart failure and to harvest tissues for histology and molecular analyses. Anesthesia was induced and maintained as described in Chapter IV, Section II. The animal was placed on the operating table in right lateral recumbency. Fluid-filled arterial and venous catheters were placed in the left carotid artery and jugular vein for blood sampling. A left thoracotomy was performed. Ribs \#4 and \#5 were resected. The pericardium was opened. An open-chest echocardiogram was performed. 
A single-tip, high-fidelity micromanometer catheter (Millar Instruments, Houston, TX) was placed in the aorta and a dual pressure-volume conductance catheter (Millar Instruments, Houston, TX) was advanced from the left atrium across the mitral valve into the left ventricle for simultaneous measurement of aortic, left atrial, and left ventricular blood pressures. A transit-time ultrasonic flow probe (Transonics, Ithaca, NY) was placed around the pulmonary artery to measure cardiac output. A silicone catheter (7French, Access Technologies, Skokie, IL) was implanted in the left atrial appendage chamber for injection of $15 \mu \mathrm{m}$ fluorescent-labeled polystyrene microspheres. The depth and angle of catheter entry parallel to the surface of the left atrial appendage ensured that the catheter did not interfere with mitral valve function.

\section{Experimental Design}

In each animal, blood pressure and flow waveforms were recorded for 30 seconds to determine the hemodynamic severity of heart failure. A single color of fluorescentlabeled microspheres (5.25 million microspheres) was injected into the left atrial catheter. Simultaneously, a reference blood sample was withdrawn from the arterial line at a rate of $15 \mathrm{ml} / \mathrm{min}$ for 100 seconds. The microsphere technique enabled the precise measurement of regional blood flow in vascular beds of interest as described in Chapter IV, Section II. 
Quantification of Microspheres and End-Organ Blood Flow

At the completion of the study, while under anesthesia, euthanasia was performed with a fatal intravenous bolus injection of Beuthanasia-D Special $(1 \mathrm{ml} / 5 \mathrm{~kg})$. The heart was removed and photographed. The ventricles were sectioned into a multi-level map (Figure 7). One to two gram tissue sections from the left ventricular free wall, right ventricular free wall, interventricular septum, left ventricular epicardium, mid-myocardium, and endocardium, kidney, liver, spleen, small bowel, lung, skin, skeletal muscle, brainstem, cerebellum, and frontal lobe were collected. Tissue samples and reference blood samples were sent to IMT/Stason Laboratories (Irvine, CA) for automated digestion and counting of fluorescent microspheres using flow cytometry and calculation of tissue specific blood flows in $\mathrm{ml} / \mathrm{min} / \mathrm{g}$ of tissue. Regional myocardial blood-flow maps were constructed on a piece-by-piece basis.

\section{$\underline{\text { Histology }}$}

Triphenyltetrazolium chloride (TTC) staining was performed on gross cross-sections of hearts to approximate the amount of infarcted myocardium. Microscopic myocardial histology was performed on left ventricular and right ventricular samples obtained from heart failure animals $(\mathrm{n}=9)$ and compared to myocardium from normal control animals $(\mathrm{n}=8)$. Paraffin-embedded tissues were sectioned at $4 \mu \mathrm{m}$, de-paraffinized, rehydrated, and stained. Regional myocardial fibrosis was quantified with Masson's trichrome staining as the ratio of area occupied by collagen stain to the area of myocardium sampled $^{101}$. Regional myocyte size was determined with FITC-conjugated wheat germ agglutinin and DAPI (Molecular Probes, Invitrogen, Carlsbad, CA) nuclear co-staining to 
delineate the cell membrane in 100 cross-sectional cells with centrally located nuclei ${ }^{102}$. Regional total cardiac apoptosis was determined with the DeadEnd Fluorometric TUNEL System (Promega, Madison, WI), which catalytically incorporates fluorescein-12-dUTP at DNA strand breaks in cells actively undergoing programmed cell death ${ }^{102}$. Nuclei were counterstained with DAPI. Myocyte-specific apoptosis was determined with a combination of Texas Red-conjugated wheat germ agglutinin, TUNEL, and DAPI staining. Images were viewed with epifluorescence microscopy (Nikon TE2000) and analyzed with Metamorph Imaging Software. For each histological stain, a minimum of three fields were analyzed from each myocardial region.

\section{Data Reduction}

All transducers were pre- and post-calibrated against known physical standards to ensure measurement accuracy. Calibration curves for the volume conductance catheter were constructed using static and dynamic tests pre- and post-experiment. Hemodynamic data were collected at $400 \mathrm{~Hz}$, signal conditioned, and $\mathrm{A} / \mathrm{D}$ converted for digital analysis using our GLP compliant data acquisition system ${ }^{75}$.

To determine the hemodynamic severity of heart failure, pressure and flow waveforms were used to derive $\mathrm{HR}, \mathrm{LVP}_{\text {end diastolic }}, \mathrm{LVP}_{\text {peak systolic }} \pm \mathrm{dP} / \mathrm{dt}, \mathrm{AoP} \mathrm{P}_{\text {mean }}, \mathrm{Ao} \mathrm{P}_{\text {systolic }}$, AoP $P_{\text {diastolic }}, \mathrm{AoP}_{\text {pulse, }} \mathrm{HR} \times \mathrm{LVP}_{\text {peak systolic }}, \mathrm{PAF}$ as an index of $\mathrm{CO}$, and $\mathrm{CO} /$ animal weight. Hemodynamic indices were calculated on a beat-to-beat basis for each 30 second data set with the Hemodynamic Evaluation and Assessment Research Tool (HEART) program ${ }^{77}$ developed in Matlab (Version 6.5, MathWorks, Natick, MA). All analyzed beats in each 
data set (approximately 30 to 50 beats/30 second data set) were averaged to obtain a single representative mean value for each calculated variable.

\section{$\underline{\text { Statistics }}$}

GraphPad, version 4.00 (Prism, La Jolla, CA) was used to perform statistical analyses and plot data. One-way repeated measures ANOVA with Tukey post-test was performed to compare weekly echocardiographic measurements. Unpaired student t-tests were performed to compare acute hemodynamics, chronic hemodynamics, end-organ blood flow, and histological findings between heart failure animals and normal animals $(n=9)^{15}$. Paired student t-tests were used to compare histological findings between the left and right ventricles within normal control and heart failure animals. All analyses were twotailed, and a p-value $<0.05$ ( $95 \%$ confidence) was considered statistically significant. All data are presented as mean \pm standard error. 


\section{Results}

\section{$\underline{\text { Survival, Clinical Findings, and Data Collected }}$}

Fifteen animals underwent selective left main coronary artery microembolization. Hemodynamics in 12 animals were studied at baseline prior to coronary microembolization and 45 minutes after microembolization. Nine animals survived the initial embolization period. These animals developed tachycardia, arrhythmias, murmurs, tachypnea, chronic coughing, and dyspnea on exertion. Serial echocardiography was performed weekly until termination. Of the nine animals, eight survived 60 days at which time an elective, terminal study was performed to measure the hemodynamic severity of heart failure, measure end-organ blood flow, and collect tissues.

\section{Echocardiography}

Target severity of chronic heart failure (approximately $40 \%$ reduction in ejection fraction) was achieved in eight animals. Figure 5 demonstrates M-Mode images at baseline (A) and 60 days after left main coronary microembolization (B) in the same animal. Increased heart rate, hypokinetic left ventricular wall motion, and marked dilatation of the left ventricular chamber are noted.

Left ventricular ejection fraction decreased in all animals (Figure 5 C) from a baseline conscious value of $81 \pm 5 \%$ to a final conscious value of $43 \pm 13 \%$ ( $p<0.01$ vs. baseline) and final anesthetized value of $29 \pm 10 \%$ ( $p<0.05 \mathrm{vs}$. final conscious). Left ventricular end-diastolic and end-systolic volumes increased in all animals (Figure 5 D) from 
baseline values of $115 \pm 45 \mathrm{ml}$ and $22 \pm 10 \mathrm{ml}$ to final values of $173 \pm 28 \mathrm{ml}$ ( $\mathrm{p}<0.05 \mathrm{vs}$.

baseline) and $101 \pm 53 \mathrm{ml}(\mathrm{p}<0.01$ vs. baseline), respectively.

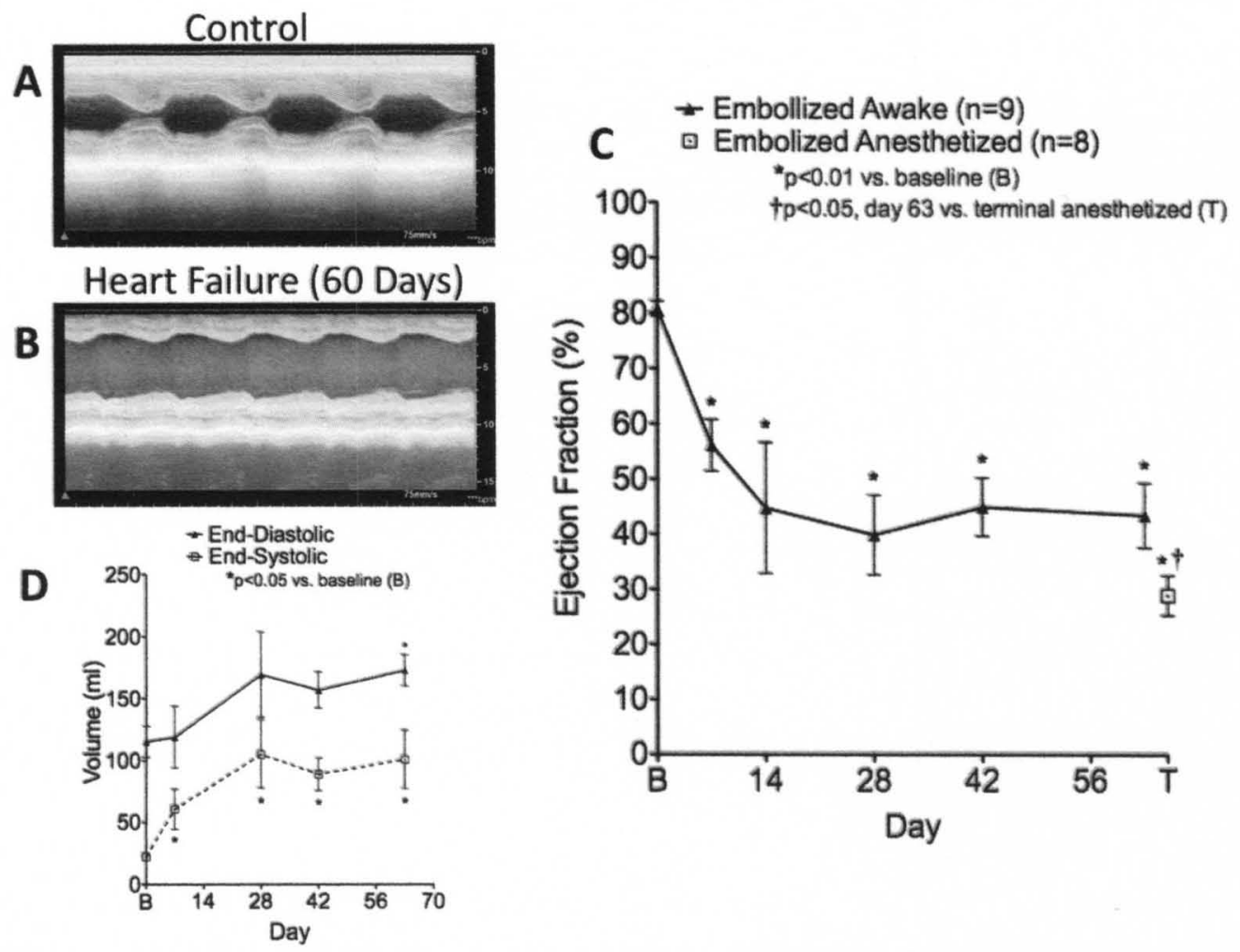

Figure 5 A, B: M-mode images at baseline and 60 days after coronary microembolization in the same animal. Left ventricular dilatation and systolic dysfunction are present. $\mathbf{C}$ : Coronary microembolization reduced the left ventricular ejection fraction by approximately $50 \%$. D: End diastolic and end-systolic left ventricular dilatation was present.

\section{$\underline{\text { Acute and Chronic Hemodynamics }}$}

Table 5 demonstrates hemodynamic variables measured at baseline and 45 minutes after left main coronary microembolization. Hallmark hemodynamic changes associated with systolic dysfunction were noted despite aggressive pharmacological support of hemodynamics. A significant increase in $\mathrm{LVP}_{\text {end diastolic }}(\mathrm{p}<0.0001)$ was accompanied by a significant decrease in $-\mathrm{dP} / \mathrm{dt}(\mathrm{p}=0.04)$ and trends toward decreased $\mathrm{LVP}_{\text {peak systolic }}$ $(\mathrm{p}=0.07), \mathrm{AoP}_{\text {mean }}(\mathrm{p}=0.14), \mathrm{AoP}_{\text {systolic }}(\mathrm{p}=0.09)$, and $\mathrm{AoP}_{\text {diastolic }}(\mathrm{p}=0.20)$. 
Table 6 demonstrates hemodynamic variables measured at 60 days after the induction of heart failure. When compared to normal calves of smaller size $(\mathrm{n}=9 \text {, mean: } 76.1 \mathrm{~kg})^{15}$, calves that underwent coronary microembolization exhibited hemodynamic changes associated with left ventricular dysfunction. A trend toward a compensatory tachycardia accompanied significantly decreased $\mathrm{LVP}_{\text {peak systolic }}(\mathrm{p}=0.008),-\mathrm{dP} / \mathrm{dt}(\mathrm{p}<0.001), \mathrm{AoP}_{\text {mean }}$ $(\mathrm{p}<0.002), \mathrm{AoP}_{\text {systolic }}(\mathrm{p}<0.002), \mathrm{AoP}_{\text {diastolic }}(\mathrm{p}=0.004)$, and CO/weight $(\mathrm{p}<0.001)$. A change in $\mathrm{LVP}_{\text {end diastolic }}$ did not occur and may have been due to ongoing diuresis used to treat respiratory distress associated with pulmonary edema.

\begin{tabular}{lccc}
\hline & $\begin{array}{c}\text { Baseline } \\
(\mathrm{n}=12)\end{array}$ & $\begin{array}{c}\text { Post-Embolization (45 min) } \\
(\mathrm{n}=12)\end{array}$ & $\mathrm{p}$-value \\
\hline $\mathrm{HR}(\mathrm{bpm})$ & $61 \pm 4$ & $66 \pm 3$ & 0.37 \\
$\mathrm{LVP}_{\text {end diastolic }}(\mathrm{mmHg})$ & $15 \pm 1$ & $23 \pm 2$ & $<0.0001$ \\
$\mathrm{LVP}_{\text {peak systolic }}(\mathrm{mmHg})$ & $106 \pm 8$ & $95 \pm 3$ & 0.07 \\
$+\mathrm{dP} / \mathrm{dt}(\mathrm{mmHg} / \mathrm{s})$ & $1,116 \pm 230$ & $930 \pm 70$ & 0.35 \\
$-\mathrm{dP} / \mathrm{dt}(\mathrm{mmHg} / \mathrm{s})$ & $-1,890 \pm 243$ & $-1,295 \pm 66$ & $<0.05$ \\
$\mathrm{AoP} P_{\text {mean }}(\mathrm{mmHg})$ & $90 \pm 9$ & $80 \pm 4$ & 0.14 \\
$\mathrm{AoP}$ & $106 \pm 8$ & $94 \pm 4$ & 0.09 \\
AoPstolic $(\mathrm{mmHg})$ & $76 \pm 9$ & $66 \pm 5$ & 0.20 \\
AoP $P_{\text {pulse }}(\mathrm{mmHg})$ & $31 \pm 2$ & $28 \pm 2$ & 0.93 \\
$\mathrm{HR} \times \mathrm{LVP} \mathrm{P}_{\text {peak systolic }}(\mathrm{bpm} \times \mathrm{mmHg})$ & $6,567 \pm 824$ & $6,306 \pm 448$ & 0.74 \\
\hline
\end{tabular}

Table 5: Hemodynamics 45 minutes post-embolization. HR, heart rate; LVP, left ventricular pressure; AoP, aortic pressure

\begin{tabular}{|c|c|c|c|}
\hline & $\begin{array}{c}\text { Baseline } \\
(n=9)\end{array}$ & $\begin{array}{l}\text { Heart Failure (60 Days) } \\
\qquad(n=8)\end{array}$ & $\mathrm{p}$-value \\
\hline HR (bpm) & $78 \pm 4$ & $88 \pm 7$ & 0.24 \\
\hline $\mathrm{LVP}_{\text {end diastolic }}(\mathrm{mmHg})$ & $16 \pm 2$ & $17 \pm 2$ & 0.68 \\
\hline $\mathrm{LVP}_{\text {peak systolic }}(\mathrm{mmHg})$ & $103 \pm 3$ & $83 \pm 6$ & $<0.01$ \\
\hline$+\mathrm{dP} / \mathrm{dt}(\mathrm{mmHg} / \mathrm{s})$ & $1,252 \pm 144$ & $1,193 \pm 195$ & 0.80 \\
\hline$-\mathrm{dP} / \mathrm{dt}(\mathrm{mmHg} / \mathrm{s})$ & $-2,527 \pm 306$ & $-984 \pm 95$ & $<0.001$ \\
\hline $\mathrm{AoP}_{\text {mean }}(\mathrm{mmHg})$ & $90 \pm 4$ & $62 \pm 7$ & $<0.01$ \\
\hline $\mathrm{AoP}_{\text {systolic }}(\mathrm{mmHg})$ & $105 \pm 3$ & $78 \pm 7$ & $<0.01$ \\
\hline AoP $P_{\text {diastolic }}(\mathrm{mmHg})$ & $73 \pm 4$ & $51 \pm 6$ & $<0.01$ \\
\hline AoP $P_{\text {pulse }}(\mathrm{mmHg})$ & $32 \pm 2$ & $28 \pm 3$ & 0.22 \\
\hline $\mathrm{HR} \times \mathrm{LVP}_{\text {peak systolic }}(\mathrm{bpm} \times \mathrm{mmHg})$ & $8,014 \pm 540$ & $7,174 \pm 586$ & 0.29 \\
\hline $\mathrm{CO}(\mathrm{L} / \mathrm{min})$ & $8.1 \pm 0.4$ & $7.4 \pm 1.0$ & 0.47 \\
\hline Weight (kg) & $78 \pm 4$ & $130 \pm 14$ & $<0.01$ \\
\hline $\mathrm{CO} /$ Weight $(\mathrm{ml} / \mathrm{min} / \mathrm{kg})$ & $105 \pm 5$ & $61 \pm 9$ & $<0.001$ \\
\hline
\end{tabular}

Table 6: Hemodynamics 60 days post-embolization. HR, heart rate; LVP, left ventricular pressure; $\mathrm{AoP}$, aortic pressure; $\mathrm{CO}$, cardiac output 


\section{End-Organ Blood Flow}

Figure 6 demonstrates end-organ blood flow in normal and chronic heart failure animals. Reduced blood flow was noted in nine of ten vascular beds studied. Blood flow reductions were quantitatively large in the kidneys, lung, brainstem, and frontal lobe, but were not statistically different in any organ.

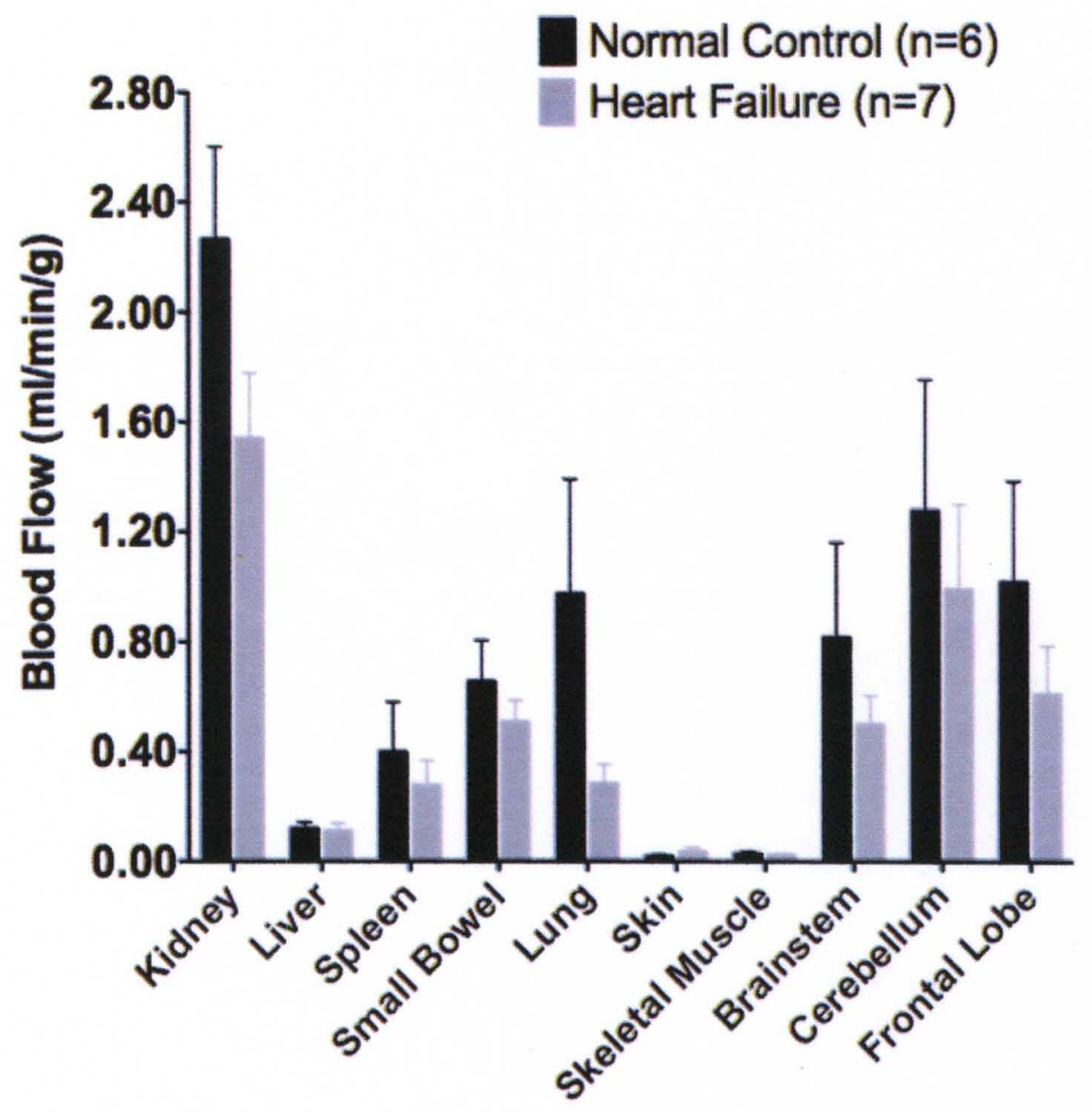

Figure 6: Sixty days after coronary microembolization, end-organ blood flow decreased systemically. However, blood flow reductions were not statistically significant in any organ and may have indicated that adequate compensation enabled animals to maintain end-organ perfusion in the lower range of normal. 


\section{$\underline{\text { Regional Myocardial Blood Flow }}$}

Figure 7 demonstrates gross heart sections and a multi-level, regional myocardial blood flow map in one animal 60 days after microembolization (A-C). This animal received the majority of the dose of microspheres in the left circumflex coronary artery. As such, a large superior and posterolateral myocardial infarction was noted in the gross heart specimen. Small infarcts are noted dispersed throughout the left ventricular free wall and interventricular septum.

The myocardial flow maps and regions of reduced myocardial blood flow corresponded well with the area of gross infarction. Regional right ventricular and anterior interventricular blood flow was largely unaffected.

Global myocardial hypoperfusion was noted (Figure 7 D, E). Left ventricular free wall blood flow decreased significantly from control values in normal animals of $0.79 \pm 0.09$ $\mathrm{ml} / \mathrm{min} / \mathrm{g}$ to $0.34 \pm 0.05 \mathrm{ml} / \mathrm{min} / \mathrm{g}(\mathrm{p}<0.01)$ in heart failure animals. Right ventricular free wall blood flow tended to decrease from control values in normal animals of $0.69 \pm 0.08$ $\mathrm{ml} / \mathrm{min} / \mathrm{g}$ to $0.50 \pm 0.10 \mathrm{ml} / \mathrm{min} / \mathrm{g}(\mathrm{p}=0.17)$ in heart failure animals. Similar reductions were noted in the epicardium $(\mathrm{p}=0.10)$, mid-myocardium $(\mathrm{p}<0.01)$, and endocardium $(\mathrm{p}<0.01)$. 

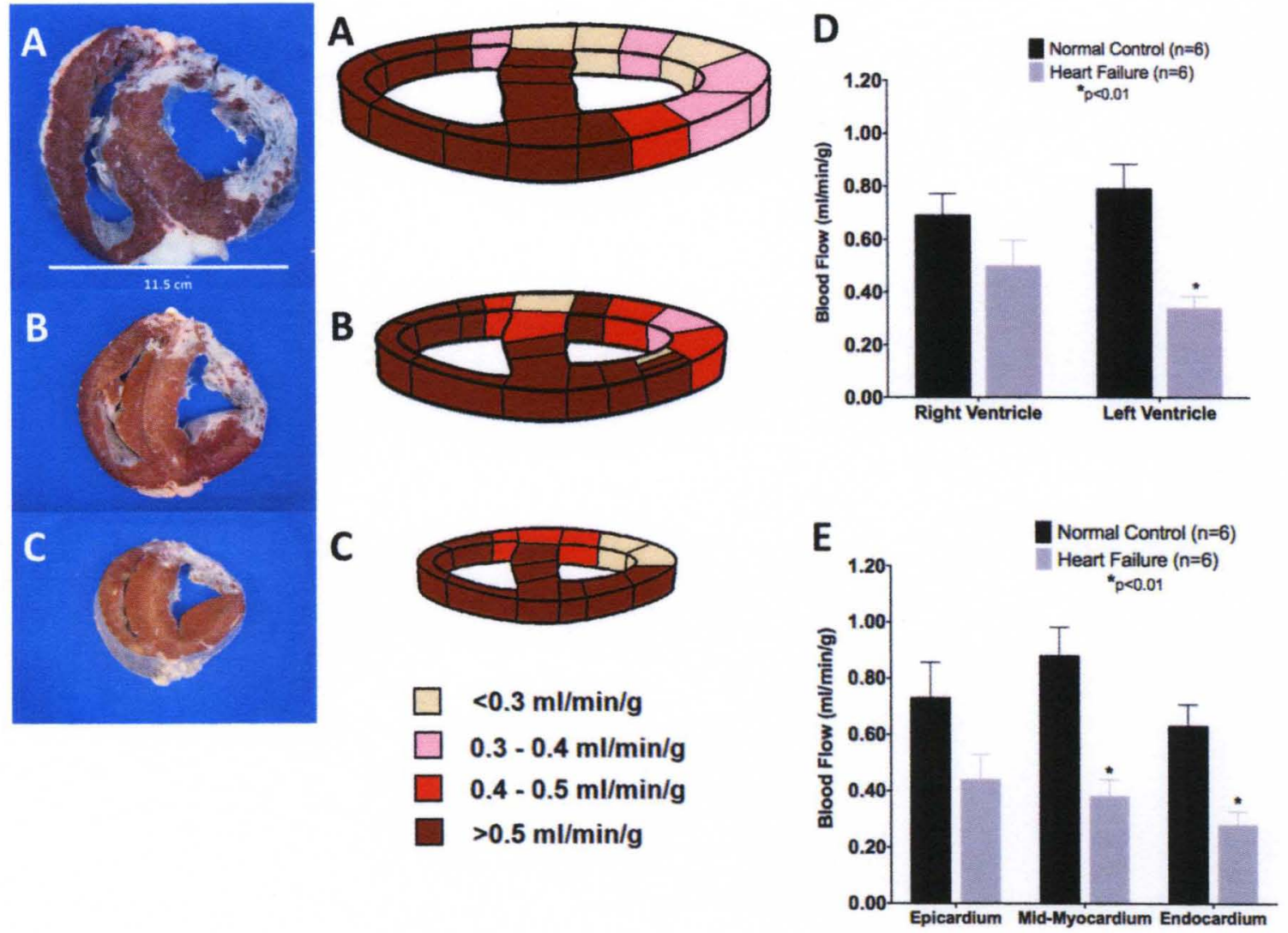

Figure 7 A-C: TTC-stained gross heart sections and a multi-level, regional myocardial blood flow map in one animal demonstrated a large superior and posterolateral myocardial infarction. The dose of microspheres was injected selectively into the left circumflex coronary artery. D, E: Global myocardial hypoperfusion was noted in heart failure animals versus normal control animals. 


\section{$\underline{\text { Histology }}$}

Figure 8 demonstrates the gross and microscopic appearances and percentage of fibrosis in the left and right ventricles in control and microembolized hearts stained with TTC and Masson's Trichrome, respectively. The heart of a control animal appeared uniform in color (Top Left Panel). The left ventricular chamber was small.

One week after left main coronary microembolization, the left ventricle exhibited mild dilatation and large and diffuse islands of unconsolidated coagulative necrosis (Middle Left Panel). The right ventricle appeared normal.

Eight weeks after coronary microembolization, the left ventricle exhibited marked dilatation with free-wall thinning and consolidation of infarcted myocardium (Bottom Left Panel). Although the right ventricular wall appeared grossly normal, marked right ventricular dilatation was noted.

Microembolized left ventricular myocardium contained more fibrosis than normal, control left ventricle ( $39 \pm 10 \%$ vs. $4 \pm 2 \%, p<0.0001)$. Right ventricular myocardium in microembolized animals also contained more fibrosis than normal, control right ventricle $(11 \pm 5 \%$ vs. $6 \pm 2 \%, p<0.05)$. In microembolized hearts, left ventricular myocardium contained greater fibrosis than right ventricular myocardium $(\mathrm{p}<0.001)$. 

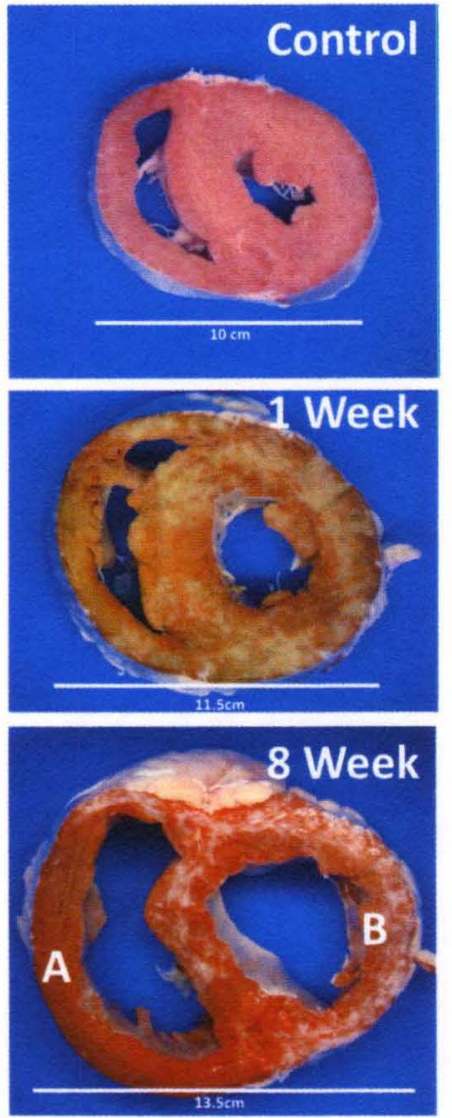
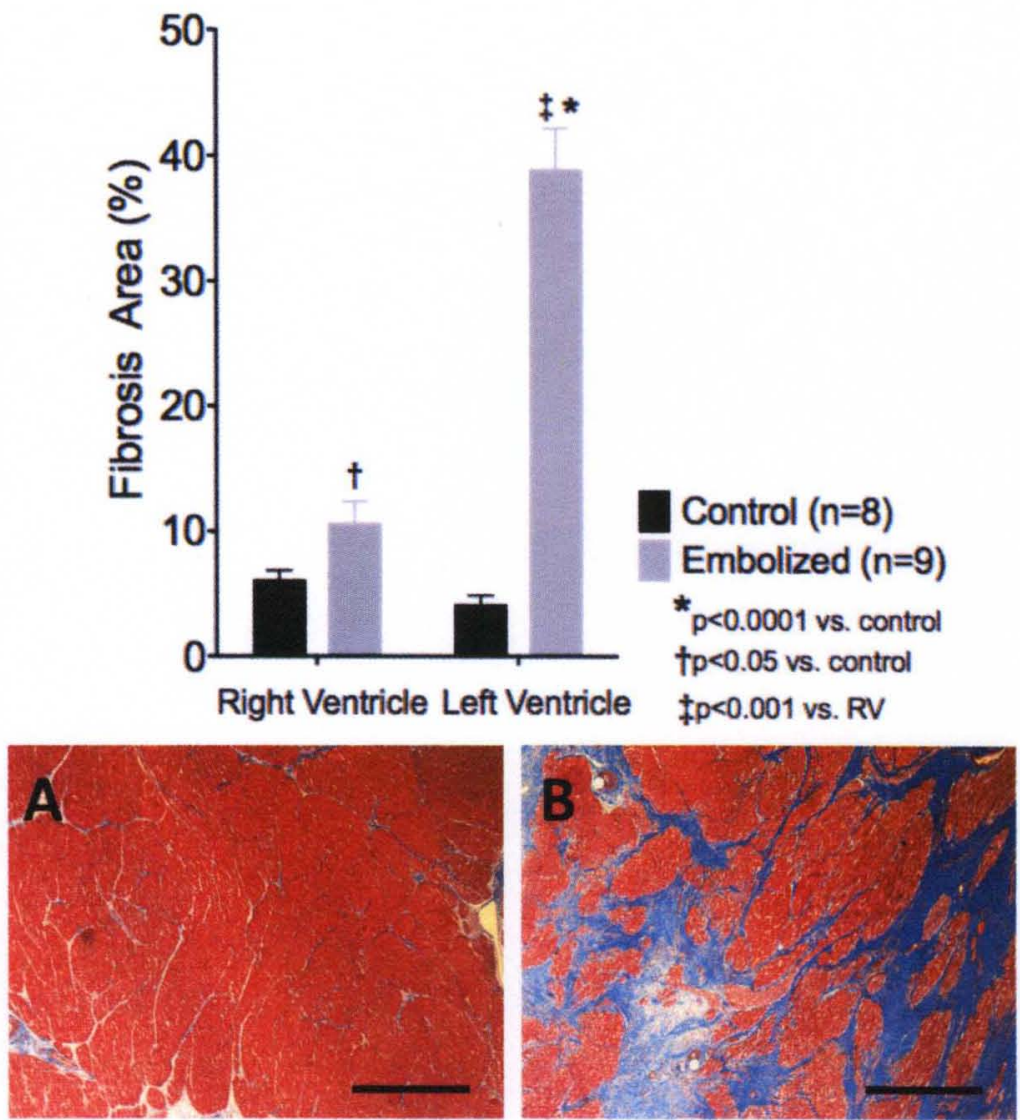

Figure 8, Left: Microembolized myocardium exhibited significant coagulative necrosis at 1 week, and consolidated infarction after 8 weeks. A: Right ventricular myocardium from a microembolized heart exhibited minimal fibrosis. B: Left ventricular myocardium from a microembolized heart exhibited diffuse infarction. Bar Graph: Compared to normal control hearts, microembolized hearts contained significantly elevated fibrosis globally. $4 \mathrm{X}$, black bar $=1,000 \mu \mathrm{m}$ 
Figure 9 demonstrates myocyte size in the left and right ventricles in control animals and animals that underwent coronary microembolization. Myocytes in the left ventricle of microembolized hearts were grossly hypertrophic as compared to left ventricular myocytes in normal, control left ventricle (E vs. C, $343 \pm 99 \mu \mathrm{m}^{2}$ vs. $146 \pm 70 \mu \mathrm{m}^{2}, \mathrm{p}<0.01$ ) and right ventricular myocytes in the same animal (E vs. D, $343 \pm 99 \mu \mathrm{m}^{2}$ vs. $205 \pm 104$ $\left.\mu \mathrm{m}^{2}, \mathrm{p}<0.05\right)$. Myocytes in the right ventricle of microembolized hearts were also hypertrophic as compared to normal, control right ventricle (D vs. B, $205 \pm 104 \mu \mathrm{m}^{2}$ vs. $\left.91 \pm 28 \mu \mathrm{m}^{2}, \mathrm{p}<0.01\right)$.

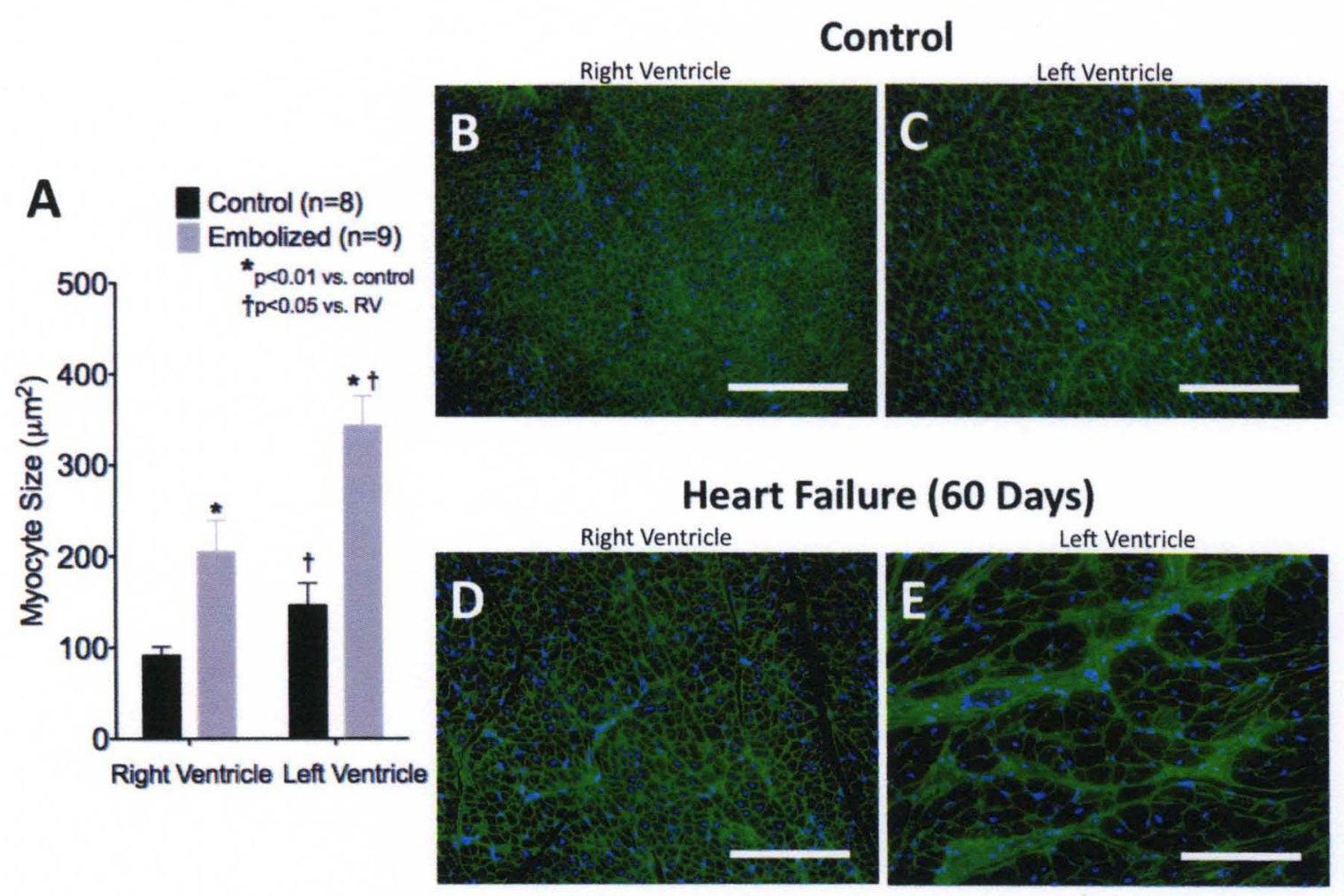

Figure 9 A: Significant myocyte hypertrophy was observed in the left and right ventricles of microembolized hearts as compared to normal control animals. Within microembolized hearts, left ventricular myocytes were significantly larger than right ventricular myocytes. B, C: Right and left ventricle from normal control animals. D, E: Right and left ventricle 60 days after coronary microembolization. 20X, white bar $=200$ $\mu \mathrm{m}$ 
Figure 10 demonstrates the incidence of total cardiac cell apoptosis in the left and right ventricles in control and microembolized hearts. The total apoptosis rate in the left and right ventricles of microembolized hearts was markedly increased as compared to normal, control left and right ventricle (left ventricle: $0.63 \pm 0.41 \%$ vs. $0.12 \pm 0.10 \%, \mathrm{p}<0.01$; right ventricle: $0.45 \pm 0.34 \%$ vs. $0.14 \pm 0.12 \%, \mathrm{p}<0.05)$. Within microembolized hearts, the apoptosis rate in the left ventricle trended toward an increase as compared to the right ventricle $(\mathrm{p}=0.08)$.

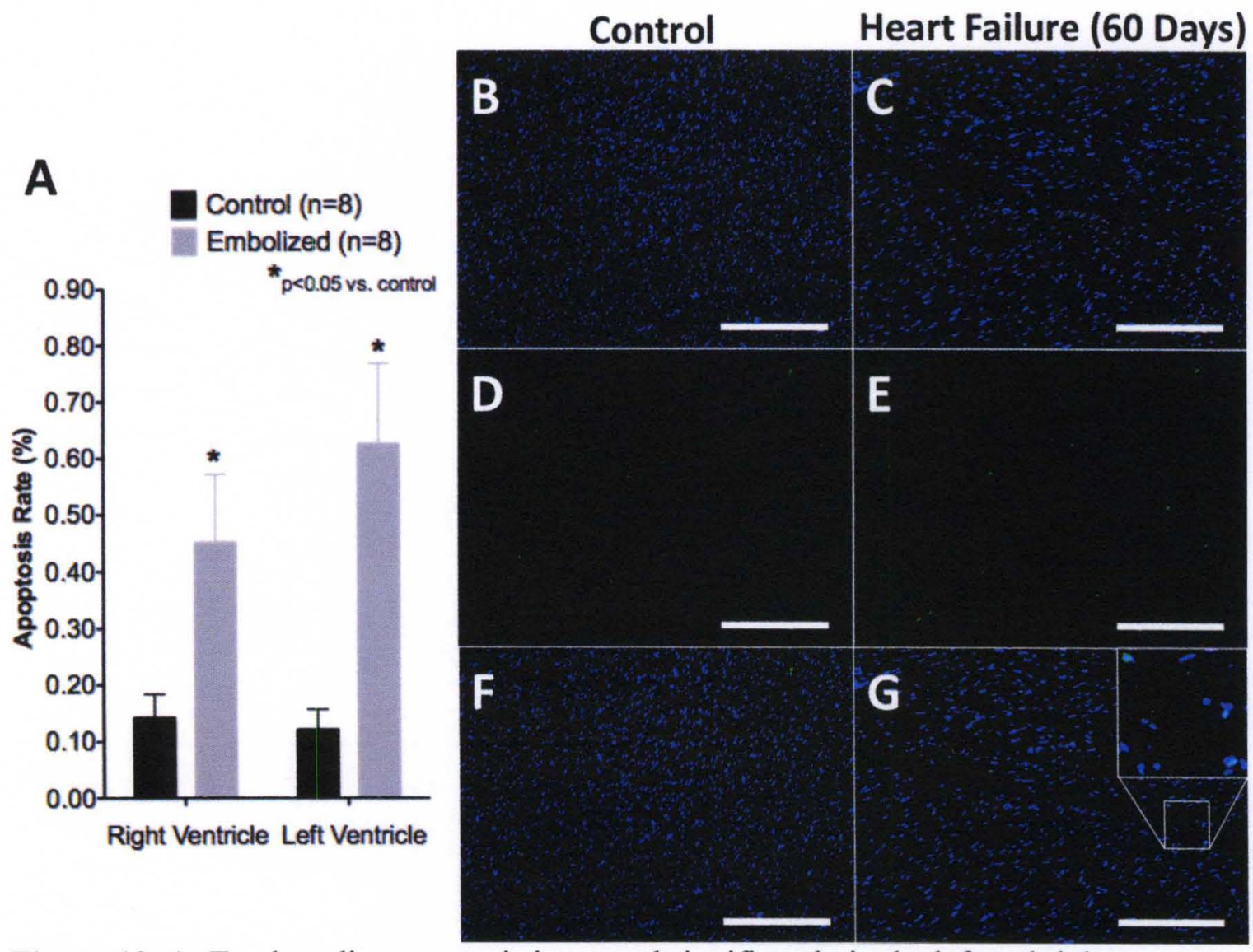

Figure 10, A: Total cardiac apoptosis increased significantly in the left and right ventricles of microembolized hearts as compared to normal control hearts. B, C: DAPI co-nuclear stain. D, E: FITC TUNEL+ stain. F, G: DAPI plus FITC overlay. Cyan nuclei indicate TUNEL + cells. 10X, white bar $=400 \mu \mathrm{m}$ 
Figure 11 demonstrates the incidence of myocyte-specific apoptosis in the left ventricle of control and microembolized hearts. Myocyte apoptosis was markedly increased in microembolized hearts as compared to normal $(0.63 \pm 0.41 \%$ vs. $0.12 \pm 0.10 \%, \mathrm{p}<0.01)$.

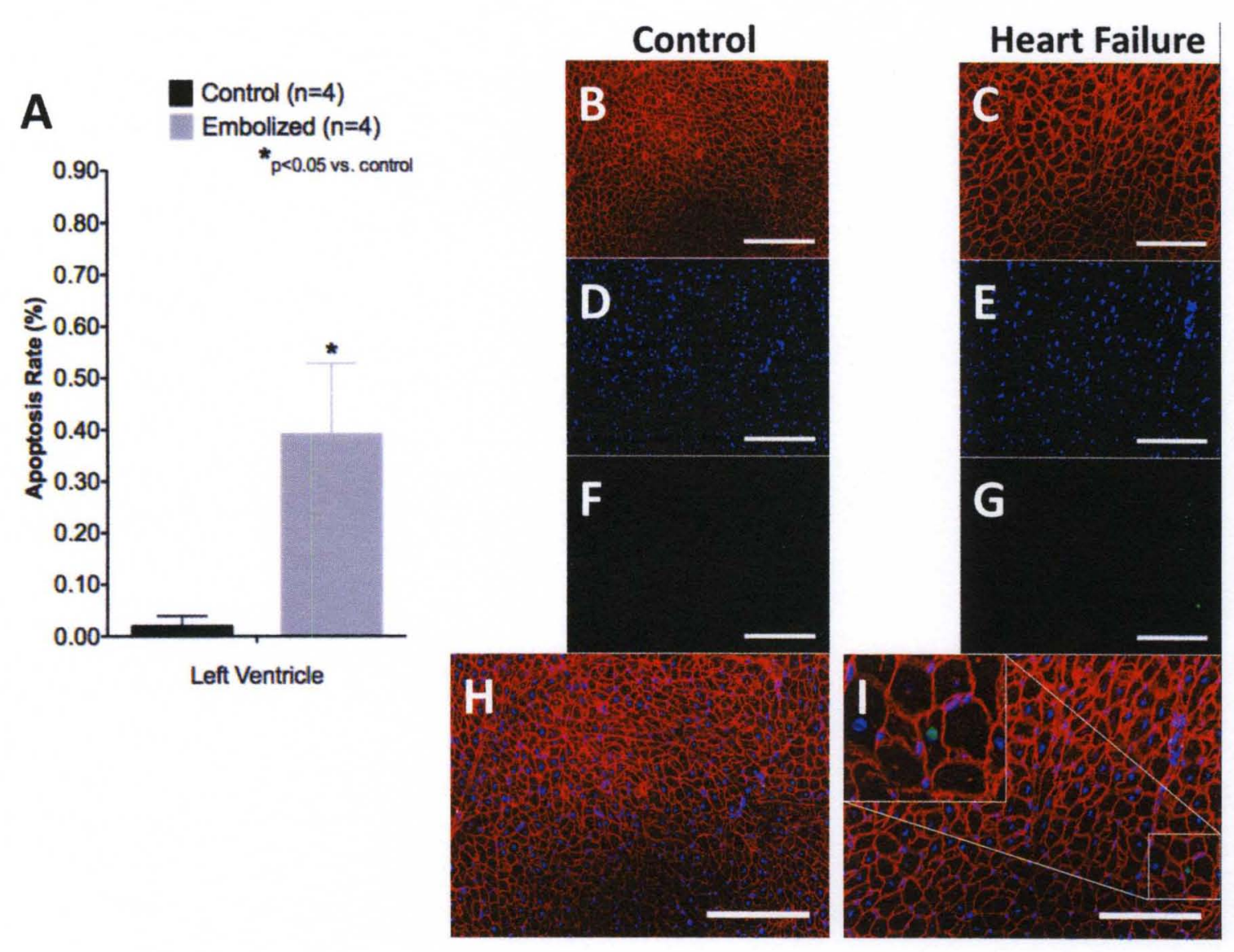

Figure 11, A: Myocyte-specific apoptosis increased significantly in microembolized hearts as compared to normal control hearts. B, C: Texas Red-conjugated wheat germ agglutinin stain. D, E: DAPI co-nuclear stain. F, G: FITC TUNEL+ stain. H, I: Texas Red plus DAPI plus FITC overlay. Cyan nuclei indicate TUNEL + cells. I: A single myocyte undergoing apoptosis is seen in the inset. In the upper right corner, a small nest of TUNEL+ cells are not myocytes and may be inflammatory cells in the extracellular matrix that are participating in ischemic, inflammatory-mediated remodeling. 20X, white bar $=200 \mu \mathrm{m}$ 
We have developed a novel bovine model of chronic, ischemic heart failure. Specifically, injection of $90 \mu \mathrm{m}$ microspheres into the left main coronary artery produced: 1) acute electrocardiographic changes consistent with severe ischemic myocardial injury, 2) a clinical profile consistent with left ventricular failure, 3) acute and chronic hemodynamic changes associated with systolic dysfunction, 4) a sustained and stable 50\% reduction in left ventricular ejection fraction, 5) left ventricular dilatation, 6) reduced regional myocardial and systemic end-organ blood flow, 7) $40 \%$ fibrosis of the left ventricle, 8) global myocyte hypertrophy, and 9) increased total cardiac and myocytespecific apoptosis. Our results establish the feasibility and validity of a bovine model of chronic, ischemic heart failure that shares many phenotypic similarities with human heart failure.

In summary, the calf is the industry standard for preclinical testing of cardiac assist devices. As such, this clinically relevant model is an appropriate platform to test acute and chronic (patho)physiological responses to LVADs and other translational therapies. This model may prove useful to develop support strategies to specifically promote reverse myocardial remodeling and myocardial recovery during prolonged mechanical circulatory support. 


\section{CHAPTER VI}

\section{Aim \#3: PARTIAL vs. FULL SUPPORT OF THE FAILING LEFT VENTRICLE WITH A CONTINUOUS-FLOW LVAD}

\section{Introduction}

If combined, the benefits of a full-support device implanted with a minimally invasive surgical approach may expand the target patient population for myocardial recovery with an LVAD. Original in silico work suggested that partial support of a failing ventricle with a continuous-flow LVAD may increase cardiac output and lower ventricular filling pressures $^{62}$. The greatest hemodynamic benefits were predicted for less-dilated and lessdysfunctional hearts. Computer simulations were validated in an acute bovine model of cardiac dysfunction in which continuous partial support at a rate of $3 \mathrm{~L} / \mathrm{min}$ decreased left atrial pressure by 6 to $7 \mathrm{mmHg}$ and increased cardiac output by greater than $1 \mathrm{~L} / \mathrm{min}^{62}$.

As LVADs are miniaturized, limited thoracotomy, subxiphoid access, thoracic keyhole access, placement of surface devices, or percutaneous implantation may permit earlier therapy in less sick patients. Minimally invasive implantation may increase acceptance 
by patients and physicians who are more likely to refer patients for less-invasive surgical therapies ${ }^{71}$. As a result, earlier intervention in less-sick patients may increase the publichealth impact of mechanical circulatory support. Additionally, these operative approaches often do not require cardiopulmonary bypass ${ }^{103}$. As a result, less postoperative coagulopathy may reduce postoperative bleeding and blood transfusions which play a role in right ventricular dysfunction and infection with LVADs ${ }^{104}$. Similarly, early clinical data suggest that partial support does not dramatically increase cardiac output and right ventricular overload and right ventricular failure are unlikely ${ }^{14}$.

Recently, a number of partial support LVADs have been developed. For example, the CircuLite Synergy Pocket Micro-Pump (CircuLite Incorporated, Saddle Brook, NJ) is a small continuous-flow LVAD the size of an AA battery $(49 \mathrm{~mm}$, outer diameter $14 \mathrm{~mm}$, $25 \mathrm{~g})^{26}$. The CircuLite LVAD is implanted via a miniature, right-sided thoracotomy without extracorporeal circulation and continuously unloads 2.5 to $3.0 \mathrm{~L} / \mathrm{min}$ of blood from the left atrium into the subclavian artery.

Less-invasive devices such as the Synergy pump provide important technical benefits. In the event of pump thrombosis, device failure, or pump-pocket infection, the device may be easily and rapidly exchanged through the original infraclavicular incision without entering the chest. An additional and unique advantage is that the implantation procedure involves a right-sided thoracotomy in which it is unlikely that adhesions will form in the anterior mediastinum and complicate median sternotomy if heart transplantation is indicated. A future design that obviates entrance into the thorax will include an inflow 
graft placed percutaneously through the subclavian vein and advanced through the interatrial septum into the left atrium. As with the current design, the outflow graft will be sewn to the subclavian artery. With this approach, the need for a thoracotomy will be eliminated, and the infraclavicular incision will be the only incision necessary to implant the entire system ${ }^{105}$. This approach will likely further increase acceptance by patients and referring physicians.

Initial results with the CircuLite device are encouraging. In an ongoing multicenter European clinical trial ${ }^{14,26,105}$, ambulatory patients on the transplant list with inotropeindependent NYHA class IIIB or IVA heart failure and preserved end-organ function demonstrated hemodynamic improvements over a 3-month follow-up (ongoing maximum support duration of eight months) $)^{14,26,105}$. Partial hemodynamic recovery included significant increases in cardiac index from $2.0 \pm 0.4$ to $2.8 \pm 0.6 \mathrm{~L} / \mathrm{min} / \mathrm{m}^{2}$, an increase in AoP $P_{\text {mean }}$ from $67 \pm 8$ to $80 \pm 9 \mathrm{mmHg}$, and a reduction in pulmonary capillary wedge pressure from $30 \pm 5$ to $18 \pm 5 \mathrm{mmHg}^{26}$. N-terminal fragment pro-brain natriuretic peptide was significantly reduced from $6,452 \pm 5,470$ to $3,209 \pm 2,379 \mathrm{pg} / \mathrm{ml}^{105}$ and suggested a reduction in myocyte stress. As predicted, right heart failure was not a clinical challenge with the CircuLite pump. During support, the acute increase in cardiac output ranged from 1.0 to $1.5 \mathrm{~L} / \mathrm{min}$ and did not overload the right ventricle ${ }^{14}$.

These preliminary results in humans suggest that partial support is not only safe but may also be an effective strategy to support less dysfunctional hearts. These findings encourage basic scientific investigation to further validate and improve this approach. 
For example, in the current European trial, implants of the CircuLite pump were performed primarily to demonstrate long-term safety and efficacy as a bridge-totransplant therapy. As such, this device has not yet been implanted with the specific goal of myocardial recovery.

Accordingly, experimental studies will be necessary to define the clinical utility of partial circulatory support for the treatment of early stages of heart failure. A major undertaking will be to evaluate whether a protocol that includes partial unloading may promote myocardial recovery and in which patient population(s). As a first step, it will be important to understand how the left ventricle should be unloaded in preparation for prolonged partial support. The major goal of Aim \#3 was to examine acute responses to partial vs. full support of the failing left ventricle with a continuous-flow LVAD. The effect of continuous unloading on the myocardial supply/demand relationship was studied in animals with chronic, ischemic heart failure. Standard indices of cardiovascular performance and regional myocardial blood flow were measured during each support mode. Implications for reverse myocardial remodeling and myocardial recovery were considered. Results of this study will assist in guiding future investigation into the chronic effects of continuous-flow mechanical circulatory support in large-animal models of chronic cardiac pathology. 


\section{Materials and Methods}

\section{$\underline{\text { Animals }}$}

Male Jersey, K-bar, and mixed-breed calves from Aim \#2 that had undergone left main coronary artery embolization and exhibited signs of chronic, ischemic heart failure ( $\mathrm{n}=9$, $130 \pm 13 \mathrm{~kg}$ ) were used. All animals received humane care and were handled in accordance with National Institutes of Health and University of Louisville animal care committee guidelines. Experimental procedures followed the University of Louisville Institutional Animal Care and Usage Committee approved protocol \#09080.

\section{$\underline{\text { Anesthesia }}$}

Animals were pre-anesthetized with Atropine $(30 \mathrm{mg}$ ) and prepared for acute, non-sterile surgery. In the operating room, general anesthesia was administered with Isoflurane (3$5 \%$ ) and room air. The animal was placed on the operating table in the right lateral recumbency. Tidal volume and respiratory rate were adjusted to maintain arterial oxygen saturation above $90 \%$. Fluid-filled arterial and venous catheters were placed in the left carotid artery and jugular vein for blood sampling. A left thoracotomy was performed. Ribs \#4 and \#5 were resected. The pericardium was opened. The animal was anticoagulated with a single bolus of intravenous Heparin (100 units $/ \mathrm{kg})$. For the remainder of the procedure, the ACT was maintained above $250 \mathrm{~s}$ with additional boluses of Heparin (1,000 to 2,000 units). 


\section{Surgical Instrumentation}

A single-tip, high-fidelity micromanometer catheter (Millar Instruments, Houston, TX) was placed in the aorta and a dual pressure-volume conductance catheter (Millar Instruments, Houston, TX) was advanced from the left atrium across the mitral valve into the left ventricle for simultaneous measurement of aortic, left atrial, and left ventricular blood pressures. A transit-time ultrasonic flow probe (Transonics, Ithaca, NY) was placed around the pulmonary artery to measure cardiac output. In six animals, a silicone catheter (7-French, Access Technologies, Skokie, IL) was advanced in the left atrial appendage chamber for administration of $15 \mu \mathrm{m}$ fluorescent-labeled polystyrene microspheres. The depth and angle of catheter entry parallel to the surface of the left atrial appendage ensured that the catheter did not interfere with mitral valve function.

\section{$\underline{\text { LVAD Implantation }}$}

A continuous-flow LVAD (HeartWare HVAD $n=4$, Thoratec HeartMate II $n=5$ ) was implanted without cardiopulmonary bypass. The outflow graft was anastomosed to the descending aorta. The left ventricular apex was cored and cannulated. The device and outflow graft were de-aired. A transit-time ultrasonic flow probe (Transonics, Ithaca, NY) was placed around the outflow graft to measure LVAD flow.

\section{Experimental Design}

In each animal, blood pressure and flow waveforms were recorded during Heart Failure Baseline (pump off, outflow graft clamped), Low Partial Support $(\sim 1.5 \mathrm{~L} / \mathrm{min}$ support, aortic valve opening every beat), High Partial Support ( $\sim 3 \mathrm{~L} / \mathrm{min}$ support, aortic valve 
opening every beat), and Full Support ( $\sim 5 \mathrm{~L} / \mathrm{min}$, aortic valve maintained closed, left ventricle maximally unloaded). Heart Failure Baseline and support modes for each device were maintained for 10 minutes each to achieve steady-state conditions prior to collection of 30 second data sets. During each condition, a single color of fluorescentlabeled microspheres (5.25 million microspheres) was injected into the left atrial catheter. Simultaneously, a reference blood sample was withdrawn from the arterial line at a rate of $15 \mathrm{ml} / \mathrm{min}$ for 100 seconds. The microsphere technique enabled the precise measurement of regional myocardial blood flow as described in Chapter IV, Section II.

In one animal, ventricular fibrillation occurred prior to the implantation of the LVAD. Open-chest cardiac massage was performed. Multiple shocks were attempted but defibrillation was unsuccessful. However, after implantation and operation of the LVAD at full support for approximately 20 minutes, the animal was successfully defibrillated. The estimated ischemic time was approximately 60 minutes. Prior to data collection, it was noted that substantial ST-segment elevation accompanied a coronary hyperemia. As a result, the regional myocardial blood flow data from this animal was not used.

\section{Quantification of Microspheres and Regional Myocardial Blood Flow}

At the completion of the study, while under anesthesia, euthanasia was performed with a fatal intravenous bolus injection of Beuthanasia-D Special $(1 \mathrm{ml} / 5 \mathrm{~kg})$. The heart was removed. One to two gram tissue sections from the left ventricular free wall, right ventricular free wall, interventricular septum, and left ventricular epicardium, midmyocardium, and endocardium were collected. Myocardial samples and reference blood 
samples were sent to IMT/Stason Laboratories (Irvine, CA) for automated digestion, counting of fluorescent microspheres with flow cytometry, and calculation of tissue specific blood flows in $\mathrm{ml} / \mathrm{min} / \mathrm{g}$ of tissue.

\section{Data Reduction}

All transducers were pre- and post-calibrated against known physical standards to ensure measurement accuracy. Calibration curves for the volume conductance catheter were constructed using static and dynamic tests pre- and post-experiment. Data were collected at $400 \mathrm{~Hz}$, signal conditioned, and A/D converted for digital analysis using our GLP compliant data acquisition system ${ }^{75}$.

To determine hemodynamic performance during each support mode, pressure and flow waveforms were used to derive LVADF, HR, SV, PAF as an index of CO, LAP, LVP end $_{\text {d }}$ diastolic, $\mathrm{LVP}_{\text {peak systolic, }} \pm \mathrm{dP} / \mathrm{dt}, \mathrm{HR} \times \mathrm{LVP}_{\text {peak systolic }}, \mathrm{AoP}_{\text {systolic }}, \mathrm{AoP}_{\text {diastolic }}, \mathrm{AoP} \mathrm{P}_{\text {mean }}$, AoP $\mathrm{P}_{\text {puse. }}$ Myocardial vascular resistance was calculated as $\mathrm{AoP}_{\text {mean }} /$ region-specific myocardial blood flow. Hemodynamic variables were calculated on a beat-to-beat basis for each 30 second data set with the Hemodynamic Evaluation and Assessment Research Tool (HEART) program ${ }^{77}$ developed in Matlab (Version 6.5, MathWorks, Natick, MA). All analyzed beats in each data set (approximately 30 to 50 beats $/ 30$ second data set) were averaged to obtain a single representative mean value for each calculated variable. 
$\underline{\text { Statistics }}$

GraphPad, version 4.00 (Prism, La Jolla, CA) was used to perform statistical analyses and plot data. One-way repeated measures ANOVA with Tukey post-test was performed for each hemodynamic index, region of myocardial blood flow, and myocardial blood flow normalized to $\mathrm{HR} \times \mathrm{LVP}_{\text {peak systolic }}$ to compare Heart Failure Baseline, Low Partial Support, High Partial Support, and Full Support modes within each animal. An unpaired student t-test was performed to compare the myocardial blood supply/demand ratio between normal and heart failure animals at baseline and during each level of support. All analyses were two-tailed, and a p-value $<0.05$ ( $95 \%$ confidence) was considered statistically significant. All data are presented as mean \pm standard error. 


\section{Results}

Table 7 demonstrates that in animals with chronic heart failure, as the level of support with a continuous-flow LVAD increased, the cardiac and systemic arterial hemodynamic profile progressively changed. An increase in continuous support increased $\mathrm{CO}$ in a dose-dependent manner. The observed increases were small and were not quantitatively different between support modes. HR did not change during LVAD support.

\section{$\underline{\text { Left Ventricular Hemodynamics }}$}

As in normal animals, left ventricular pressures demonstrated the most robust changes. The progressive increase in continuous support significantly decreased LAP $(p=0.02)$, $\mathrm{LVP}_{\text {end diastolic }}(\mathrm{p}<0.01)$, and $\mathrm{LVP}_{\text {peak systolic }}(\mathrm{p}<0.01)$ with a dose-dependent response. Reductions were greatest and indicated maximum unloading during Full Support. Smaller reductions were observed during partial-support modes. Full Support significantly reduced $+d P / d t(p<0.001)$ and $-d P / d t(p=0.03)$. However, partial-support modes did not affect $\pm \mathrm{dP} / \mathrm{dt}$.

As seen in normal animals, during Full Support the variation between end-systolic and end-diastolic pressures decreased to non-physiologically low values and resulted in chronic closure of the aortic valve. In this situation, the average $\operatorname{LVP}_{\text {peak systolic }}(57 \pm 9$ $\mathrm{mmHg})$ did not exceed the $\mathrm{AoP}_{\text {diastolic }}(67 \pm 6 \mathrm{mmHg})$. As a result, the aortic valve remained closed, and HR $x L_{\text {LPeak systolic }}$ decreased significantly $(\mathrm{p}<0.001)$ to values that are not seen in normal animals. This finding indicated that unloading the heart with a 
continuous-flow LVAD dramatically reduced myocardial metabolic demands and with a response dependent on the degree of support.

\section{Arterial Hemodynamics}

Systemic arterial pressures exhibited more robust changes than were observed in normal animals. As continuous support increased, $\mathrm{AoP}_{\text {systolic }}$ did not change. However, Ao $\mathrm{P}_{\text {diastolic }}$ increased significantly by $16 \mathrm{mmHg}(\mathrm{p}<0.001)$ and $\mathrm{AoP}_{\text {mean }}$ trended toward an increase of $8 \mathrm{mmHg}(\mathrm{p}=0.11)$. AoP $\mathrm{P}_{\text {pulse }}$ did not change during Low Partial Support. However, during High Partial Support, $\mathrm{AoP}_{\text {pulse }}$ decreased significantly from $27 \pm 3$ to $15 \pm 2 \mathrm{mmHg}(\mathrm{p}<0.0001)$, which was comparable to the reduction observed in normal animals during Full Support. Importantly, during Full Support, the arterial pulse pressure was significantly reduced from $27 \pm 3$ to $5 \pm 1 \mathrm{mmHg}$ ( $\mathrm{p}<0.0001)$. In contrast, during Low Partial Support, AoP pulse did not change from Heart Failure Baseline.

\section{Myocardial Blood Supply/Demand Relationship}

In animals with chronic heart failure, continuous support of the left ventricle did not affect right ventricular myocardial vascular resistance or blood flow. However, in the left ventricle and interventricular septum, increasing levels of continuous support significantly reduced the cardiac workload, and increased the myocardial vascular resistance (Table 8) with a dose-dependent response. However, the increase in vascular resistance was not as pronounced as in normal animals, and regional left ventricular 


\begin{tabular}{|c|c|c|c|c|c|c|c|c|c|c|c|c|c|c|}
\hline$n=8$ & $\begin{array}{l}\text { LVADF } \\
\text { (L/min) }\end{array}$ & $\begin{array}{c}\text { HR } \\
\text { (bpm) }\end{array}$ & $\begin{array}{l}\text { LV SV } \\
\text { (mi) }\end{array}$ & $\begin{array}{c}\text { PAF } \\
(L / \min )\end{array}$ & $\begin{array}{c}\text { LAP } \\
\text { (mmHo) }\end{array}$ & $\begin{array}{l}\text { LVP } \text { end dilustolic } \\
(\mathbf{m m H g})\end{array}$ & $\begin{array}{l}\text { LVP ponk aystotic } \\
(\mathbf{m m H g})\end{array}$ & $\begin{array}{c}+\mathrm{dP} / \mathrm{dt} \\
(\mathrm{mmHg} / \mathrm{s})\end{array}$ & $\begin{array}{c}-\mathrm{dP} / \mathrm{dt} \\
(\mathrm{mmH} / \mathrm{s})\end{array}$ & $\begin{array}{l}\text { HR } \times \text { LVP } \text { peak systollk } \\
(\text { bpm } \times \text { mmHg) }\end{array}$ & $\begin{array}{l}\text { AOP }_{\text {man }} \\
(\mathrm{mmHg})\end{array}$ & $\begin{array}{l}\text { AoP sytolk } \\
(\mathrm{mmHg})\end{array}$ & $\begin{array}{l}\text { AOP doetetilic } \\
(\mathrm{mmHg})\end{array}$ & $\begin{array}{l}\text { AoP puise } \\
(\mathrm{mmHg})\end{array}$ \\
\hline ANOVA p-value & $<0.0001$ & 0.94 & $<0.0001$ & 0.19 & 0.02 & $<0.01$ & $<0.001$ & $<0.001$ & 0.03 & $<0.001$ & 0.13 & 0.37 & $<0.001$ & $p<0.0001$ \\
\hline Heart Fal & $0.0 \pm$ & $86 \pm 8$ & $89 \pm 12$ & $7.3 \pm 0.9$ & $16 \pm 2$ & $19 \pm 3$ & $84 \pm 6$ & 1,09 & $-1,054 \pm 160$ & 7,01 & $62 \pm 7$ & $78 \pm 7$ & $51 \pm 6$ & $27 \pm 3$ \\
\hline Low Partlal Support & $2.3 \pm 0.3^{*}$ & $86 \pm 7$ & $66 \pm 11^{*}$ & $7.7 \pm 1.1$ & $13 \pm 2$ & $16 \pm 2$ & $84 \pm 4$ & $1,106 \pm 216$ & $-1,050 \pm 96$ & $7,068 \pm 500$ & $67 \pm 5$ & $80 \pm 5$ & $57 \pm 5$ & $22 \pm 2$ \\
\hline Mlgh Partial Support & $3.7 \pm 0.4^{*} \uparrow$ & $85 \pm 9$ & $48 \pm 9 *$ & $7.6 \pm 1.1$ & $13 \pm 3$ & $15 \pm 2$ & $83 \pm 6$ & $1,007 \pm 185$ & $-973 \pm 140$ & $6,902 \pm 629$ & $71 \pm 7$ & $79 \pm 8$ & $64 \pm 6^{*}$ & $15 \pm 2 * \dagger$ \\
\hline Full Support & $6.2 \pm 1.1 * t \neq$ & $85 \pm 7$ & $20 \pm 5^{*} \downarrow \neq$ & $7.9 \pm 1.3$ & $10 \pm 2 *$ & $12 \pm 2^{*}$ & $57 \pm 9 *+\neq$ & $606 \pm 68^{*}+\ddagger$ & $-635 \pm 137 * \dagger$ & $4,558 \pm 428 * \dagger \neq$ & $70 \pm 6$ & $73 \pm 7$ & $67 \pm 6 * \dagger$ & $5 \pm 1^{* \dagger \ddagger}$ \\
\hline
\end{tabular}

Table 7: Hemodynamics during partial vs. full support of the failing left ventricle with a continuous flow LVAD. LVADF, left ventricular assist device flow; HR, heart rate; LV SV, left ventricular stroke volume; PAF, pulmonary artery flow; LAP, left atrial pressure; LVP, left ventricular pressure; AoP, aortic pressure; ${ }^{*} \mathrm{p}<0.05$, support mode vs. Heart Failure Baseline; $\uparrow \mathrm{p}<0.05$, support mode vs. Low Partial Support; $₫ \mathrm{p}<0.05$, support mode vs. High Partial Support 
blood flow did not change (Table 9). Vascular resistance and blood flow in the epicardial region did not change. Likely, the coronaries and large coronary arterioles were less responsive than in normal control animals, in which large increases in epicardial vascular resistance were observed.

\begin{tabular}{|c|c|c|c|c|c|c|}
\hline$\overline{n=5}$ & $\begin{array}{c}\text { RV } \\
(\mathrm{mmHg} / \mathrm{ml} / \mathrm{min} / \mathrm{g})\end{array}$ & $\begin{array}{c}\mathrm{LV} \\
(\mathrm{mmHg} / \mathrm{ml} / \mathrm{min} / \mathrm{g})\end{array}$ & $\begin{array}{c}\text { Septum } \\
(\mathrm{mmHg} / \mathrm{ml} / \mathrm{min} / \mathrm{g})\end{array}$ & $\begin{array}{c}\text { Epicardium } \\
(\mathrm{mmH} / \mathrm{m} / \mathrm{min} / \mathrm{g})\end{array}$ & $\begin{array}{c}\text { Mid-Myocardium } \\
(\mathrm{mmHg} / \mathrm{ml} / \mathrm{min} / \mathrm{g})\end{array}$ & $\begin{array}{r}\text { Endocardium } \\
(\mathrm{mmH} / \mathrm{g} / \mathrm{m} / \mathrm{min} / \mathrm{g})\end{array}$ \\
\hline ANOVA $p$-value & $p=0.98$ & $p=0.04$ & $p=0.01$ & $p=0.61$ & $p<0.01$ & $p=0.31$ \\
\hline Heart Failure Baseline & $175 \pm 29$ & $164 \pm 20$ & $136 \pm 22$ & $160 \pm 27$ & $140 \pm 21$ & $199 \pm 52$ \\
\hline Low Partial Support & $167 \pm 25$ & $187 \pm 45$ & $141+17$ & $168 \pm 29$ & $159 \pm 27$ & $197 \pm 42$ \\
\hline High Partial Support & $175 \pm 12$ & $206 \pm 34$ & $170 \pm 17$ & $200 \pm 33$ & $172 \pm 23$ & $252 \pm 63$ \\
\hline Full Support & $167 \pm 13$ & $249 \pm 25^{*}$ & $194 \pm 24 *+$ & $194 \pm 24$ & $217 \pm 20 * \dagger$ & $217 \pm 20$ \\
\hline
\end{tabular}

Table 8: Regional myocardial vascular resistance during partial vs. full support of the failing left ventricle with a continuous flow LVAD. RV, right ventricle; LV, left ventricle; ${ }^{*} p<0.05$, Full Support vs. Heart Failure Baseline; ${ }^{*} \mathrm{p}<0.05$, support mode vs. Heart Failure Baseline; $\dagger \mathrm{p}<0.05$, support mode vs. Low Partial Support

\begin{tabular}{|c|c|c|c|c|c|c|}
\hline$n=5$ & $\begin{array}{c}\text { RV } \\
(\mathrm{ml} / \mathrm{min} / \mathrm{g})\end{array}$ & $\begin{array}{c}\mathrm{LV} \\
(\mathrm{ml} / \mathrm{min} / \mathrm{g})\end{array}$ & $\begin{array}{c}\text { Septum } \\
(\mathrm{mi} / \mathrm{min} / \mathrm{g})\end{array}$ & $\begin{array}{l}\text { Epicardium } \\
(\mathrm{m} / \mathrm{min} / \mathrm{g})\end{array}$ & $\begin{array}{c}\text { Mid-Myocardium } \\
(\mathrm{ml} / \mathrm{min} / \mathrm{g})\end{array}$ & $\begin{array}{l}\text { Endocardium } \\
(\mathrm{ml} / \mathrm{min} / \mathrm{g})\end{array}$ \\
\hline ANOVA p-value & $p=0.81$ & $p=0.85$ & $p=0.13$ & $p=0.83$ & $\mathrm{p}=0.18$ & $p=0.48$ \\
\hline $\begin{array}{l}\text { Heart Failure Baseline } \\
\text { Low Partial Support } \\
\text { High Partial Support } \\
\text { Full Support }\end{array}$ & $\begin{array}{l}0.40 \pm 0.04 \\
0.45 \pm 0.06 \\
0.43 \pm 0.05 \\
0.45 \pm 0.03\end{array}$ & $\begin{array}{l}0.41 \pm 0.04 \\
0.44 \pm 0.08 \\
0.40 \pm 0.08 \\
0.45 \pm 0.03\end{array}$ & $\begin{array}{l}0.51 \pm 0.05 \\
0.52 \pm 0.05 \\
0.44 \pm 0.05 \\
0.40 \pm 0.05\end{array}$ & $\begin{array}{l}0.41 \pm 0.02 \\
0.40 \pm 0.06 \\
0.39 \pm 0.06 \\
0.40 \pm 0.05\end{array}$ & $\begin{array}{l}0.49 \pm 0.05 \\
0.49 \pm 0.08 \\
0.46 \pm 0.08 \\
0.35 \pm 0.04\end{array}$ & $\begin{array}{l}0.39 \pm 0.06 \\
0.40 \pm 0.06 \\
0.35 \pm 0.07 \\
0.32 \pm 0.70\end{array}$ \\
\hline
\end{tabular}

Table 9: Regional myocardial blood flow during partial vs. full support of the failing left ventricle with a continuous flow LVAD. RV, right ventricle; $L V$, left ventricle

To characterize the relationship between myocardial blood supply and demand, regional myocardial blood flow was normalized to HR $x$ LVP $_{\text {peak systolic }}$ (Table 10). During partial support modes, the ratio between left ventricular workload and left ventricular myocardial blood flow did not change. However, during full support the supply/demand ratio improved significantly in the left ventricular free wall $(\mathrm{p}=0.04)$ and interventricular septum $(\mathrm{p}<0.01)$ to values comparable to control values obtained in normal animals.

Figure 12 summarizes the gross physiological changes observed during continuous unloading of the failing left ventricle. 
Comparison to Normal Animals

Without support, the myocardial blood supply/demand relationship in the left ventricle demonstrated lower values in microembolized hearts as compared to normal, control hearts ( $\mathrm{p}=0.06$ ). In normal hearts, support with a continuous-flow LVAD did not change this ratio. However, in microembolized hearts, this difference decreased with greater levels of support (Low Partial Support $\mathrm{p}=0.12$, High Partial Support $\mathrm{p}=0.24$, Full Support $p=0.47)$ and indicated normalization of this relationship toward baseline values.

\begin{tabular}{|c|c|c|}
\hline$n=5$ & $\begin{array}{c}\text { LV/HRXLVP } \\
\text { (ml/min } / 100 \mathrm{~g} / \mathrm{bpm} \cdot \mathrm{mmHg})\end{array}$ & $\begin{array}{c}\text { Septum/HRXLVP } \\
\text { (ml/min } / 100 \mathrm{~g} / \mathrm{bpm} \cdot \mathrm{mmHg})\end{array}$ \\
\hline ANOVA p-value & $p=0.04$ & $\mathrm{p}<0.01$ \\
\hline $\begin{array}{l}\text { Heart Failure Baseline } \\
\text { Low Partial Support } \\
\text { High Partial Support } \\
\text { Full Support }\end{array}$ & $\begin{array}{c}0.0054 \pm 0.0007 \\
0.0064 \pm 0.0008 \\
0.0057 \pm 0.0007 \\
0.0079 \pm 0.0014^{*}\end{array}$ & $\begin{array}{c}0.0066 \pm 0.0009 \\
0.0077 \pm 0.0009 \\
0.0066 \pm 0.0008 \\
0.0099 \pm 0.0013^{*} \neq\end{array}$ \\
\hline
\end{tabular}

Table 10: Regional myocardial blood supply/demand relationship during partial vs. full unloading of the failing left ventricle with a continuous flow LVAD. LV, left ventricle; HR, heart rate; LVP, left ventricular pressure; ${ }^{*} \mathrm{p}<0.05$, Full Support vs. Heart Failure Baseline; $\ddagger \mathrm{p}<0.05$, support mode vs. High Partial Support

\section{Normal Animals}

Cardiac Workload

Myocardial Vascular Resistance

Myocardial Flow

Flow/Workload

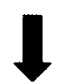

Heart Failure Animals
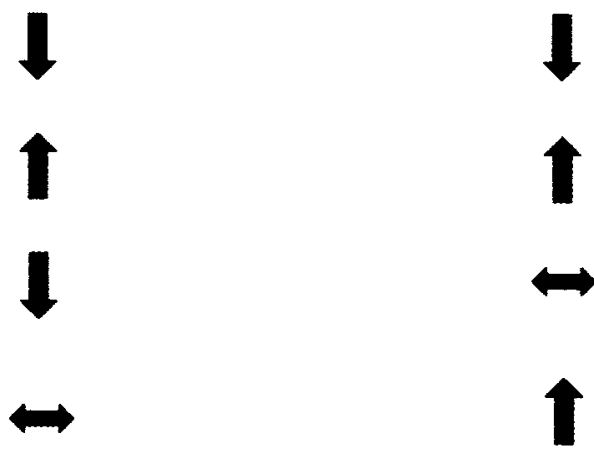

Figure 12: During support of the failing left ventricle with a continuous-flow LVAD, cardiac workload decreased, and myocardial vascular resistance increased with a dose-dependent response. However, myocardial blood flow did not change because diastolic blood pressure was significantly greater during LVAD support and increased the driving force for coronary blood flow. As a result, the ratio between blood supply/demand improved to values observed in normal control animals. These findings suggested that in animals with chronic heart failure, the heart may have been operating at an insufficient ratio of blood supply/demand, and a coronary reserve was not present. 


\section{Conclusions}

The study of partial vs. full support of the left ventricle with a continuous-flow LVAD was possible in animals with cardiac pathology. Specifically, in animals with chronic, ischemic heart failure, 1) a systemic flow reserve was not present, and any level of support with a continuous-flow LVAD augmented systemic flows, 2) full support with a continuous-flow LVAD deranged pulsatility, whereas partial support preserved a more normal pulsatile profile, 3 ) full but not partial support of the failing left ventricle with an LVAD normalized the blood supply/demand relationship, 4) divergent results observed in normal animals vs. heart failure animals suggested that mechanical circulatory support studies should be conducted in large-animal models of chronic cardiac pathology. These results will assist to guide future in vivo studies to examine myocardial and arterial remodeling during chronic partial vs. full support of the heart with a continuous-flow LVAD.

\section{$\underline{\text { Systemic Effects }}$}

In animals with chronic heart failure, a systemic flow reserve was absent. At any level of support with a continuous-flow LVAD, CO increased and HR did not change. This finding in animals with chronic heart failure was not unexpected and suggested that any level of flow augmentation with a continuous-flow LVAD may improve systemic arterial blood flow. As such, partial-support with a continuous-flow LVAD in patients with chronic heart failure may be a successful therapy for patients with hypoperfused end organs. 


\section{Effects on the Heart}

In the failing heart, full support with a continuous-flow LVAD deranged the normal profile of pulsatile cardiac hemodynamics. As continuous support increased, the peak left ventricular pressure $(57 \pm 9 \mathrm{mmHg})$ dropped below the arterial diastolic pressure $(67 \pm 6 \mathrm{mmHg})$. Insufficient preload was available to eject through the aortic valve, which did not open. As a result, the workload of the heart was dramatically reduced to values that are not observed in bovids. As in normal animals, during continuous unloading of the failing left ventricle, cardiac workload decreased, and myocardial vascular resistance increased with a significant dose-dependent response. However, in contrast to normal animals, during full support of animals with chronic heart failure, a significantly increased diastolic blood pressure increased coronary perfusion despite dramatically reduced myocardial metabolic demands. Importantly, the ratio of blood supply/demand improved to values observed in normal control animals. These findings suggested that in animals with chronic heart failure, a coronary reserve was not present and the heart may have been operating at an insufficient ratio of blood supply/demand. The lack of a change in vascular resistance and blood flow in the epicardial region during any level of support further suggested that coronary vasoreactivity was impaired such that coronary vasoconstriction did not occur, thereby ensuring adequate myocardial blood flow.

Partial support provided inadequate reduction of myocardial metabolism and augmentation of diastolic blood pressure to improve the blood supply/demand relationship. As a result, it seems that partial support may be inappropriate as the first step in a multistep protocol to provide prolonged unloading toward myocardial recovery. 
Heart Failure

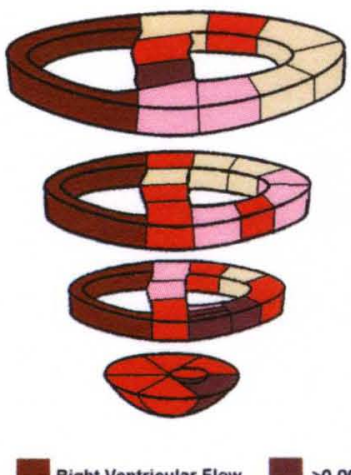

Right Ventricular Flow
Partial Support - Low

(1.5 L/min)

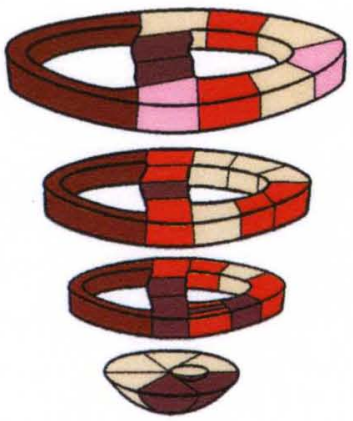

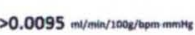

Partial Support - High

(3 L/min)

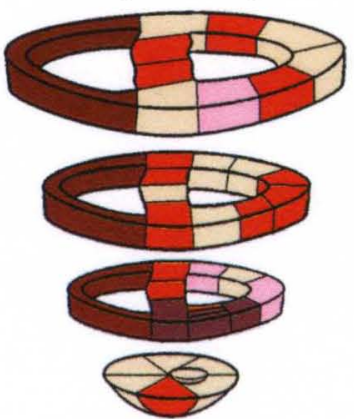

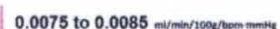

Full Support

(5 L/min)

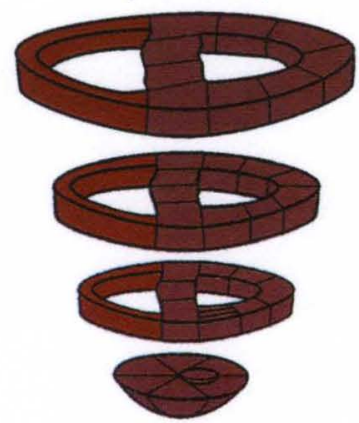

$<0.0075$ miminin/liogeropm mm

Figure 13, Left Myocardial Map: In animals with ischemic heart failure, the left ventricle operated at a reduced myocardial blood supply demand/demand ratio. Center Myocardial Maps: Immediately after the implantation of an LVAD, partial support was ineffective at rebalancing this relationship. Right Myocardial Map: However, full support normalized the blood supply/demand relationship throughout the left ventricle and interventricular septum.

Yet, full support of the failing left ventricle with an LVAD did restore a normal myocardial blood supply/demand relationship (Figure 13). This novel finding suggests that during the immediate postoperative period after the implantation of an LVAD, the heart should be fully unloaded.

This conclusion should be interpreted with caution. Full support decreased the

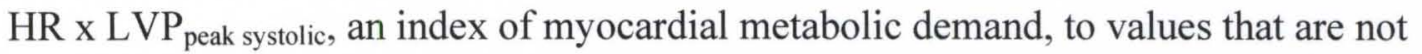
encountered in bovids. In heart failure, moderate reductions in metabolic demands are likely favorable, especially if the goal of treatment is myocardial recovery. However, the optimal reduction in cardiac metabolism which allows the heart to rest while still maintaining a partial workload has not been established, and excessive myocardial 
unloading in which the heart performs too little work may induce myocardial atrophy ${ }^{29,30}$ and fibrosis ${ }^{31,32}$.

Nonetheless, full support of the failing left ventricle by a continuous-flow LVAD has resulted in myocardial recovery ${ }^{9}$. Yet, myocardial recovery has most frequently been reported in patients that received pulsatile ventricular assistance ${ }^{5,6}$. This critical finding suggests that variations in the ventricular pressure-volume relationship and cardiac workload may be important to reverse myocardial remodeling during heart failure. It is unclear how variations in stroke work affect myocardial remodeling. However, it is known that normal ventricular geometry depends on a consistent physiologic pressurevolume relationship. As we have demonstrated, partial unloading preserved this relationship and permitted ejection though the aortic valve on every beat. These findings suggest a mechanism by which low native-heart volume output and loss of myocardial mechanical stretch may cause the heart to become a stiff and non-functional chamber.

Therefore, it remains to be determined how long temporary full support with a continuous-flow LVAD is necessary before a transition to partial support is safe. Only after interrupting the progressive hemodynamic deterioration of heart failure, normalizing autonomic tone, and restoring normal end-organ perfusion may the heart regain adequate function and be weaned to a partial-support mode. At that time, the reinstatement of a partial cardiac workload may prevent unfavorable remodeling that is characteristic of prolonged complete unloading of the failing left ventricle. Long-term studies in our model of chronic, ischemic heart failure are necessary to determine the length of full 
support prior to a transition to partial support that may prevent myocyte atrophy and left ventricular fibrosis.

\section{Effects on the Arterial System and Emerging Novel Pathologies}

In the arteries of animals with chronic heart failure, full support of the left ventricle with a continuous-flow LVAD deranged the normal profile of pulsatile arterial hemodynamics. As continuous support increased, arterial diastolic pressure increased significantly, and the $\mathrm{AoP}_{\text {pulse }}$ collapsed to $5 \pm 1 \mathrm{mmHg}$, a value which is not compatible with life in mammals in nature ${ }^{28}$. This finding has important implications for prolonged LVAD therapy. Although increased diastolic blood pressure favors an increase in myocardial and end-organ blood flow, chronic non-pulsatile blood flow may alter the structure and physiological reactivity of arteries and arterioles. As the $\mathrm{AoP}_{\text {pulse }}$ decreases, vascular resistance increases. Indeed, we have reported acute increases in vascular impedance in human patients in response to continuous-flow mechanical circulatory support $^{106}$. Acute physiologic studies in canines have demonstrated that systemic vascular resistance is inversely related to $\mathrm{AoP}_{\text {pulse }}$ and that systemic vascular resistance during non-pulsatile circulation is as much as $134 \%$ of that during pulsatile circulation ${ }^{107}$. Chronic studies in goats undergoing prolonged, non-pulsatile cardiopulmonary bypass demonstrated atrophic changes in the tunica media of the aorta that included decreased total smooth muscle volume, reduced cell size, changes in the constituent volume ratio of collagen and elastin, and decreased number of myofilaments and chromatin in smooth muscle cells ${ }^{108}$. Additional studies in the same model demonstrated decreased arterial vasoconstrictive response to norepinephrine ${ }^{109}$ and phenylephrine ${ }^{110}$ and suggested that 
non-pulsatile blood flow affects vascular reactivity. Overall, the net effect of prolonged non-pulsatile blood flow is endothelial remodeling, loss of arterial reactivity, and extracellular matrix remodeling, which alter arterial visco-elastic performance characteristics and produces stiff and unresponsive arteries.

It may be speculated that changes to the endothelium may contribute to novel pathologies observed in patients with prolonged non-pulsatile blood flow. For example, recent reports have documented an increased incidence in refractory diastolic hypertension ${ }^{57,58}$, ischemic and hemorrhagic stroke ${ }^{86}$, acquired von Willebrand disease ${ }^{87,88}$, and gastrointestinal arteriovenous malformations and bleeding ${ }^{89}$ in patients with continuousflow LVADs. These cardiovascular pathologies likely share a common etiology related to the absence of pulsatile stretch of arteries and/or the influence of high, pulseless shear stress on the endothelium. Although causality and mechanism remain to be determined, effects of prolonged diastolic hypertension with a narrow pulse pressure on the vasculature (and heart) may be a limiting factor in long-term patient outcomes.

\section{Clinical Implications}

These findings have important clinical implications for device development, selection, operation, and weaning. If combined, the benefits of a full-support device implanted with a minimally invasive surgical approach may expand the target patient population for myocardial recovery with an LVAD. As LVADs are miniaturized, limited thoracotomy, subxiphoid access, thoracic keyhole access, placement of surface devices, or percutaneous implantation may permit initial full support which is later reduced to partial 
support. Minimally invasive implantation may increase acceptance by patients and physicians who are more likely to refer patients for less-invasive surgical therapies ${ }^{71}$. Earlier intervention in less-sick patients may increase the public-health impact of mechanical circulatory support. Additionally, these operative approaches often do not require cardiopulmonary bypass ${ }^{103}$. As a result, less postoperative coagulopathy may reduce postoperative bleeding and blood transfusions which play a role in right ventricular dysfunction and infection with LVADs ${ }^{104}$.

In summary, partial support with a continuous-flow LVAD is feasible and may preserve a more normal cardiac and systemic arterial hemodynamic profile. However, partial support may not be appropriate as the initial step in the clinical management of patients with chronic heart failure. Only after a period of full support may the level of support be reduced. Additional studies are needed to determine the duration of full support necessary prior to prolonged partial support. 


\section{CHAPTER VII}

\section{SUMMARY AND FUTURE RESEARCH DIRECTIONS}

\section{Summary of Findings}

1) Left main coronary artery microembolization induced chronic, ischemic heart failure in calves. A stable and reproducible large-animal model of chronic heart failure is possible with many phenotypic similarities to clinical heart failure.

2) In normal animals and animals with chronic heart failure, full but not partial support with a continuous-flow LVAD deranged the physiological profile of pulsatile cardiac and arterial hemodynamics.

3) In normal animals, neither full nor partial support with a continuous-flow LVAD affected the myocardial blood supply/demand relationship. However, 
in animals with chronic heart failure, full but not partial support normalized the myocardial blood supply/demand relationship.

4) Divergent results were observed between normal animals and animals with chronic heart failure. Normal animals do not reproduce the complex pathophysiological presentation of chronic heart failure and are not ideal for validation and proper translation of mechanical circulatory support strategies into clinical practice.

In order to translate basic scientific findings from the bench into the clinic, an appropriate and clinically relevant large-animal model is necessary. We have developed a bovine model of chronic, ischemic heart failure that reproduces the complex pathophysiological presentation of functional, neurohormonal, and architectural derangements that are typical in chronic heart failure. This model is relevant for preclinical testing of cardiac devices and other translational therapies.

In this model, complete unloading of the failing left ventricle rebalanced the myocardial blood supply/demand relationship. However, full-support with a continuous-flow LVAD dramatically changed cardiac and systemic arterial hemodynamics, which may have longterm consequences such as myocardial and arterial remodeling.

In contrast, partial support was unable to normalize the blood supply/demand relationship. Yet, partial support augmented systemic flows and preserved a normal 
profile of pulsatile hemodynamics in which the aortic valve opened on every beat. Accordingly, why not combine the two modes of support? Our findings suggest that in the immediate postoperative period after the implantation of an LVAD, complete unloading of the failing left ventricle will rebalance the myocardial blood supply/demand relationship. After a period of full support, it may be effective to reduce support and restore native pulsatility.

Chronic studies are necessary to determine whether a transition to partial support may prevent myocardial atrophy and fibrosis that is seen with prolonged full support while still maintaining adequate end-organ blood flow. These studies should not be performed in normal animals. Our bovine model of chronic, ischemic heart failure is appropriate for such a study. 


\section{Future Directions}

Recent international experience with continuous-flow devices has progressively improved clinical outcomes and the quality of life of patients that receive mechanical circulatory support. New databanks for implantable cardiac devices such as INTERMACS will increase this trend. As devices are miniaturized for earlier support with less-invasive operative approaches, the incidence and prevalence of long-term mechanical circulatory support is likely to increase globally.

Less-invasive surgical approaches and strategies of long-term partial unloading of the heart must be further investigated and refined. Invasive full-support devices may still be reserved as a final treatment option for patients with life-threatening, end-stage heart failure as a bridge to heart transplantation or as a destination therapy. In contrast, lessinvasive partial-support devices may prove successful for the management of less-severe heart failure and relieve heart transplantation waiting lists as a destination therapy or as a bridge to myocardial recovery. Partial-support devices may interrupt the progressive hemodynamic deterioration of heart failure, improve symptoms and quality of life, promote reverse myocardial remodeling, and allow for device explantation in select patients.

With these goals in mind, additional chronic studies on effects of full and partial support are needed to investigate mechanisms of pathological remodeling, reverse myocardial remodeling, functional myocardial recovery, and pathophysiological responses to 
mechanical circulatory support. The mechanisms of histological changes in the myocardium and conduit arteries are largely unknown. Endothelial cells are affected by altered pulsatility and shear stress, but the role(s) of the endothelium in remodeling processes are unknown. Similarly, angiogenesis is dependent on pulsatility and shear stress and may be affected by systemic flow alterations with a continuous-flow LVAD.

Interactions between the autonomic nervous system and flow alterations with a continuous-flow LVAD have not been defined but likely include altered baroreceptor reflex sensitivity, catecholamine release, and arterial tone. These processes, which are influenced by hemodynamic alterations, may affect end-organ blood flow, functional capacity, and potential for recovery.

Going forward, experiments may be designed in which animals receive prolonged partial or full support (or a combination of the two) with a continuous-flow LVAD. In these studies it will be possible to further understand acute and chronic responses to continuous-flow mechanical circulatory support.

Our model of chronic, ischemic heart failure is an appropriate and clinically relevant heart failure substrate. Chronic studies will assist to further understand basic pulsatile physiology as well as to define the clinical utility of partial support toward myocardial recovery. 
Ultimately, proper patient selection will be critical to achieve success with any device. Device therapy should be tailored to patient needs. As such, careful examination of preclinical and clinical experiences with current and future generations of implantable devices will determine the relative utility for different strategies of mechanical circulatory support. 


\section{REFERENCES}

1. Mielniczuk L, Mussivand T, Davies R, Mesana TG, Masters RG, Hendry PJ, Keon WJ, Haddad HA. Patient selection for left ventricular assist devices. Artif Organs. Feb 2004;28(2):152-157.

2. Eurotransplant. Eurotransplant Annual Report. accessible at www.eurotransplant.nl. 2009.

3. Stehlik J, Edwards LB, Kucheryavaya AY, Aurora P, Christie JD, Kirk R, Dobbels F, Rahmel AO, Hertz MI. The Registry of the International Society for Heart and Lung Transplantation: twenty-seventh official adult heart transplant report--2010. J Heart Lung Transplant. Oct 2010;29(10):1089-1103.

4. Birks EJ, Yacoub MH, Banner NR, Khaghani A. The role of bridge to transplantation: should LVAD patients be transplanted? Curr Opin Cardiol. Mar 2004;19(2):148-153.

5. Frazier $\mathrm{OH}$, Myers TJ. Left ventricular assist system as a bridge to myocardial recovery. Ann Thorac Surg. Aug 1999;68(2):734-741.

6. Birks EJ, Tansley PD, Hardy J, George RS, Bowles CT, Burke M, Banner NR, Khaghani A, Yacoub MH. Left ventricular assist device and drug therapy for the reversal of heart failure. $N$ Engl J Med. Nov 2 2006;355(18):1873-1884. 
7. Burkhoff D, Klotz S, Mancini DM. LVAD-induced reverse remodeling: basic and clinical implications for myocardial recovery. J Card Fail. Apr 2006;12(3):227239.

8. Simon MA, Kormos RL, Murali S, Nair P, Heffernan M, Gorcsan J, Winowich S, McNamara DM. Myocardial recovery using ventricular assist devices Prevalence, clinical characteristics, and outcomes. Circulation. Aug 30 2005;112(9):132-I36.

9. Birks EJ, George RS, Hedger M, Bahrami T, Wilton P, Bowles CT, Webb C, Bougard R, Amrani M, Yacoub MH, Dreyfus G, Khaghani A. Reversal of severe heart failure with a continuous-flow left ventricular assist device and pharmacological therapy: a prospective study. Circulation. Feb 1 2011;123(4):381-390.

10. Bartoli CR, Dowling RD. The future of adult cardiac assist devices: Novel systems and mechanical circulatory support strategies Cardiology Clinics. 2011; In Press.

11. Farrar DJ, Bourque K, Dague CP, Cotter CJ, Poirier VL. Design features, developmental status, and experimental results with the Heartmate III centrifugal left ventricular assist system with a magnetically levitated rotor. Asaio J. May-Jun 2007;53(3):3101-315.

12. Slaughter MS, Sobieski MA, 2nd, Tamez D, Horrell T, Graham J, Pappas PS, Tatooles AJ, LaRose J. HeartWare miniature axial-flow ventricular assist device: design and initial feasibility test. Tex Heart Inst J. 2009;36(1):12-16. 
13. Hoshi H, Shinshi T, Takatani S. Third-generation blood pumps with mechanical noncontact magnetic bearings. Artif Organs. May 2006;30(5):324-338.

14. Meyns BP, Simon A, Klotz S, Wittwer T, Schlensak C, Rega F, Burkhoff D. Clinical benefits of partial circulatory support in New York Heart Association Class IIIB and Early Class IV patients. Eur J Cardiothorac Surg. Oct 82010.

15. Bartoli CR, Wilson GC, Giridharan GA, Slaughter MS, Sherwood LC, Spence PA, Prabhu SD, Koenig SC. A novel subcutaneous counterpulsation device: acute hemodynamic efficacy during pharmacologically induced hypertension, hypotension, and heart failure. Artif Organs. Jul 2010;34(7):537-545.

16. Sales VL, McCarthy PM. Understanding the C-pulse device and its potential to treat heart failure. Curr Heart Fail Rep. Mar 2010;7(1):27-34.

17. Smith EJ, Reitan O, Keeble T, Dixon K, Rothman MT. A first-in-man study of the Reitan catheter pump for circulatory support in patients undergoing high-risk percutaneous coronary intervention. Catheter Cardiovasc Interv. Jun 1 2009;73(7):859-865.

18. Baldwin JT, Borovetz HS, Duncan BW, Gartner MJ, Jarvik RK, Weiss WJ, Hoke TR. The National Heart, Lung, and Blood Institute Pediatric Circulatory Support Program. Circulation. Jan 3 2006;113(1):147-155.

19. Fumoto H, Horvath DJ, Rao S, Massiello AL, Horai T, Takaseya T, Arakawa $Y$, Mielke N, Chen JF, Dessoffy R, Fukamachi K, Golding LA. In vivo acute performance of the Cleveland Clinic self-regulating, continuous-flow total artificial heart. J Heart Lung Transplant. Jan 2010;29(1):21-26. 
20. Fukamachi K, Saeed D, Massiello AL, Horvath DJ, Fumoto H, Horai T, Zahr R, Shalli S, Anzai T, Dessoffy R, Catanese J, Chen JF, Zhou Q, Benefit S, Alfini S, Golding LA. Development of DexAide right ventricular assist device: update II. Asaio J. Nov-Dec 2008;54(6):589-593.

21. Gazzoli F, Alloni A, Pagani F, Pellegrini C, Longobardi A, Ricci D, Rinaldi M, Vigano M. Arrow CorAide left ventricular assist system: initial experience of the cardio-thoracic surgery center in Pavia. Ann Thorac Surg. Jan 2007;83(1):279282.

22. Sugiki H, Nakashima K, Vermes E, Loisance D, Kirsch M. Temporary right ventricular support with Impella Recover RD axial flow pump. Asian Cardiovasc Thorac Ann. Aug 2009;17(4):395-400.

23. Krishnamani R, DeNofrio D, Konstam MA. Emerging ventricular assist devices for long-term cardiac support. Nat Rev Cardiol. Feb 2010;7(2):71-76.

24. Jeevanandam V, Jayakar D, Anderson AS, Martin S, Piccione W, Jr., Heroux AL, Wynne J, Stephenson LW, Hsu J, Freed PS, Kantrowitz A. Circulatory assistance with a permanent implantable IABP: initial human experience. Circulation. Sep 24 2002;106(12 Suppl 1):I183-188.

25. Yamazaki K, al. e. Next Generation LVAD "EVAHEART": Current Status of Japanese Clinical Trial. Journal of Cardiac Failure. 2006;12(8):Suppl. .

26. Meyns B, Klotz S, Simon A, Droogne W, Rega F, Griffith B, Dowling R, Zucker MJ, Burkhoff D. Proof of concept: hemodynamic response to long-term partial ventricular support with the synergy pocket micro-pump. J Am Coll Cardiol. Jun $302009 ; 54(1): 79-86$. 
27. Hayward CS, Peters WS, Merry AF, Ruygrok PN, Jansz P, O'Driscoll G, Larbalestier RI, Smith JA, Ho B, Legget ME, Milsom FP. Chronic extra-aortic balloon counterpulsation: First-in-human pilot study in end-stage heart failure. $J$ Heart Lung Transplant. Dec 2010;29(12):1427-1432.

28. Bartoli CR, Giridharan GA, Litwak KN, Sobieski M, Prabhu SD, Slaughter MS, Koenig SC. Hemodynamic Responses to Continuous versus Pulsatile Mechanical Unloading of the Failing Left Ventricle. Asaio J. Jul 62010.

29. Kinoshita M, Takano H, Taenaka Y, Mori H, Takaichi S, Noda H, Tatsumi E, Yagura A, Sekii H, Akutsu T. Cardiac disuse atrophy during LVAD pumping. ASAIO Trans. Jul-Sep 1988;34(3):208-212.

30. Kinoshita M, Takano H, Takaichi S, Taenaka Y, Nakatani T. Influence of prolonged ventricular assistance on myocardial histopathology in intact heart. Ann Thorac Surg. Feb 1996;61(2):640-645.

31. Oriyanhan $W$, Tsuneyoshi $H$, Nishina $T$, Matsuoka S, Ikeda T, Komeda M. Determination of optimal duration of mechanical unloading for failing hearts to achieve bridge to recovery in a rat heterotopic heart transplantation model. $J$ Heart Lung Transplant. Jan 2007;26(1):16-23.

32. Klotz S, Foronjy RF, Dickstein ML, Gu A, Garrelds IM, Danser AH, Oz MC, D'Armiento J, Burkhoff D. Mechanical unloading during left ventricular assist device support increases left ventricular collagen cross-linking and myocardial stiffness. Circulation. Jul 19 2005;112(3):364-374. 
33. Voitl P, Vollkron M, Bergmeister H, Wieselthaler G, Schima H. Coronary hemodynamics and myocardial oxygen consumption during support with rotary blood pumps. Artif Organs. Jan 2009;33(1):77-80.

34. Rose EA, Gelijns AC, Moskowitz AJ, Heitjan DF, Stevenson LW, Dembitsky W, Long JW, Ascheim DD, Tierney AR, Levitan RG, Watson JT, Meier P, Ronan NS, Shapiro PA, Lazar RM, Miller LW, Gupta L, Frazier OH, Desvigne-Nickens P, Oz MC, Poirier VL. Long-term mechanical left ventricular assistance for endstage heart failure. $N$ Engl J Med. Nov 15 2001;345(20):1435-1443.

35. Reitz BA. Mechanical devices and US Food and Drug Administration (FDA) approval. Semin Thorac Cardiovasc Surg Pediatr Card Surg Annu. 2006:123-127.

36. Thoratec. Thoratec Announces Filing of PMA Seeking Destination Therapy Approval for HeartMate II. [press release]. 2009.

37. Slaughter MS, Rogers JG, Milano CA, Russell SD, Conte JV, Feldman D, Sun B, Tatooles AJ, Delgado RM, Long JW, Wozniak TC, Ghumman W, Farrar DJ, Frazier OH, Investigators HI. Advanced Heart Failure Treated with ContinuousFlow Left Ventricular Assist Device. New Engl J Med. Dec 3 2009;361(23):22412251.

38. Undar A. Myths and truths of pulsatile and nonpulsatile perfusion during acute and chronic cardiac support. Artif Organs. May 2004;28(5):439-443.

39. Leiva MC, Tolosa JE, Binotto CN, Weiner S, Huppert L, Denis AL, Huhta JC. Fetal cardiac development and hemodynamics in the first trimester. Ultrasound Obstet Gynecol. Sep 1999;14(3):169-174. 
40. Baba A, Dobsak P, Mochizuki S, Saito I, Isoyama T, Takiura K, Shibata M, Abe Y, Chinzei T, Vasku J, Imachi K. Evaluation of pulsatile and nonpulsatile flow in microvessels of the bulbar conjunctiva in the goat with an undulation pump artificial heart. Artif Organs. Oct 2003;27(10):875-881.

41. Orime Y, Shiono M, Hata H, Yagi S, Tsukamoto S, Okumura H, Nakata K, Kimura S, Hata M, Sezai A, Sezai Y. Cytokine and endothelial damage in pulsatile and nonpulsatile cardiopulmonary bypass. Artif Organs. Jun $1999 ; 23(6): 508-512$.

42. Sezai A, Shiono M, Orime Y, Nakata K, Hata M, lida M, Kashiwazaki S, Kinoshita J, Nemoto M, Koujima T, Furuichi M, Eda K, Hirose H, Yoshino T, Saitoh A, Taniguchi Y, Sezai Y. Major organ function under mechanical support: comparative studies of pulsatile and nonpulsatile circulation. Artif Organs. Mar $1999 ; 23(3): 280-285$.

43. Undar A, Masai T, Yang SQ, Eichstaedt HC, McGarry MC, Vaughn WK, Fraser $\mathrm{CD}$, Jr. Pulsatile perfusion improves regional myocardial blood flow during and after hypothermic cardiopulmonary bypass in a neonatal piglet model. Asaio J. Jan-Feb 2002;48(1):90-95.

44. Orime $\mathrm{Y}$, Shiono M, Nakata K, Hata M, Sezai A, Yamada H, Iida M, Kashiwazaki S, Nemoto M, Kinoshita J, Kojima T, Saito T, Sezai Y. The role of pulsatility in end-organ microcirculation after cardiogenic shock. Asaio J. SepOct 1996;42(5):M724-729. 
45. Nakata K, Shiono M, Orime Y, Hata M, Sezai A, Saitoh T, Sezai Y. Effect of pulsatile and nonpulsatile assist on heart and kidney microcirculation with cardiogenic shock. Artif Organs. Jun 1996;20(6):681-684.

46. Murkin JM, Martzke JS, Buchan AM, Bentley C, Wong CJ. A randomized study of the influence of perfusion technique and $\mathrm{pH}$ management strategy in 316 patients undergoing coronary artery bypass surgery. II. Neurologic and cognitive outcomes. J Thorac Cardiovasc Surg. Aug 1995;110(2):349-362.

47. Thompson T, Minami K, Dramburg W, Vyska K, Koerfer R. The influence of pulsatile and nonpulsatile extracorporeal circulation on fluid retention following coronary artery bypass grafting. Perfusion. Jul 1992;7(3):201-211.

48. Watarida S, Mori A, Onoe M, Tabata R, Shiraishi S, Sugita T, Nojima T, Nakajima Y, Matsuno S. A clinical study on the effects of pulsatile cardiopulmonary bypass on the blood endotoxin levels. J Thorac Cardiovasc Surg. Oct 1994;108(4):620-625.

49. Litwak KN, Kihara S, Kameneva MV, Litwak P, Uryash A, Wu Z, Griffith BP. Effects of continuous flow left ventricular assist device support on skin tissue microcirculation and aortic hemodynamics. Asaio J. Jan-Feb 2003;49(1):103-107.

50. Kihara S, Litwak KN, Nichols L, Litwak P, Kameneva MV, Wu Z, Kormos RL, Griffith BP. Smooth muscle cell hypertrophy of renal cortex arteries with chronic continuous flow left ventricular assist. Ann Thorac Surg. Jan 2003;75(1):178-183; discussion 183.

51. Ohnishi H, Itoh T, Nishinaka T, Tatsumi E, Fukuda T, Oshikawa M, Shioya K, Tsukiya T, Takewa Y, Homma A, Uesho K, Sato K, Takano H, Taenaka Y. 
Morphological changes of the arterial systems in the kidney under prolonged continuous flow left heart bypass. Artif Organs. Nov 2002;26(11):974-979.

52. Ootaki C, Yamashita M, Ootaki Y, Kamohara K, Weber S, Klatte RS, Smith WA, Massiello AL, Emancipator SN, Golding LA, Fukamachi K. Reduced pulsatility induces periarteritis in kidney: role of the local renin-angiotensin system. $J$ Thorac Cardiovasc Surg. Jul 2008;136(1):150-158.

53. Saito S, Westaby S, Piggot D, Dudnikov S, Robson D, Catarino PA, Clelland C, Nojiri C. End-organ function during chronic nonpulsatile circulation. Ann Thorac Surg. Oct 2002;74(4):1080-1085.

54. Potapov EV, Loebe M, Abdul-Khaliq H, Koster A, Stein J, Sodian R, Kopitz M, Hausmann H, Noon GP, DeBakey ME, Hetzer R. Postoperative course of S-100B protein and neuron-specific enolase in patients after implantation of continuous and pulsatile flow LVADs. $J$ Heart Lung Transplant. Dec 2001;20(12):13101316.

55. Chow G, Roberts IG, Edwards AD, Lloyd-Thomas A, Wade A, Elliott MJ, Kirkham FJ. The relation between pump flow rate and pulsatility on cerebral hemodynamics during pediatric cardiopulmonary bypass. $J$ Thorac Cardiovasc Surg. Oct 1997;114(4):568-577.

56. Chow G, Roberts IG, Harris D, Wilson J, Elliott MJ, Edwards AD, Kirkham FJ. Stockert roller pump generated pulsatile flow: cerebral metabolic changes in adult cardiopulmonary bypass. Perfusion. Mar 1997;12(2):113-119. 
57. Haft J, Armstrong W, Dyke DB, Aaronson KD, Koelling TM, Farrar DJ, Pagani FD. Hemodynamic and exercise performance with pulsatile and continuous-flow left ventricular assist devices. Circulation. Sep 11 2007;116(11 Suppl):I8-15.

58. Garcia S, Kandar F, Boyle A, Colvin-Adams M, Lliao K, Joyce L, John R. Effects of pulsatile- and continuous-flow left ventricular assist devices on left ventricular unloading. J Heart Lung Transplant. Mar 2008;27(3):261-267.

59. Saito S, Nishinaka $T$, Westaby $S$. Hemodynamics of chronic nonpulsatile flow: implications for LVAD development. Surg Clin North Am. Feb 2004;84(1):61-74.

60. De Boer RA, Pinto YM, Van Veldhuisen DJ. The imbalance between oxygen demand and supply as a potential mechanism in the pathophysiology of heart failure: the role of microvascular growth and abnormalities. Microcirculation. Apr 2003;10(2):113-126.

61. Baldwin JT, Mann DL. NHLBI's program for VAD therapy for moderately advanced heart failure: the REVIVE-IT pilot trial. J Card Fail. Nov 2010;16(11):855-858.

62. Morley D, Litwak K, Ferber P, Spence P, Dowling R, Meyns B, Griffith B, Burkhoff D. Hemodynamic effects of partial ventricular support in chronic heart failure: results of simulation validated with in vivo data. $J$ Thorac Cardiovasc Surg. Jan 2007;133(1):21-28.

63. Entwistle JW, 3rd. Short- and long-term mechanical ventricular assistance towards myocardial recovery. Surg Clin North Am. Feb 2004;84(1):201-221. 
64. Birks EJ, George RS. Molecular changes occurring during reverse remodelling following left ventricular assist device support. J Cardiovasc Transl Res. Dec 2010;3(6):635-642.

65. Rose AG, Park SJ. Pathology in patients with ventricular assist devices: a study of 21 autopsies, 24 ventricular apical core biopsies and 24 explanted hearts. Cardiovasc Pathol. Jan-Feb 2005;14(1):19-23.

66. Ziv O, Dizon J, Thosani A, Naka Y, Magnano AR, Garan H. Effects of left ventricular assist device therapy on ventricular arrhythmias. $\mathrm{J} \mathrm{Am} \mathrm{Coll} \mathrm{Cardiol.}$ May $32005 ; 45(9): 1428-1434$.

67. Vollkron M, Voitl P, Ta J, Wieselthaler G, Schima H. Suction events during left ventricular support and ventricular arrhythmias. J Heart Lung Transplant. Aug 2007;26(8):819-825.

68. Potapov EV, Loforte A, Weng Y, Jurmann M, Pasic M, Drews T, Loebe M, Hennig E, Krabatsch T, Koster A, Lehmkuhl HB, Hetzer R. Experience with over 1000 implanted ventricular assist devices. J Card Surg. May-Jun 2008;23(3):185194.

69. Kavarana MN, Pessin-Minsley MS, Urtecho J, Catanese KA, Flannery M, Oz MC, Naka Y. Right ventricular dysfunction and organ failure in left ventricular assist device recipients: a continuing problem. Ann Thorac Surg. Mar $2002 ; 73(3): 745-750$.

70. Kirklin JK, Naftel DC, Kormos RL, Stevenson LW, Pagani FD, Miller MA, Ulisney KL, Baldwin JT, Young JB. Third INTERMACS Annual Report: The 
evolution of destination therapy in the United States. $J$ Heart Lung Transplant. Feb 2011;30(2):115-123.

71. Casula R, Athanasiou $T$, Foale R. Recent advances in minimal-access cardiac surgery using robotic-enhanced surgical systems. Expert Rev Cardiovasc Ther. Jul 2004;2(4):589-600.

72. Koenig SC, Pantalos GM, Gillars KJ, Ewert DL, Litwak KN, Etoch SW. Hemodynamic and pressure-volume responses to continuous and pulsatile ventricular assist in an adult mock circulation. Asaio J. Jan-Feb 2004;50(1):15-24.

73. Bartoli CR, Okabe K, Akiyama I, Coull B, Godleski JJ. Repeat microsphere delivery for serial measurement of regional blood perfusion in the chronically instrumented, conscious canine. J Surg Res. Mar 2008;145(1):135-141.

74. Hale SL, Alker KJ, Kloner RA. Evaluation of nonradioactive, colored microspheres for measurement of regional myocardial blood flow in dogs. Circulation. Aug 1988;78(2):428-434.

75. Koenig SC, Woolard C, Drew G, Unger L, Gillars K, Ewert D, Gray L, Pantalos G. Integrated data acquisition system for medical device testing and physiology research in compliance with good laboratory practices. Biomed Instrum Technol. May-Jun 2004;38(3):229-240.

76. Rooke GA, Feigl EO. Work as a correlate of canine left ventricular oxygen consumption, and the problem of catecholamine oxygen wasting. Circ Res. Feb $1982 ; 50(2): 273-286$. 
77. Schroeder MJ, Perreault B, Ewert DL, Koenig SC. HEART: an automated beatto-beat cardiovascular analysis package using Matlab. Comput Biol Med. Jul 2004;34(5):371-388.

78. Tune JD, Gorman MW, Feigl EO. Matching coronary blood flow to myocardial oxygen consumption. J Appl Physiol. Jul 2004;97(1):404-415.

79. Tsai AG, Johnson PC, Intaglietta M. Oxygen gradients in the microcirculation. Physiol Rev. Jul 2003;83(3):933-963.

80. Haga JH, Li YS, Chien S. Molecular basis of the effects of mechanical stretch on vascular smooth muscle cells. $J$ Biomech. 2007;40(5):947-960.

81. Bertho E, Gagnon G. A comparative study in three dimension of the blood supply of the normal interventricular septum in human, canine, bovine, porcine, ovine and equine heart. Dis Chest. Sep 1964;46:251-262.

82. Goldstein AH, Monreal G, Kambara A, Spiwak AJ, Schlossberg ML, Abrishamchian AR, Gerhardt MA. Partial support with a centrifugal left ventricular assist device reduces myocardial oxygen consumption in chronic, ischemic heart failure. J Card Fail. Mar 2005;11(2):142-151.

83. Moritz A, Fujimoto LK, Wollenek G, Schima H, Schreiner W, Windisch A, Windberger U, Losert U. Sustained heart failure induced by repeated microsphere injections for left ventricular assist device testing. ASAIO Trans. Jul-Sep 1989;35(3):455-458.

84. Eya K, Tuzun E, Conger J, Chee HK, Byler D, Nojiri C, Frazier OH, Kadipasaoglu K. Effect of pump flow mode of novel left ventricular assist device 
upon end organ perfusion in dogs with doxorubicin induced heart failure. ASAIO $J$ Jan-Feb 2005;51(1):41-49.

85. Borenstein N, Chetboul V, Bruneval P, Hekmati M, Tissier R, Behr L, Derumeaux G, Montarras D. Non-cultured cell transplantation in an ovine model of non-ischemic heart failure. Eur J Cardiothorac Surg. Mar 2007;31(3):444-451.

86. Lahpor J, Khaghani A, Hetzer R, Pavie A, Friedrich I, Sander K, Struber M. European results with a continuous-flow ventricular assist device for advanced heart-failure patients. Eur J Cardiothorac Surg. Jul 172009.

87. Klovaite J, Gustafsson F, Mortensen SA, Sander K, Nielsen LB. Severely impaired von Willebrand factor-dependent platelet aggregation in patients with a continuous-flow left ventricular assist device (HeartMate II). J Am Coll Cardiol. Jun 9 2009;53(23):2162-2167.

88. Geisen U, Heilmann C, Beyersdorf F, Benk C, Berchtold-Herz M, Schlensak C, Budde U, Zieger B. Non-surgical bleeding in patients with ventricular assist devices could be explained by acquired von Willebrand disease. Eur $J$ Cardiothorac Surg. Apr 2008;33(4):679-684.

89. Crow S, John R, Boyle A, Shumway S, Liao K, Colvin-Adams M, Toninato C, Missov E, Pritzker M, Martin C, Garry D, Thomas W, Joyce L. Gastrointestinal bleeding rates in recipients of nonpulsatile and pulsatile left ventricular assist devices. J Thorac Cardiovasc Surg. Jan 2009;137(1):208-215.

90. Monnet E, Chachques JC. Animal models of heart failure: what is new? Ann Thorac Surg. Apr 2005;79(4):1445-1453. 
91. Nart P, Thompson H, Barrett DC, Armstrong SC, McPhaden AR. Clinical and pathological features of dilated cardiomyopathy in Holstein-Friesian cattle. $V e t$ Rec. Sep 18 2004;155(12):355-361.

92. Nart P, Williams A, Thompson H, Innocent GT. Morphometry of bovine dilated cardiomyopathy. J Comp Pathol. May 2004;130(4):235-245.

93. Weber KT, Malinin TI, Dennison BH, Fuqua JM, Jr., Speaker DM, Hastings FW. Experimental myocardial ischemia and infarction. Production of diffuse myocardial lesions in unanesthetized calves. Am J Cardiol. Jun 1972;29(6):793802.

94. Ailawadi G, Kron IL. New strategies for surgical management of ischemic cardiomyopathy. Expert Rev Cardiovasc Ther. Apr 2008;6(4):521-530.

95. Devlin G, Matthews K, McCracken G, Stuart S, Jensen J, Conaglen J, Bass J. An ovine model of chronic stable heart failure. J Card Fail. Jun 2000;6(2):140-143.

96. Huang Y, Hunyor SN, Jiang L, Kawaguchi O, Shirota K, Ikeda Y, Yuasa T, Gallagher G, Zeng B, Zheng X. Remodeling of the chronic severely failing ischemic sheep heart after coronary microembolization: functional, energetic, structural, and cellular responses. Am J Physiol Heart Circ Physiol. Jun 2004;286(6):H2141-2150.

97. Huang Y, Kawaguchi O, Zeng B, Carrington RA, Horam CJ, Yuasa T, AbdulHussein N, Hunyor SN. A stable ovine congestive heart failure model. A suitable substrate for left ventricular assist device assessment. $A S A I O J$. Sep-Oct 1997;43(5):M408-413. 
98. Monreal G, Gerhardt MA, Kambara A, Abrishamchian AR, Bauer JA, Goldstein AH. Selective microembolization of the circumflex coronary artery in an ovine model: Dilated, ischemic cardiomyopathy and left ventricular dysfunction. $J$ Card Fail. Apr 2004;10(2):174-183.

99. Zietkiewicz M, Perek B, Meyns B, Mesotten L, Dispersyn G, Nishimura Y, Flameng W. Chronic heart failure model induced by coronary embolization in sheep. Int J Artif Organs. Jul 1999;22(7):499-504.

100. Sabbah HN, Stein PD, Kono T, Gheorghiade M, Levine TB, Jafri S, Hawkins ET, Goldstein S. A canine model of chronic heart failure produced by multiple sequential coronary microembolizations. Am J Physiol. Apr 1991;260(4 Pt 2):H1379-1384.

101. Hamid T, Gu Y, Ortines RV, Bhattacharya C, Wang G, Xuan YT, Prabhu SD. Divergent tumor necrosis factor receptor-related remodeling responses in heart failure: role of nuclear factor-kappaB and inflammatory activation. Circulation. Mar 17 2009;119(10):1386-1397.

102. Wang G, Hamid T, Keith RJ, Zhou G, Partridge CR, Xiang X, Kingery JR, Lewis RK, Li Q, Rokosh DG, Ford R, Spinale FG, Riggs DW, Srivastava S, Bhatnagar A, Bolli R, Prabhu SD. Cardioprotective and antiapoptotic effects of heme oxygenase-1 in the failing heart. Circulation. May 4 2010;121(17):1912-1925.

103. Frazier OH. Implantation of the Jarvik 2000 left ventricular assist device without the use of cardiopulmonary bypass. Ann Thorac Surg. Mar 2003;75(3):10281030. 
104. Hunt SA. Mechanical circulatory support: new data, old problems. Circulation. Jul 31 2007;116(5):461-462.

105. Klotz S, Meyns B, Simon A, Wittwer T, Rahmanian P, Schlensak C, Tjan TT, Scheld HH, Burkhoff D. Partial mechanical long-term support with the CircuLite Synergy pump as bridge-to-transplant in congestive heart failure. Thorac Cardiovasc Surg. Feb 2010;58 Suppl 2:S173-178.

106. Travis AR, Giridharan GA, Pantalos GM, Dowling RD, Prabhu SD, Slaughter MS, Sobieski M, Undar A, Farrar DJ, Koenig SC. Vascular pulsatility in patients with a pulsatile- or continuous-flow ventricular assist device. $J$ Thorac Cardiovasc Surg. Feb 2007;133(2):517-524.

107. Angell James JE, Daly Mde B. Effects of graded pulsatile pressure on the reflex vasomotor responses elicited by changes of mean pressure in the perfused carotid sinus-aortic arch regions of the dog. J Physiol. Apr 1971;214(1):51-64.

108. Nishimura T, Tatsumi E, Takaichi S, Taenaka Y, Wakisaka Y, Nakatani T, Masuzawa T, Takewa Y, Nakamura M, Endo S, Nakata M, Takano H. Prolonged nonpulsatile left heart bypass with reduced systemic pulse pressure causes morphological changes in the aortic wall. Artif Organs. May 1998;22(5):405-410.

109. Nishimura $T$, Tatsumi E, Nishinaka $T$, Taenaka $Y$, Masuzawa $T$, Nakata $M$, Takano H. Diminished vasoconstrictive function caused by long-term nonpulsatile left heart bypass. Artif Organs. Aug 1999;23(8):722-726.

110. Nishinaka T, Tatsumi E, Nishimura T, Shioya K, Ohnishi H, Taenaka Y, Takano $H$. Change in vasoconstrictive function during prolonged nonpulsatile left heart bypass. Artif Organs. May 2001;25(5):371-375. 


\section{CURRICULUM VITAE}

Carlo Renato G Bartoli, M.S., M.L.A.

crbart02@louisville.edu

1117 Baxter Ave \#B3

Louisville, KY 40204

(413) 262-2120

\section{EDUCATION}

2013

2011

2010

2007

2004

\section{UNIVERSITY OF LOUISVILLE SCHOOL OF MEDICINE}

Doctor of Medicine, M.D.

USMLE Step 1 Score: 252 (99)

Doctor of Philosophy, Ph.D. - Physiology and Biophysics Advisor, Sumanth D. Prabhu

Graduate Dean's Citation

Master of Science, M.S. - Physiology and Biophysics

GPA 4.000

\section{HARVARD UNIVERSITY}

Master of Liberal Arts, M.L.A. - Biological Technology

GPA 3.5000

\section{CORNELL UNIVERSITY}

Bachelor of Science, B.S. - Biology

Magna Cum Laude

With High Honors in Physiology Research

GPA 3.7923 


\section{HONORS \& AWARDS}

2011

John Richard Binford Memorial Award

University of Louisville School of Graduate Studies

2011

Graduate Dean's Citation

University of Louisville School of Graduate Studies

2011

Sponsored Research Tuition Award, University of Louisville Department of Physiology and Biophysics

2010

2010

2009

2008

Semifinalist, National TYLENOL Scholarship

University of Louisville

$1^{\text {st }}$ Place (Co-recipient), Engineering Collaboration Award, Research! Louisville, University of Louisville

$1^{\text {st }}$ Place, Medical Student Research Award

Research! Louisville, University of Louisville

$1^{\text {st }}$ Place, Engineering Collaboration Award, Research! Louisville, University of Louisville

2008

Thomas B. Calhoon Physiology Prize Finalist

University of Louisville, School of Medicine

2008

Summer Research Scholar

University of Louisville, School of Medicine

2007-2013 MD/PhD Student Fellowship James Graham Brown Cancer Foundation

2007

Summer Research Scholar

University of Louisville, School of Medicine

2007

Poster of Honorable Mention

Harvard School of Public Health Symposium

2004

Magna Cum Laude

Cornell University, Department of Biology

2004

High Honors in Physiology Research

Cornell University, Department of Biology

2004 Golden Key Honor Society

Cornell University, Class of 2004 
2003-2004 Biology Honors Program

Cornell University

2003-2004

AE $\Delta$ National Pre-Medical Honor Society Cornell University

2003

American Heart Association Summer Fellow

Cornell University, Department of Biomedical Sciences

2000-2004 Dean's List

Cornell University

2000-2001 William Carran Scholar

Cornell University

$2000 \quad$ National Cum Laude Society

The Williston Northampton School (High School)

1999, 2000 National Advanced Placement Scholar

With Distinction

'95, '98, '99 Maxima Cum Laude

National Latin Exam

1997

Cum Laude

National Latin Exam

\section{RESEARCH SUPPORT}

EPA RD-83479801-0 (Consultant)

$01 / 01 / 11-12 / 31 / 15$

Harvard School of Public Health, Clean Air Research Center

$\$ 1,487,597$

University of Louisville Sponsored Research Tuition Award

Department of Physiology and Biophysics

$01 / 02 / 11-05 / 14 / 11$

NIH T35 ES-14559

07/01/08-08/08/08

Summer Research Scholar, University of Louisville

$\$ 3,800$

Summer Research Scholar, University of Louisville

07/01/07-08/10/07

$\$ 3,000$ 


\section{BOOK CHAPTERS}

1. Bartoli CR, Anderson M, Dowling RD. The Total Artificial Heart: Bridge-To-Transplant and Destination Therapy for End-Stage Biventricular Heart Failure. Cardiothoracic Surgery Review. $1^{\text {st }}$ Edition. Lippincott Williams \& Wilkins. 2011.

\section{PEER REVIEWED PUBLICATIONS}

1. Bartoli CR, Brittian KR, Giridharan GA, Koenig SC, Prabhu SD. Bovine model of doxorubicin-induced chronic heart failure. Journal of Biomedicine and Biotechnology. 2011, 2011:758736.

2. Bartoli CR, Godleski JJ, Verrier RL. Mechanisms mediating adverse effects of air pollution on cardiovascular hemodynamic function and vulnerability to cardiac arrhythmias. Air Quality, Atmosphere, and Health. 2011, 4:53-63.

3. Bartoli CR, Dowling RD, Wilson GC, Giridharan GA, Slaughter MS, Sherwood LC Spence PA, Prabhu SD, Koenig SC. A novel subcutaneous counterpulsation device: Acute hemodynamic responses to pharmacologically-induced hypertension, hypotension, and heart failure. Response to Letter to the Editor. Artificial Organs. 2011, 35(1):93-5.

4. Bartoli CR, Nadar MM, Godleski JJ. Capsule thickness correlates with vascular density and blood flow within foreign-body capsules surrounding surgically implanted subcutaneous devices. Artificial Organs. 2010, 34(10);857-861.

5. Nadar MM, Bartoli CR, Kasdan ML. Lipomas of the hand: a review and 13 patient case series. ePlasty, 2010, 10:e66.

6. Bartoli CR, Wilson GC, Giridharan GA, Slaughter MS, Sherwood LC Spence PA, Prabhu SD, Koenig SC. A novel subcutaneous counterpulsation device: Acute hemodynamic responses to pharmacologically-induced hypertension, hypotension, and heart failure. Artificial Organs. 2010, 34(7):537-45.

7. Bartoli CR, Giridharan GA, Litwak KN, Sobieski M, Prabhu SD, Slaughter MS, Koenig SC. Hemodynamic responses to continuous versus pulsatile unloading of the failing left ventricle. ASAIOJ. 2010, 56(5):410-6.

8. Slaughter MS, Ising MS, Tamez D, O'Driscoll G, Voskoboynikov N, Bartoli CR, Koenig SC, Giridharan GA. Increase in circadian variation of flow after continuous flow ventricular assist device 
implantation. Journal of Heart and Lung Transplant. 2010, 29(6):695-7.

9. Bartoli CR, Spence PA, Giridharan GA. Novel J-stents reduce the risk of embolic stroke in vitro. Neuroradiology. 2010, 52(5):345-7.

10. Bartoli CR, Godleski JJ. Blood flow in the foreign-body capsule surrounding surgically implanted subcutaneous devices. Journal of Surgical Research. 2010, 158(1): 147-154.

11. Bartoli CR, Wellenius GA, Coull BA, Diaz EA, Lawrence J, Akiyama I, Okabe K, Verrier RL, Godleski JJ. Concentrated ambient particles alter myocardial blood flow during acute ischemia in conscious canines. Environmental Health Perspectives. 2009, 117(3): 333337.

12. Bartoli CR, Wellenius GA, Diaz EA, Lawrence J, Coull BA, Akiyama I, Lee LM, Katz T, Okabe K, Verrier RL, Godleski JJ. Acute mechanisms of particulate air pollution-induced arterial blood pressure changes. Environmental Health Perspectives. 2009, 117(3): 361-366.

13. Slaughter MS, Bartoli CR, Sobieski MA, Pantalos GM, Giridharan GA, Dowling RD, Prabhu SD, Farrar DJ, Koenig SC. Intraoperative evaluation of the HeartMate II flow estimator. Journal of Heart and Lung Transplant. 2009, 28(1):39-43.

14. Bartoli CR, Okabe K, Akiyama I, Godleski JJ. Repeat microsphere delivery for serial measurement of regional blood perfusion in the chronically instrumented, conscious canine. Journal of Surgical Research. 2008, 145(1):135-41.

15. Bartoli CR, Akiyama I, Okabe K, Diaz EA, Godleski JJ. Permanent tracheostomy for long-term respiratory studies. Journal of Surgical Research. 2008, 145(1):124-9.

16. Gelzer AR, Koller ML, Otani NF, Fox JJ, Enyeart MW, Hooker GJ, Riccio ML, Bartoli CR, Gilmour RF. Dynamic mechanism for initiation of ventricular fibrillation in vivo. Circulation. 2008, 9;118(11):1123-9.

17. Kumar K, Nearing BD, Bartoli CR, Kwaku KF, Belardinelli L, Verrier RL. Effect of Ranolazine on ventricular vulnerability and defibrillation threshold in the intact porcine heart. Journal of Cardiovascular Electrophysiology. 2008, 19(10):1073-9.

18. Bartoli CR, Akiyama I, Godleski JJ, Verrier RL. Long-term pericardial catheterization is associated with minimum foreign body response. Catheterization and Cardiovascular Interventions. 2007, 70(2):221227.

19. Bartoli CR, Okabe K, Akiyama I, Verrier RL, Godleski JJ. Technique for implantation of chronic indwelling aortic access catheters. Journal of Investigative Surgery. 2006, 19(6): 397-405.

20. Bartoli CR, Nadar MM, Kasdan ML. An atypical case of anesthesiainduced reverse Takotsubo cardiomyopathy in a 30-year-old male 
with post-traumatic stress disorder. Journal of Cardiothoracic and Vascular Anesthesia, In Press.

21. Bartoli CR, Dowling RD. The future of adult cardiac assist devices: Novel systems and mechanical circulatory support strategies. Cardiology Clinics, In Press.

\section{PRESENTED ABSTRACTS (* Award Winner, $\dagger$ Oral Presentation)}

1. $†$ Giridharan GA, Bartoli CR, Spence PA, Koenig SC, Dowling RD. Retrograde cerebral, aortic, and myocardial blood flow during IABP support. Proceedings of The American Society for Artificial Internal Organs, Washington, D.C., June 2011.

2. * Luckett AJ, Bartoli CR, Brittian K, Koenig SC, Spence PA, Dowling $\mathrm{RD}$, D'Souza SE. A novel method for quantifying bovine von Willebrand factor and its cleaving protease, ADAMTS-13: Implications for acquired von Willebrand disease in LVAD patients. Proceedings of Research! Louisville, Louisville, KY, October 2010.

3. * Bartoli CR, Spence PA, Giridharan GA. Novel J-stents reduce the risk of embolic stroke in vitro. Proceedings of Research! Louisville, Louisville, KY, October 2009.

4. Slaughter MS, Ising MS, Tamez D, O'Driscoll G, Voskoboynikov N, Bartoli CR, Koenig SC, Giridharan GA. Reappearance of a normal circadian rhythm after ventricular assist device implantation. Journal of Cardiac Failure. 2009, 15(6): S51.

5. * Bartoli CR, Wilson GC, Giridharan GA, Slaughter MS, Sobieski M, Prabhu SD, Spence PA, Koenig SC. Testing of a subcutaneous counterpulsation device for the treatment of heart failure over a physiological range of hemodynamic conditions. Proceedings of Research! Louisville, Louisville, KY, October 2008.

6. Nadar MM, Bartoli CR, Greenberg RB. Medical school biostatistics and epidemiology curriculum analysis: suggestions for improvement at the University of Louisville. Proceedings of Research! Louisville, Louisville, KY, October 2008.

7. Bartoli CR, Koenig SC, Giridharan GA, Slaughter MS, Sobieski M, Dowling RD, Prabhu SD, Spence PA. Testing of a subcutaneous counterpulsation device for the treatment of heart failure over a physiological range of hemodynamic conditions. Proceedings of The American Society for Artificial Internal Organs, San Francisco, CA, June 2008.

8. Bartoli CR, Wellenius GA, Diaz EA, Lawrence J, Coull BA, Akiyama I, Lee LM, Katz T, Okabe K, Verrier RL, Godleski JJ. Mechanisms of particulate air pollution-induced arterial blood pressure changes. Proceedings of Research! Louisville, Louisville, KY, October 2007. 
9. Bartoli CR, Wellenius GA, Diaz EA, Lawrence J, Coull BA, Akiyama I, Lee LM, Katz T, Okabe K, Verrier RL, Godleski JJ. Mechanisms of particulate air pollution-induced arterial blood pressure changes. Proceedings of The Department of Pathology, Brigham and Women's Hospital Research Celebration, Boston, MA, May 2007.

10. * Bartoli CR, Wellenius GA, Diaz EA, Lawrence J, Coull BA, Akiyama I, Lee LM, Katz T, Okabe K, Verrier RL, Godleski JJ. Godleski. Mechanisms of particulate air pollution-induced arterial blood pressure changes. Proceedings of The Harvard School of Public Health Symposium, Boston, MA, May 2007.

11. Kumar K, Bartoli CR, Nearing BD, Verrier RL. Antiarrhythmic mechanisms of Ranolazine in an in vivo porcine model. New England Electrophysiology Society, Boston, MA, April 2007.

12. Bartoli CR, Diaz EA, Lawrence J, Coull BA, Akiyama I, Katz T, Lee LM, Wellenius GA, Verrier RL, Godleski JJ. Increased baroreceptor reflex sensitivity attenuates air pollution induced, $\alpha$ adrenergic mediated hypertension. Proceedings of The United States Environmental Protection Agency, Role of Air Pollution in Cardiovascular Disease, Durham, NC, October 2006.

13. Bartoli CR, Akiyama I, Okabe K, Godleski JJ. Permanent tracheostomy for long-term respiratory studies in canines. Proceedings of The Academy Of Surgical Research, Scottsdale, AZ, September 2006.

14. Bartoli CR, Diaz EA, Lawrence J, Katz T, Okabe K, Lee LM, Wellenius GA, Verrier RL, Godleski JJ. Exposure to concentrated ambient air particles raises systemic blood pressure in canines. Proceedings of The American Thoracic Society, San Diego, CA, May 2006.

15. Bartoli CR, Diaz EA, Lawrence J, Katz T, Lee LM, Wellenius GA, Verrier RL, Godleski JJ. Exposure to concentrated ambient air particles raises systemic blood pressure in canines. Proceedings of The Harvard School of Public Health, Department of Environmental Health Symposium, Boston, MA, April 2006.

\section{PROFESSIONAL SOCIETIES}

2005-present Academy of Surgical Research

2007-present American Medical Association

2007-present American Medical Student Association

2008-present American Society for Artificial Internal Organs 


\section{PEER REVIEWER}

2007-present Catheterization and Cardiovascular Interventions

2011-present American Society for Artificial Internal Organs

2011-present Archives of Toxicology

BIOMEDICAL

CONSULTING

2008-present SCR Inc.

2009-present Hemoshield (Co-Inventor)

2009-present Telescopic Electrocautery Knife (Co-Inventor) 